\title{
Modeling global water use for the 21st century: the Water Futures and Solutions (WFaS) initiative and its approaches
}

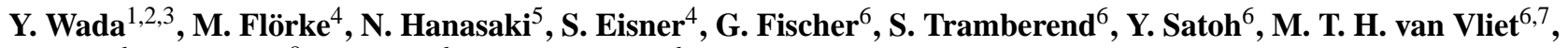

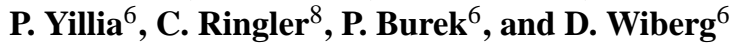 \\ ${ }^{1}$ Department of Physical Geography, Utrecht University, Heidelberglaan 2, 3584 CS Utrecht, the Netherlands \\ ${ }^{2}$ NASA Goddard Institute for Space Studies, 2880 Broadway, New York, NY 10025, USA \\ ${ }^{3}$ Center for Climate Systems Research, Columbia University, 2880 Broadway, New York, NY 10025, USA \\ ${ }^{4}$ Center for Environmental Systems Research, University of Kassel, Kassel, Germany \\ ${ }^{5}$ National Institute for Environmental Studies, Tsukuba, Japan \\ ${ }^{6}$ International Institute for Applied Systems Analysis, Laxenburg, Austria \\ ${ }^{7}$ Earth System Science, Climate Change and Adaptive Land and Water Management, Wageningen University and Research \\ Centre, Wageningen, the Netherlands \\ ${ }^{8}$ International Food Policy Research Institute, Washington, D.C., USA
}

Correspondence to: Y. Wada(y.wada@uu.nl)

Received: 2 July 2015 - Published in Geosci. Model Dev. Discuss.: 13 August 2015

Revised: 21 November 2015 - Accepted: 5 January 2016 - Published: 21 January 2016

\begin{abstract}
To sustain growing food demand and increasing standard of living, global water use increased by nearly 6 times during the last 100 years, and continues to grow. As water demands get closer and closer to the water availability in many regions, each drop of water becomes increasingly valuable and water must be managed more efficiently and intensively. However, soaring water use worsens water scarcity conditions already prevalent in semi-arid and arid regions, increasing uncertainty for sustainable food production and economic development. Planning for future development and investments requires that we prepare water projections for the future. However, estimations are complicated because the future of the world's waters will be influenced by a combination of environmental, social, economic, and political factors, and there is only limited knowledge and data available about freshwater resources and how they are being used. The Water Futures and Solutions (WFaS) initiative coordinates its work with other ongoing scenario efforts for the sake of establishing a consistent set of new global water scenarios based on the shared socio-economic pathways (SSPs) and the representative concentration pathways (RCPs). The WFaS "fasttrack" assessment uses three global water models, namely H08, PCR-GLOBWB, and WaterGAP. This study assesses the state of the art for estimating and projecting water use re-
\end{abstract}

gionally and globally in a consistent manner. It provides an overview of different approaches, the uncertainty, strengths and weaknesses of the various estimation methods, types of management and policy decisions for which the current estimation methods are useful. We also discuss additional information most needed to be able to improve water use estimates and be able to assess a greater range of management options across the water-energy-climate nexus.

\section{Introduction}

Water demand has been increasing and continues to grow globally, as the world population grows and nations become wealthier and consume more. The global population more than quadrupled in the last 100 years, currently exceeding 7 billion people. Growing food demands and increasing standards of living raised global water use ( $\sim$ withdrawal) by nearly 8 times from $\sim 500$ to $\sim 4000 \mathrm{~km}^{3} \mathrm{yr}^{-1}$ over the period 1900-2010 (Falkenmark et al., 1997; Shiklomanov, 2000a, b; Vörösmarty et al., 2005; Wada et al., 2013a). Irrigation is the dominant water use sector $(\approx 70 \%)$ (Döll and Siebert, 2002; Haddeland et al., 2006; Bondeau et al., 2007; Wisser et al., 2010; Wada et al., 2013b). 
As water demands approach the total renewable freshwater resource availability, each drop of freshwater becomes increasingly valuable and water must be managed more efficiently and intensively (Llamas et al., 1992; Konikow and Kendy, 2005; Konikow, 2011; Famiglietti et al., 2011; Gleeson et al., 2012; Wada et al., 2012a, b). Increasing water use aggravates the water scarcity conditions in (semi-)arid regions (e.g., India, Pakistan, northeastern China, the Middle East and North Africa), where lower precipitation limits available surface water and increases the risk of being unable to maintain sustainable food production and economic development (Arnell, 1999, 2004; World Water Assessment Programme, 2003; Hanasaki et al., 2008a, b; Döll et al., 2003, 2009; Kummu et al., 2010; Vörösmarty et al., 2010; Wada et al., 2011a, b; Taylor et al., 2013; Wada and Bierkens, 2014). In these regions, the available surface water resources are often not enough to meet intense irrigation, particularly during crop growing seasons (Rodell et al., 2009; Siebert et al., 2010).

Planning for economic and agricultural development and investments requires that we prepare projections of water supply and demand balances in the future. However, estimations at the global scale are complicated because of limited available observational data and the interactions of a combination of important environmental, social, economic, and political factors, such as global climate change, population growth, land use change, globalization and economic development, technological innovations, political stability and the extent of international cooperation. Because of these interconnections, local water management has global impacts, and global developments have local impacts. Planning water systems without consideration of the larger system could result in missed synergistic opportunities, efficiencies, or lost investments. Furthermore, climate change and other factors external to water management, such as the recent financial crisis and instability of food prices, are demonstrating accelerating trends or more frequent disruptions (World Water Assessment Programme, 2003; Puma et al., 2015). These create new risks and uncertainties for water managers and those who determine the direction of policies that impact water management. In spite of these water management challenges and the increasing complexity of dealing with them, only limited knowledge and data are available about freshwater resources and how they are being used. At the same time, data collection and monitoring can be costly, and benefits and tradeoffs between investments in monitoring versus investments in other types of development should be considered.

The Water Futures and Solutions (WFaS) initiative is a collaborative, stakeholder-informed, global effort applying systems analysis to develop scientific evidence and tools for the purpose of identifying water-related policies and management practices that work together coherently across scales and sectors to improve human well-being through enhanced water security. A key, essential component of the WFaS anal- ysis is the assessment of global water supply and demand balances, both now and into the future, and the state-of-theart methods used to understand the extent of water resource challenges faced around the world. This paper focuses on the estimation of global, sectoral water use (i.e., withdrawals), a highly uncertain component of global water assessments, and provides the first multi-model analysis of global water use for the 21st century, based on water scenarios designed to be consistent with the community-developed shared socioeconomic pathways being prepared for the latest IPCC assessment report.

This study contributes preliminary work toward the goal of improving our understanding of global water use behavior in order to assess tradeoffs and synergies among management options. It assesses the state of the art for estimating and projecting water withdrawals regionally and globally in a consistent manner, providing an overview of different approaches, the uncertainties, strengths and weaknesses of the various estimation methods, and types of management and policy decisions for which the current estimation methods are useful. A common set of water scenarios, developed by $\mathrm{WFaS}$, is employed to compare resulting estimations of three different approaches. Additional information and advances that are most needed to improve our estimates and be able to assess a greater range of management options across the water-energy-climate nexus are also discussed.

\section{Review of current modeling approaches for global water use per sector}

To quantify available water resources across a large scale, a number of global hydrological or water resource models have been recently developed (Yates, 1997; Nijssen et al., 2001a, b; Oki et al., 2001). A few of the hydrologic modeling frameworks have associated methods to estimate water demand, so that the supply-demand balances can be assessed. Only a very limited number attempt to cover all of the major water uses: domestic, industrial (energy/manufacturing), and agricultural (livestock/irrigation) uses. Three of these models, H08, PCR-GLOBWB, and WaterGAP, are applied to the analysis in this paper. In this section, the calculation of sectoral water use among the three models is briefly discussed together with other modeling approaches (i.e., other models). We refer to Appendix A1 for detailed model descriptions of the three models (H08, PCR-GLOBWB, and WaterGAP).

Alcamo et al. (2003a, b) developed the WaterGAP model (spatial resolution on a $0.5^{\circ}$ by $0.5^{\circ}$ grid or $55 \mathrm{~km}$ by $55 \mathrm{~km}$ at the Equator), which simulates the surface water balance and water use, i.e., water withdrawal and consumptive water use, from agricultural, industrial, and domestic sectors at the global scale. Döll et al. (2003, 2009) used an improved version of the WaterGAP model $\left(0.5^{\circ}\right)$ (Alcamo et al., 2007; Flörke et al., 2013; Portmann et al., 2013) to simulate globally the reduction of surface water availability by 
consumptive water use. The differentiation between surface water and groundwater as the sources of water withdrawals were described in Döll et al. (2012), while a sensitivity analysis and the latest improvements in the WaterGAP model can be found in Müller Schmied et al. (2014). Later, Hanasaki et al. (2008a, b, 2010) and Pokhrel et al. (2012a, b) developed the H08 $\left(0.5^{\circ}\right)$ and MATSIRO $\left(0.5^{\circ}\right)$ models, respectively. Both models incorporate the anthropogenic effects including irrigation and reservoir regulation into global water balance calculations. Wada et al. (2010, 2011a, b, 2014a, b) and Van Beek et al. (2011) developed the PCR-GLOBWB model $\left(0.5^{\circ}\right)$ that calculates the water balance and water demand per sector. The model also incorporates groundwater abstraction at the global scale.

It is important to note that difference among models remains significantly large due to different modeling frameworks and assumptions among different models (Gosling et al., 2010, 2011; Haddeland et al., 2011; Davie et al., 2013; Wada et al., 2013a, b). Schewe et al. (2014) highlights large uncertainties associated with both global climate models and water models. Variability among water models (nine models) is particularly pronounced in many areas with declining water resources (Haddeland et al., 2011). However, Schewe et al. (2014) focused on water scarcity assessment using per capita water availability only, and thus did not account for water use explicitly. Furthermore, most studies have focused on historical reconstruction of global water use for model validation, and so far very few assessments have been built on the shared socio-economic pathways (SSPs) and the representative concentration pathways (RCPs) in combination to evaluate the impacts of global change on water resources (e.g., Hanasaki et al. 2013a, b; Arnell and LloydHughes, 2014). Moreover, there are no assessments that use a multi-model framework to investigate the future trends in global water use. The Water Futures and Solutions (WFaS; http://www.iiasa.ac.at/WFaS) initiative coordinates its work with other ongoing scenario efforts for the sake of establishing new global water scenarios that are consistent across sectors. For this purpose, initial scenarios based on the SSPs and RCPs are being developed in the context of the Intergovernmental Panel on Climate Change (IPCC) 5th Assessment Report (AR5) (Van Vuuren et al., 2011; Arnell, 2010; Moss et al., 2010). The WFaS "fast-track" assessment uses the three global water models that include both water supply and demand, namely H08, PCR-GLOBWB and WaterGAP.

This section investigates methods used for calculating water withdrawals in the different sectors, concentrating on how these methods are used in the WFaS "fast-track" models to provide quantified scenario estimates.

\subsection{Agriculture}

\subsubsection{Livestock}

Water is used for livestock in various ways, including for growing and producing livestock feed, for direct consumption by livestock, and for livestock processing. While livestock water demand remains a minor but rapidly growing sector in most countries, there are exceptions, such as in Botswana, where livestock water use accounts for $23 \%$ of the country's total water use (Steinfeld et al., 2006). Livestock production systems are also well known for being significant water polluters (Steinfeld et al. 2006). Intensive and extensive livestock systems have vastly different livestock water needs. In extensive systems, livestock are on the move, and often exposed to higher temperatures, increasing drinking water demands; at the same time (Wada et al., 2014a, b), these animals can meet a substantial share of this demand through foraging. In intensive systems, on the other hand, water use for cooling and maintenance can be far larger than direct drinking water demand and livestock feed is generally provided as dry matter meeting less of animal water demands.

Estimation of water use differs between approaches. Most global models include only the direct animal watering or drinking component (Alcamo et al., 2003a, b). The International Food Policy Research Institute (IFPRI) uses consumptive use, rather than withdrawals in estimating livestock water demand. Return flows to the surface water and groundwater system are not calculated (Msangi et al., 2014). In PCR-GLOBWB and WaterGAP, livestock water withdrawal (= consumption, no return flow) is estimated by multiplying livestock numbers with water consumptive use per unit of livestock, including beef, chicken, eggs, milk, pork, poultry, sheep and goats. Global distribution of major livestock types (cattle, buffalo, sheep, goats, pigs, and poultry) are usually obtained from FAO (2007). Livestock water demand is omitted in H08. Drinking water requirements vary by animal species and age, animal diet, temperature and production system. However, in current water models only drinking water requirements for different livestock type under changing temperature has been included (Wada et al., 2014a, b). In water embedded in various livestock feeds is part of rainfed or irrigation water demand, and maintaining feedlots, for slaughtering and livestock processing is incorporated in industrial water demand (Döll et al., 2009; Flörke et al., 2013; Wada et al., 2014a, b).

\subsubsection{Irrigation}

Irrigation is particularly important as it comprises nearly $70 \%$ of the total water use, which also has a large seasonal variability due to the various growing seasons of different crops. In addition, the irrigation water use varies spa- 
tially depending on cropping practices and climatic conditions (Doorenbos and Pruitt, 1977).

In general, water use (= demand) for irrigation (WI) can be estimated by the following equation:

$\mathrm{WI}=\mathrm{AEI} \cdot \mathrm{UIA} \cdot \mathrm{WRCI} \cdot \frac{1}{\mathrm{IE}}$,

where WI is the water demand for irrigation $\left(\mathrm{m}^{3}\right)$, AEI is the area equipped for irrigation (hectare or $\mathrm{m}^{2}$ ), UIA is the utilization intensity of irrigated land, i.e., ratio of irrigated land actually irrigated over extent of land equipped for irrigation (dimensionless), and WRCI is the total crop water requirement per unit of irrigated area to be met by irrigation water, i.e., the difference between total crop water requirements and the part supplied by soil moisture from precipitation (m). WRCI is the total crop water requirements per unit of irrigated area depending on climate, crop type and multi-cropping conditions, and can be affected by specific crop management practices (dimensionless). IE is the efficiency of irrigation that accounts for the losses during water transport and irrigation application (dimensionless). The main parameters to estimate irrigation water demand are further discussed.

Area equipped for irrigation (AEI): area equipped to provide water (via irrigation) to crops. It includes areas equipped for full/partial control irrigation, equipped lowland areas, and areas equipped for spate irrigation. Changes in a country's area equipped for irrigation will depend on several economic, technological and political factors, which determine the need, economic profitability and biophysical viability of irrigation expansion (Freydank and Siebert, 2008). Key factors included among these are the following: (i) availability of land and water, (ii) reliability of water supply and access to water; (iii) irrigation impact (achievable yield increase and/or stabilization of yields and reduced variability); (iv) growth of demand for agricultural produce due to demographic and economic changes; (v) availability of land resources with rain-fed potential for conversion to agriculture (where available, these might be preferable and cheaper to develop rather than expanding irrigation); (vi) existing current yield gaps in rain-fed and/or irrigated land; (vii) cost of irrigation; (viii) profitability, economic means available and support policies to invest in irrigation; and (ix) state food security and self-reliance policies (Thenkabail et al., 2006; Siebert et al., 2005; Rost et al., 2008; Portmann et al., 2010).

Utilization intensity of irrigated land (UIA) is given by the ratio of actually irrigated land to land equipped for irrigation (Fischer et al., 2007). There are four main factors that may affect actual utilization of areas equipped for irrigation. First, in a context of increased competitiveness (e.g., due to sector liberalization) and possibly shrinking land intensity, actually irrigated areas may decrease more than the area equipped for irrigation. Second, in a context where additional areas are equipped for irrigation to reduce drought risk, i.e., as a safeguard against "bad" years, the effect could be an increase of area equipped for irrigation but an overall reduction of utilization of these areas, because such areas would not be irrigated every year. Third, when water availability deteriorates (or cost of irrigation/groundwater increases), farmers may be forced to reduce utilization of the land equipped for irrigation due to lack or unreliability of water supply. Fourth, it is conceivable that under poor economic conditions and incentives, some areas equipped for irrigation will not be well maintained and may become unusable.

Total crop water requirements per unit of irrigated area (WRCI) are the difference between total crop water requirements and the part supplied by soil moisture from precipitation. WRCI accounts for the multiple use of irrigated land within 1 year (cropping intensity), i.e., on the ratio of harvested irrigated crop area to the extent of actually irrigated land (Fischer et al., 2007). Cropping intensity on irrigated land generally depends on several factors: (i) the thermal regime of a location, which determines how many days in a year are available for crop growth and how many crops in sequence can possibly be cultivated; (ii) irrigation water availability and reliability of water supply, which may limit multicropping despite suitable thermal conditions; and (iii) sufficient availability of inputs, agricultural labor and/or mechanization (Döll and Siebert, 2002; Bondeau et al., 2007; Fischer et al., 2007). In the case of terrain limitations for mechanization and labor shortages, e.g., due to rapid urbanization and rural employment outside agriculture, prevailing economic reasons may not allow the realization of the climatic multi-cropping potential (e.g., such as has been happening in some eastern provinces of China, where multi-cropping factors have been decreasing in recent years despite potential improvements due to warming). In general, however, future changes in irrigation intensity will tend to increase with global warming in the world's temperate zones, but may be limited or even decrease where seasonal water availability is a major constraint (Wada et al., 2013b).

Irrigation efficiency (IE): as used here, measures the overall effectiveness of an irrigation system in terms of the ratio of crop irrigation water requirements over irrigation water withdrawals (Döll and Siebert, 2002; Gerten et al., 2007). Overall irrigation efficiency is a function of the type of irrigation used (e.g., sprinkler, drip irrigation) and the technology being used within each type. Future changes will largely depend on investments being made to shift to more efficient irrigation types and to updating each type's technology to stateof-the-art, and to some extent will depend on crop type (for instance, paddy rice needs flood irrigation, for some crops sprinklers cannot be used, for some drip irrigation may be too expensive) and possibly new cultivation practices (Fischer et al., 2007). Therefore, judging future irrigation efficiency requires an inventory/estimation of the status quo (current distribution by type of irrigation and crops irrigated) and a projection of future irrigation systems and related technology assumptions. Current IE estimates are available per region and per country from Döll and Siebert (2002), Rohwer et 


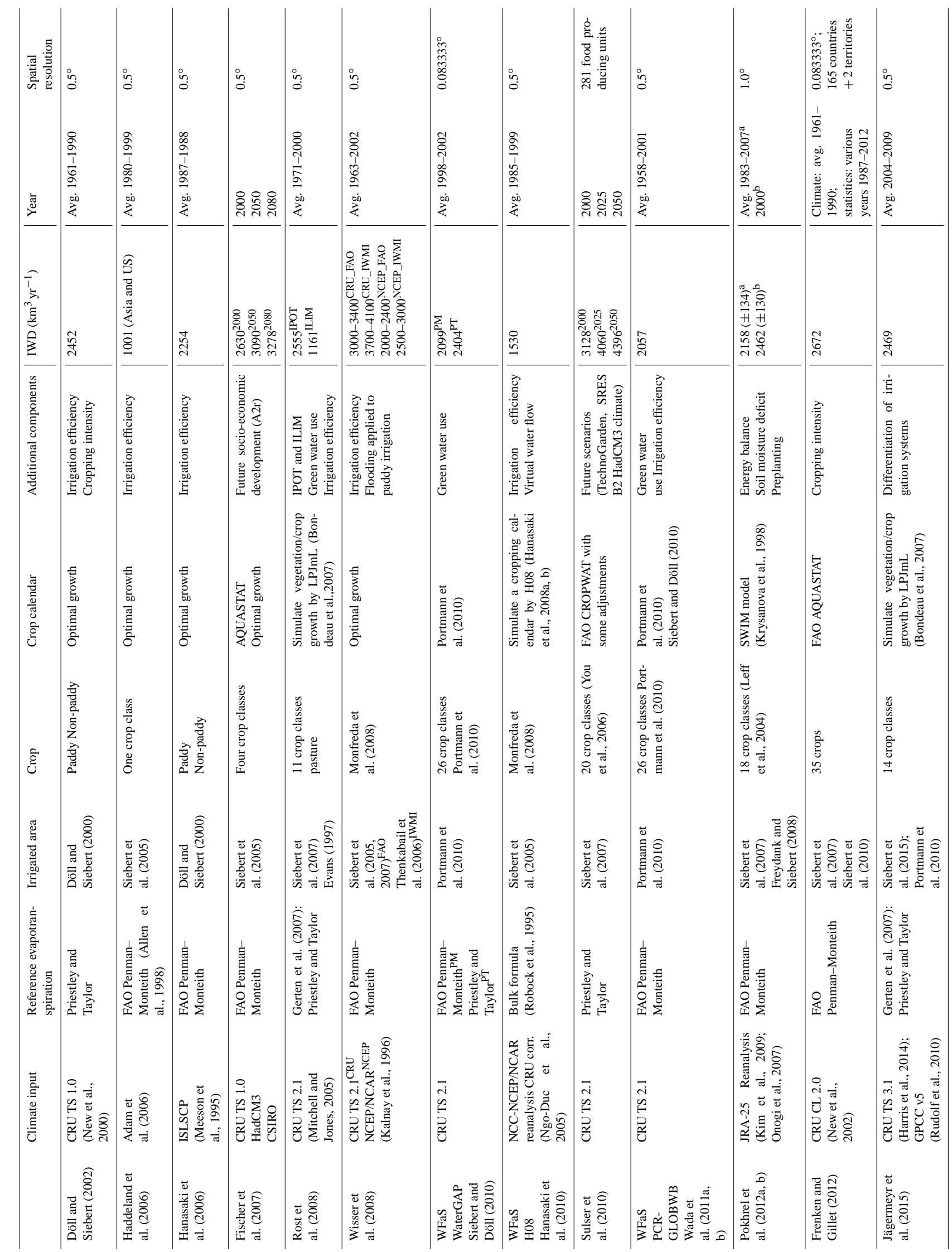


al. (2007), Rost et al. (2008), and Frenken and Gillet (2012). A recent study by Jägermeyr et al. (2015) estimates water withdrawal and irrigation system efficiencies by major system type (surface, sprinkler, drip) for the period 2004-2009.

Various studies have applied Eq. (1), or variations of it, to estimate irrigation water demand globally in different ways (Smith, 1992; Döll and Siebert, 2002; Rost et al., 2008; Sulser et al., 2010; Siebert and Döll, 2010; Frenken and Gillet, 2012). A summary of these studies, and the methods and associated parameters applied, are shown in Table 1, with the methods used in H08 (Hanasaki et al., 2010), WaterGAP (Siebert and Döll, 2010), and PCR-GLOBWB (Wada et al., 2011a, b) highlighted. In brief, H08 simulates the crop calendar using climate conditions (Hanasaki et al., 2010), while PCR-GLOBWB and WaterGAP use a prescribed crop calendar, such as that compiled by Portmann et al. (2010). Not used in this study, but in the latest development, H08 (Hanasaki et al., 2013a, b) and PCR-GLOBWB (Wada et al., 2014b) use an irrigation scheme that separately parameterizes paddy and non-paddy crops and that dynamically links with the daily surface and soil water balance. This enables a more physically accurate representation of the state of the daily soil moisture condition, and associated evaporation and crop transpiration over irrigated areas. Common scenario projections of future land use changes and irrigated areas are still being developed to make model results comparable, given the variety and complexity of agricultural water use estimate methods used. Agricultural water use for these models will therefore not be part of the discussion in this paper, but will be presented in a separate paper. Note that in the WFaS "fast-track" scenario assumptions, we have already developed the storylines of agricultural sector (see Appendix A). To realize these scenario assumptions, key parameters listed in Eq. (1) and associated data have also been developed along with the agricultural storylines (see Appendix A).

\subsection{Industry}

\subsubsection{Primary energy extraction}

Water is essential for the extraction of primary energy resources and, increasingly, for irrigation of biofuel crops. The most water-intensive aspect of biofuel production is growing the feedstock (Moraes et al., 2011). The amount of water used may appear minor at the global level but water requirements for biofuel production must be viewed in the context of local water resources, especially when irrigation water is required. The extraction of conventional oil and natural gas generally require relatively modest amounts of water. However, water requirements are growing considerably with expansion into unconventional resources such as shale gas and oil sands, which are much more water intensive (DOE, 2006). Many parts of the coal fuel cycle are also water intensive, with consequences for local water resources.
There are limited approaches in use for calculating or projecting water demands for primary energy extraction or production. The International Energy Agency (IEA) uses a comprehensive review of published water withdrawal and consumption factors for relevant stages of oil, gas, coal and biofuels production to quantify water requirements for primary energy production. Average water factors for production chains are typically obtained from the most recent sources available, and as much as possible from operational rather than theoretical estimates (WEO, 2012). These are then compiled into source-to-carrier ranges for each fuel source and disaggregated by the energy production chain and expressed as withdrawal and consumption, and applied for each scenario and modeling region over the projection period. Normally, water withdrawal and consumption factors for conventional oil and gas extraction are universal, whereas water factors for biofuels are location-specific given that irrigation water requirements for biomass feedstock can vary depending on different regions.

H08, PCR-GLOBWB, and WaterGAP used in this analysis do not specifically calculate the water use for primary energy extraction, except for the agriculture water use for energy crops. Other water use for primary energy extraction is lumped into aggregate parameters of industrial and energy water use (Table 2).

\subsubsection{Electricity production}

Worldwide, freshwater withdrawals for cooling of thermoelectric (fossil-fuelled, biomass, nuclear) power plants contribute considerable parts of total water withdrawals $\left(627 \mathrm{~km}^{3} \mathrm{yr}^{-1}\right.$ in 2010) (Flörke et al., 2013). Compared with other sectors, thermoelectric power is one of the largest water users in regions such as the United States (40\%) (King et al., 2008) and Europe (43\% of total surface water withdrawals) (Rübbelke and Vögele, 2011). The total water withdrawn needed for cooling of power plants depends mainly on cooling system type, source of fuel, and installed capacity.

In general, to estimate water withdrawals, a distinction is made between power plants using once-through systems, which have high water withdrawals, and power plants and recirculation (tower) cooling systems that require smaller amounts of surface water withdrawal, but water consumption is higher (due to evaporative losses) compared to oncethrough systems (Koch and Vögele, 2009). Although hydropower also consumes water due to evaporation in reservoirs (Mekonnen and Hoekstra, 2012) and also requires sufficient water availability to maintain hydropower production levels, we focus in this subsection on water demands for thermoelectric power, as this is overall the dominant water user for electricity. We note that the models used in this study include thermoelectric water use only. However, evaporation from hydropower reservoirs can be substantial (Wiberg and Strzepek, 2005), but is not easily separated from other uses, since most reservoirs are multi-purpose and the detailed in- 
formation on reservoir uses and operations is limited worldwide.

There are different approaches varying in complexity and input data to quantify thermoelectric water use. Davies et al. (2013) and Hejazi et al. (2014) use GCAM to establish lower-, median, and upper-bound estimates of current electric-sector water withdrawals and consumption for 14 macro-regions worldwide. More detailed approaches to calculate thermoelectric water withdrawal on power-plantspecific level, also including installed capacity, river water temperature and environmental legislations, were developed by Koch and Vögele (2009). Van Vliet et al. (2012, 2013) assessed the vulnerability of thermoelectric power plants in Europe and the United States and modified their equations for use on a daily time step to include limitations in surface water withdrawal for thermoelectric cooling (see Eqs. 2a and 2b). The equations show that during warm periods water withdrawal $q$ increases in order to discharge the same waste heat load and maintain electricity production at full capacity.

Once-through cooling systems:

$$
\begin{aligned}
q & =\mathrm{KW} \cdot \frac{1-\eta_{\text {total }}}{\eta_{\text {elec }}} \\
\cdot & \frac{(1-\alpha)}{\rho_{\mathrm{W}} \cdot C_{\mathrm{p}} \cdot \max \left(\min \left(\left(T l_{\max }-T w\right), \Delta T l_{\max }\right), 0\right)}
\end{aligned}
$$

Recirculation (tower) cooling systems:

$$
\begin{aligned}
q & =\mathrm{KW} \cdot \frac{1-\eta_{\text {total }}}{\eta_{\text {elec }}} \\
\cdot & \frac{(1-\alpha) \cdot(1-\beta) \cdot \omega \cdot \mathrm{EZ}}{\rho_{\mathrm{W}} \cdot C_{\mathrm{p}} \cdot \max \left(\min \left(\left(T l_{\max }-T_{\mathrm{w}}\right), \Delta T l_{\max }\right), 0\right)},
\end{aligned}
$$

where $q$ is the daily cooling water demand $\left(\mathrm{m}^{3} \mathrm{~s}^{-1}\right), \mathrm{KW}$ is the installed capacity (MWh), $\eta_{\text {total }}$ is the total efficiency $(\%), \eta_{\mathrm{elec}}$ is the electric efficiency $(\%), \alpha$ is the share of waste heat not discharged by cooling water $(\%), \beta$ is the share of waste heat released into the air, and $\omega$ is the correction factor accounting for effects of changes in air temperature and humidity within a year. EZ is the densification factor, $\rho_{\mathrm{W}}$ is the density freshwater $\left(\mathrm{kg} \mathrm{m}^{-3}\right), C_{\mathrm{p}}$ is the heat capacity of water $\left(\mathrm{J} \mathrm{kg}^{-1}{ }^{\circ} \mathrm{C}^{-1}\right), T l_{\max }$ is the maximum permissible temperature of the cooling water $\left({ }^{\circ} \mathrm{C}\right), \Delta T l_{\max }$ is the maximum permissible temperature increase of the cooling water $\left({ }^{\circ} \mathrm{C}\right)$, and $T_{\mathrm{w}}$ is the daily mean river temperature $\left({ }^{\circ} \mathrm{C}\right)$.

In addition to water use modeling approaches, some studies have presented overview tables of thermoelectric water withdrawal and consumption rates per technology and cooling system based on literature review (Davies et al., 2013; Gleick, 2003; Kyle et al., 2013). These overview tables can provide a useful basis for establishing water demands for electricity on a macro-level. The choice of which approach is most suitable for estimating water demands for electricity strongly depends on the spatial and temporal scale and the availability of input data. Use of water withdrawal or consumption rates from integrated assessment models is mainly suitable for global and large-scale assessments. Total industrial water demand estimates of water models such as H08 and PCR-GLOBWB are also developed mainly for global assessments, as these estimates are mainly derived based on country values of economic variables. WaterGAP is also a global water model, but originally uses power plant data aggregated to gridded level to represent regional spatial variability in thermoelectric water demands. Power-plantspecific approaches, as presented by Koch and Vögele (2009) and Van Vliet et al. (2012, 2013), provide detailed estimates for thermoelectric water uses on high spatial and temporal levels, but also have high requirements with regard to input data (e.g., installed capacity, cooling system type, efficiency, water temperature, environmental legislation of each power plant).

The WaterGAP model simulates global thermoelectric water use (withdrawal and consumption) by multiplying the annual electricity production $\left(\mathrm{EP}_{i}\right)$ with the water use intensity of the power plant $\left(\mathrm{WI}_{i}\right)$, which depends on cooling system and plant type $\left(\mathrm{CS}_{i}\right)$ (Vassolo and Döll, 2005; Flörke et al., 2013). The total annual thermal power plant water withdrawal (TPWW) in each grid cell is then calculated as the sum of the withdrawals of all power plants within the cell. The WaterGAP model uses the World Electric Power Plants Data Set of the Utility Data Institute (UDI, 2004) to obtain power plant characteristics (i.e., cooling system and plant type). Flörke et al. $(2011,2012)$ further developed this approach for gridded projections of future thermoelectric water demands in Europe by including rates of technological change $\left(\mathrm{Tch}_{\mathrm{TPi}}\right)$, resulting in the following equation.

$\mathrm{TPWW}=\sum_{i=1}^{n} \mathrm{EP}_{i} \cdot \mathrm{WWI}_{i}\left(\mathrm{CS}_{i}, \mathrm{PT}_{i}\right) \cdot \mathrm{Tch}_{\mathrm{TP}}$

where TPWW is the total annual thermal power plant water withdrawal in each grid cell $\left(\mathrm{m}^{3} \mathrm{yr}^{-1}\right), \mathrm{EP}_{i}$ is the electricity produced by thermal power plant $i$ within the cell $\left(\mathrm{MWh} \mathrm{yr}^{-1}\right), \mathrm{WWI}_{i}$ is the power-plant-specific water withdrawal intensity $\left(\mathrm{m}^{3} \mathrm{MWh}^{-1}\right)$ that depends on cooling system $\left(\mathrm{CS}_{i}\right)$ and plant type $\left(\mathrm{PT}_{i}\right)$, and $\mathrm{Tch}_{\mathrm{TPi}}$ is the technological change for water cooling in thermal power plants (dimensionless). $n$ is the number of stations in the grid cell.

All three models used here calculate both water withdrawal and water consumption for industrial uses. They also all consider technological and structural changes in their simulation of future industrial water use. While WaterGAP makes a distinction between thermoelectric and manufacturing water use and calculates them separately, the other two global water models, PCR-GLOBWB (Van Beek et al., 2011; Wada et al., 2011a, b) and H08 (Hanasaki et al., 2008a, b) calculate aggregated industrial water demands only. H08 calculates future water use driven by total electricity production, while PCR-GLOBWB uses GDP, total electricity production, and total energy consumption. Industrial water use is calcu- 
Table 2. Summary of industrial water withdrawal estimation models in this study.

\begin{tabular}{|c|c|c|c|c|}
\hline Reference & Model & Sector & Drivers & Parameters \\
\hline \multirow[t]{2}{*}{$\begin{array}{l}\text { WFaS WaterGAP } \\
\text { Flörke et al. (2013) }\end{array}$} & \multirow{4}{*}{$\begin{array}{l}\text { Time-series regression } \\
\text { by individual countries } \\
\text { and regions }\end{array}$} & Manufacture & $\begin{array}{l}\text { Manufacturing gross } \\
\text { value added }\end{array}$ & \multirow[t]{2}{*}{$\begin{array}{l}\text { Calibrated from time- } \\
\text { series data }\end{array}$} \\
\hline & & $\begin{array}{l}\text { Thermal electricity } \\
\text { production }\end{array}$ & $\begin{array}{l}\text { Thermal electricity } \\
\text { production }\end{array}$ & \\
\hline $\begin{array}{l}\text { WFaS PCR-GLOBWB } \\
\text { Wada et al. }(2014 a, b)\end{array}$ & & \multirow[t]{2}{*}{ Industry } & $\begin{array}{l}\text { GDP, electricity pro- } \\
\text { duction, energy con- } \\
\text { sumption, household } \\
\text { consumption }\end{array}$ & \multirow[t]{2}{*}{$\begin{array}{l}\text { Set from literature re- } \\
\text { views and time-series } \\
\text { data }\end{array}$} \\
\hline $\begin{array}{l}\text { WFaS H08 } \\
\text { Hanasaki et al. (2013a, b) }\end{array}$ & & & Electricity production & \\
\hline
\end{tabular}

lated for individual countries with subsequent downscaling to a $0.5^{\circ}$ by $0.5^{\circ}$ grid. While $\mathrm{H} 08$ downscaling is according to total population distributions, PCR-GLOBWB and WaterGAP (in the case of manufacturing water use) downscale to urban areas only. It should be noted that the differences in these approaches can result in significantly different projections even with the same set of scenario assumptions. The results of WaterGAP simulation, in particular, may differ substantially for regions where cooling water use for thermal electricity production or manufacturing water use has a large proportion of the total industrial water use.

\subsubsection{Manufacturing}

Large-scale or global water models, including H08 and PCR-GLOBWB, estimate an aggregated industrial water use (manufacturing and energy production combined) (Shen et al., 2008; Wada et al., 2011a, b; Hanasaki et al., 2013a, b). Hejazi et al. (2014) enhanced the GCAM model to calculate manufacturing water withdrawals as the difference between total industrial water withdrawals and the energy-sector water withdrawals for fourteen regions for the base year 2005 . The energy-related water withdrawals are simulated by the same model. Furthermore, estimates of manufacturing water consumption are based on an exogenous ratio of consumption to withdrawals given by Vassolo and Döll (2005). For future periods the base year manufacturing water withdrawals and consumption are scaled with total industrial output. Past and future freshwater use in the United States has been reported from Brown et al. (2011) for the different waterrelated sectors, describing the estimation of future water use to the year 2040 by extending past trends. Manufacturing and commercial withdrawals are projected based on estimates of future population and income and assumptions about the rate of change in withdrawal per dollar of income. Specifically, withdrawals are projected as population times (dollars of income/capita) times (withdrawal/dollar of income).
H08 and PCR-GLOBWB lump manufacturing and energy water withdrawals into aggregated industrial water withdrawals. In this analysis, only WaterGAP calculates water use of the manufacturing and thermoelectric sectors separately (Flörke et al., 2013). Manufacturing water withdrawal (MWW per year) is simulated for each country annually by using a specific manufacturing structural water use intensity (MSWI, $\mathrm{m}^{3}$ (USD const. year 2000 of base year 2005) multiplied by the gross value added (GVA) per country and year $(t)$ and a technological change factor (TC) to account for technological improvements to safe water.

$$
\mathrm{MWW}_{t}=\mathrm{MSWI}_{2005} \cdot \mathrm{GVA}_{t} \cdot \mathrm{TC}_{t}\left[\mathrm{~m}^{3} \text { year }^{-1}\right]
$$

Manufacturing water consumption is calculated for the time period 1950 to 1999 on the basis of consumptive water-use coefficients from Shiklomanov (2000a, b). For the years 2000 to 2010 , manufacturing water consumption is calculated as the difference between manufacturing withdrawals and return flows, which are derived from data on generated wastewater (Flörke et al., 2013). For future projections, scenariospecific consumptive water-use coefficients can be derived according to the future pathway as well as technological change factors.

\subsection{Households (domestic sector)}

Domestic water use accounts for $12 \%$ of the global total (Hanasaki et al., 2008a, b; Flörke et al., 2013; Wada et al., 2014a, b). However, available global models and scenarios of domestic withdrawals are limited. Earlier attempts to model domestic water withdrawal are summarized in Table 3.

The WaterGAP model was the first global water model that included a sub-model to project future domestic water use globally at grid-scale resolution (Alcamo et al., 2003a, b). WaterGAP uses a multiple regression model with population and GDP per capita as independent variables. Historical change in domestic water use are explained by categorizing them as structural and technological changes. Structural 
Table 3. Summary of domestic water withdrawal estimation models in earlier studies.

\begin{tabular}{|c|c|c|c|}
\hline References & Model & Drivers & Parameters \\
\hline Alcamo et al. (2003a, b) & $\begin{array}{l}\text { Time-series regression by } \\
\text { individual countries and re- } \\
\text { gions }\end{array}$ & Population, GDP per capita & Calibrated from time-series data \\
\hline $\begin{array}{l}\text { WFaS WaterGAP } \\
\text { Flörke et al. (2013) }\end{array}$ & & Population, GDP per capita & \\
\hline $\begin{array}{l}\text { WFaS PCR-GLOBWB } \\
\text { Wada et al. }(2014 a, b)\end{array}$ & & Population & $\begin{array}{l}\text { Set from literature reviews and } \\
\text { time-series data }\end{array}$ \\
\hline \multicolumn{4}{|l|}{$\begin{array}{l}\text { WFaS H08 } \\
\text { Hanasaki et al. }(2013 a, b)\end{array}$} \\
\hline Shen et al. (2008) & $\begin{array}{l}\text { National regression in a sin- } \\
\text { gle year }\end{array}$ & Population, GDP per capita & Calibrated at the year of 2000 \\
\hline \multicolumn{4}{|l|}{ Hayashi et al. (2013) } \\
\hline IMPACT & National regression & $\begin{array}{l}\text { Population, GDP per capita, in- } \\
\text { come elasticity of demand }\end{array}$ & Literature reviews \\
\hline
\end{tabular}

change refers to the observation that water use intensity, or per capita water use, grows rapidly for countries with low but increasing income, and slows down in countries with high income. Technological change is the general trend that water use for each service becomes smaller over time due to improvement in the water use efficiency of newer devices. One of the key challenges of this approach is calibration of the parameters. Sufficient amounts of reliable data are essential for calibration, although published historical time series of water withdrawals are limited for many countries. Alcamo et al. (2003a, b) calibrated the key parameters regionally using the data compiled by Shiklomanov (2000a, b) and nationally where data were available. Flörke et al. (2013) updated the model and parameters by collecting country-level domestic water use data for 50 individual countries and 27 regions. Wada et al. (2014a, b) developed a similar model as Alcamo et al. (2003a, b) and Flörke et al. (2013) and projected national domestic water withdrawal for the whole 21 st century.

Shen et al. (2008) proposed a model with different formulations from Alcamo et al. (2003a, b). They assumed that the future water use level of developing countries will converge with that of present developed countries as economic growth continues. They first plotted per capita GDP and water use at present by countries. Then they adopted a logarithmic model and regressed with the data that represent the present global relationship between per capita GDP and water use. Hayashi et al. (2013) adopted the same model as Shen et al. (2008), while they made regression separately from urban and rural areas since the accessibility to tap water is substantially different. Because their models do not require historical timeseries data of regions and countries, it is easy to calibrate the model parameter. In contrast, the results are presented under a strong assumption that the path of growth in domestic water use is globally uniform.

The estimated model parameters mentioned above represent historical relationships between domestic water withdrawal and socio-economic factors. It remains uncertain whether maintaining these parameters throughout the $21 \mathrm{st}$ century is a valid approach, since future scenarios such as SSPs depict substantially different future conditions. Hanasaki et al. (2013a, b) developed a set of national projections on domestic water withdrawal globally for the $21 \mathrm{st}$ century based on the latest developed SSPs. They adopted a model similar to Alcamo et al. (2003a, b) and prepared parameter sets mainly based on literature review that are compatible with the five different views of a world in the future as depicted in the SSPs. Although arbitrariness is included in the parameter setting, this approach enables us to project water use for the world that is substantially different from that realized in the past.

In the current analysis, H08 uses the method described by Hanasaki et al. (2013a, b), PCR-GLOBWB uses Wada et al. (2014a, b), and WaterGAP uses the method described in Flörke et al. (2013) (see Table 3). In contrast to the industrial sector, the methods applied by the three water models to calculate domestic water use are similar, and are driven primarily by population numbers while based on per capita water use (or withdrawal) intensities. All three models calculate both water withdrawal and consumptive water use, the latter subtracting the return flow to the rivers and groundwater. National numbers of domestic water use are distributed to a $0.5^{\circ}$ by $0.5^{\circ}$ grid according to the gridded total population numbers for all three models. H08 primarily uses population numbers and per capita water use as input socio-economic variables. WaterGAP is driven by population numbers and 
GDP per capita, while PCR-GLOBWB is also driven by population numbers, but additionally considers GDP, total electricity production, and energy consumption for the calculation of per capita water use and associated future trend similar to the water use intensity calculation in the industrial sector (see Appendix A1). In addition, assumptions on technological change rates are considered by all three models whereas WaterGAP also takes into account structural changes.

\subsection{Environmental flow requirements}

As pressure grows on many of the world's river basins, it becomes increasingly critical to balance the competing needs among different water use sectors and ecosystems. Environmental flows refer to the amount of water that needs to be allocated for the maintenance of aquatic ecosystem services (Dyson et al., 2003; Pastor et al., 2014). Various factors contribute to the health of river ecosystems, including discharge (streamflow), the physical structure of the channel and riparian zone, water quality, channel management, level of exploitation, and the physical barriers to connectivity (Acreman and Dunbar, 2004; Smakhtin et al., 2004, 2006).

Early definitions of environmental flows were premised on the importance of maintaining a fixed minimum flow, but all aspects of a flow regime (including floods, medium, and low flows) are important, and changes to any part of the regimes may impact or influence the overall ecosystem and provision of ecosystem services (Pahl-Wostl et al., 2013; Acreman and Dunbar, 2004). Environmental flow requirements should therefore not only address the amount of water needed, but also issues of timing and duration of river flows (Smakhtin et al., 2006). In order to accommodate these seasonal and inter-annual variations, environmental flow requirements must vary over space and time in order to meet and supply the ecosystem services as outlined by various stakeholders (Pahl-Wostl et al., 2013). Action on environmental flow requirements have been offset and limited by (1) lack of understanding of environmental flow benefits, (2) uncoordinated management of water resources, (3) low priority given to environmental flows in allocation processes, (4) limiting environmental flows to low flow requirements, (5) not paying attention to the impacts of too much water, and (6) the difficulties of coordinating complex environmental flows (Richter, 2010).

Estimated calculations of environmental water requirements (EWRs), which are the sum of ecologically relevant low-flow and high-flow components to ensure a scenario of "fair" ecosystem service delivery, vary depend on hydrological regimes, but are generally in the range of $20-50 \%$ of renewable water resources (Smakhtin et al., 2004). They are highest in the rivers of the equatorial belt (Amzaon and Congo), where there is stable rainfall, and for river systems that are lake-regulated (Canada, Finland), or those that are influenced by a high percentage of groundwater generated

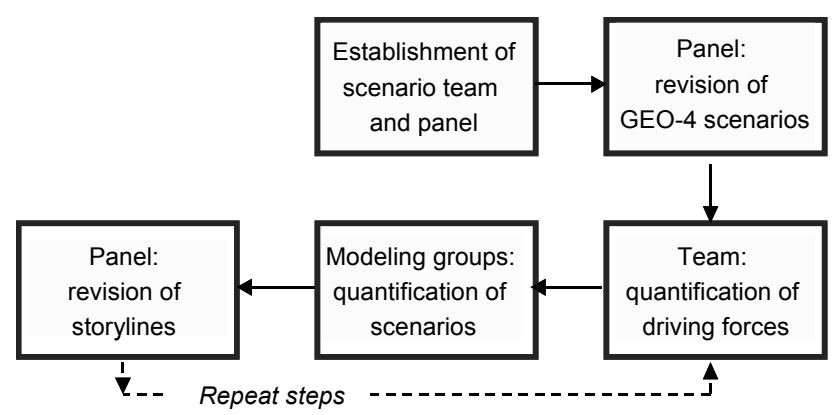

Figure 1. The interaction between the qualitative and quantitative scenario development in the SAS (story and simulation) approach (simplified from Alcamo, 2008).

baseflow (northern and central Europe, or swamps (Siberia). However, estimates of EWRs are much lower for areas with highly variable monsoon-driven rivers, rivers of arid areas, and those with high snowmelt flows (Asia, Africa, and Arctics). Varying, simplistic approaches have been used to estimate EWRs. In IMPACT, for example, environmental flow is specified as a share of average annual runoff) (Rosegrant et al., 2012). When data are unavailable in a particular food producing unit, an iterative procedure is used. The initial value for environmental flows is assumed to be $10 \%$ with additional increments of $20-30 \%$ if navigation requirements are significant (for example in the Yangtze River basin); 10$15 \%$ if environmental reservation is legally enshrined, as in most developed countries; and 5-10\% for arid and semi-arid regions where ecological requirements, such as salt leaching, are high (for example, Central Asia) (Rosegrant et al., 2012).

The H08 method uses an empirical model that estimates the amount of river discharge that should be kept in the channel to maintain the aquatic ecosystem, which is based on case studies of regional practices, while the river discharge should ideally be unchanged for the preservation of the natural environment (Hanasaki et al., 2008a, b). PCR-GLOBWB equates EFRs to $Q_{90}$, i.e., the streamflow that is exceeded $90 \%$ of the time, following the study of Smakhtin et al. (2004). WaterGAP also follows the method of Smakhtin et al. (2004), but also incorporates the concepts of hydrological variability and river ecosystem integrity. This paper focuses on domestic and industrial use, and therefore EWRs will not be analyzed with the results.

\section{Application of future water demand modeling for the Water Futures and Solutions (WFaS) initiative}

\subsection{The WFaS scenario approach}

Within WFaS, qualitative scenarios of water availability and demand are being developed that are broadly consistent with scenarios being developed for other sectors and that incorporate feedback from stakeholders where possible (Fig. 1). 
Table 4. Assumptions applied in the WFaS "fast-track" scenario runs, deployed at country level.

\begin{tabular}{|c|c|c|c|}
\hline WFaS "fast-track" scenario & $\begin{array}{l}\text { SSP1 } \\
\text { (sustainability quest) }\end{array}$ & $\begin{array}{l}\text { SSP2 } \\
\text { (business as usual) }\end{array}$ & $\begin{array}{l}\text { SSP3 } \\
\text { (divided world) }\end{array}$ \\
\hline WFaS scenario acronym & SUQ & BAU & DIV \\
\hline \multicolumn{4}{|l|}{ Socio-economics } \\
\hline Population & SSP1 (IIASA-VIC v9) & SSP2 (IIASA-VIC v9) & SSP3 (IIASA-VIC v9) \\
\hline Urban population & SSP1 (NCAR) & SSP2 (NCAR) & SSP3 (NCAR) \\
\hline GDP & SSP1 (OECD $\left.{ }^{\mathrm{a}} \mathrm{v} 9\right)$ & SSP2 (OECD v9) & SSP3 (OECD v9) \\
\hline $\begin{array}{l}\text { Value added in the } \\
\text { manufacturing }{ }^{\mathrm{b}} \text {-related } \\
\text { GEO- } 4 \text { scenario }\end{array}$ & $\begin{array}{l}\text { SSP1 and UNEP-GEO4 } \\
\text { "Sustainability First" }\end{array}$ & $\begin{array}{l}\text { SSP } 2 \text { and UNEP-GEO4 } \\
\text { "Markets First" }\end{array}$ & $\begin{array}{l}\text { SSP3 and UNEP-GEO4 } \\
\text { "Security First" }\end{array}$ \\
\hline Energy consumption $(\mathrm{KTOE})^{\mathrm{c}}$ & $\begin{array}{l}\text { SSP1-RCP4.5 } \\
\text { (MESSAGE) }\end{array}$ & SSP2-RCP6.0 (MESSAGE) & SSP3-RCP6.0 (MESSAGE) \\
\hline Electricity production $(\mathrm{GWh})^{\mathrm{c}}$ & SSP1-RCP4.5 (MESSAGE) & SSP2-RCP6.0 (MESSAGE) & SSP3-RCP6.0 (MESSAGE) \\
\hline $\begin{array}{l}\text { Technological \& } \\
\text { structural changes }\end{array}$ & \multicolumn{3}{|c|}{$\begin{array}{l}\text { Assumptions for technologic change rates interpret the respective SSP narrative, } \\
\text { differentiated by a country's socio-economic ability to cope with water-related } \\
\text { risks and its exposure to hydrologic challenges. The latter was achieved by } \\
\text { grouping countries into "hydro-economic classes" (assumption details in Table 5). }\end{array}$} \\
\hline
\end{tabular}

a OECD Env-Growth Model; ${ }^{\mathrm{b}}$ This is only required for WaterGAP. The share of manufacturing gross value added in total GDP is taken from the UNEP GEO4 Driver Scenarios distributed by International Futures (pardee.du.edu); ${ }^{\mathrm{c}}$ Preliminary results (October 2013) from from IIASA - MESSAGE-MACRO model consistent with population and GDP projections for each SSP. The MESSAGE model (Model for Energy Supply Strategy Alternatives and their General Environmental Impact) generated results for 23 regions, which were disaggregated to country level using the distribution of population and GDP from the SSP database hosted at IIASA.

In the first step ("fast-track"), the SSP storylines, already the result of a multi-year community effort across sectors, have been extended with relevant critical dimensions affecting water availability and use. The SSPs offer the possibility for experimentation by a wide range of researchers extending the “original" SSPs in various dimensions (O'Neill et al., 2015). However, SSPs were developed by the climate change community with a focus of the key elements for climate policy analysis, i.e., less or no information is given related to the water sector. Therefore WFaS has extended SSP storylines and has developed a classification system called hydro-economic (HE) classes to describe different conditions in terms of a country's or region's ability to cope with water-related risks and its exposure to complex hydrological conditions, which affect its development in the scenarios (Fischer et al., 2015). Critical water dimensions have been assessed qualitatively and quantitatively for each SSP and HE class (classified using GDP per capita and four indicators describing hydrologic complexity). Several climate and socio-economic pathways are being analyzed in a coordinated multi-model assessment process involving sector and integrated assessment models, water demand models and different global hydrological models. Integration and synthesis of results will produce a first set of quantified global water scenarios that include consistency in climate, socio-economic developments (e.g., population, economic, energy) and water resources, with this paper focusing on aspects of water demand.
The focus of this chapter is to describe the water demand modeling, i.e., the underlying drivers and assumptions as well as the model results. The WFaS assessment has initially employed a "fast-track" analysis to produce well-founded yet preliminary scenario estimates following the SSP storylines and to apply available quantifications of socio-economic variables and climate model projections of the RCPs from the Inter-Sectoral Impact Model Intercomparison Project (ISIMIP; Warszawski et al., 2014).

\subsection{Scenario assumptions for the WFaS "fast-track" analysis}

In WFaS the SSP narratives were enriched with relevant critical dimensions of the main water use sectors agriculture, industry, and domestic for the development of a first set of assumptions applied in global water models. This is achieved for various conditions in terms of a country or region's ability to cope with water-related risks and its exposure to complex hydrological conditions. For this purpose a hydro-economic (HE) classification has been developed, assigning each country in a two-dimensional space of coping capacity and hydrologic complexity (see Appendix A2). Critical water dimensions were evaluated qualitatively and quantitatively for each SSP and HE class classified with GDP and available renewable water resources (Fischer et al., 2015). In the WFaS "fast-track" analysis we have selected three SSP-based sce- 
Table 5. Scenario assumptions for technology and structural change in the industry and domestic sector.

\begin{tabular}{|c|c|c|c|c|c|}
\hline & & \multicolumn{4}{|c|}{ Hydro-economic (HE) classification $^{\mathrm{a}}$} \\
\hline & & HE-1 & HE-2 & HE-3 & HE-4 \\
\hline $\begin{array}{l}\text { Socio-economic capacity to cope } \\
\text { with water-related risks }\end{array}$ & & Low (poor) & High (rich) & High (rich) & Low (poor) \\
\hline $\begin{array}{l}\text { Exposure to hydrologic } \\
\text { complexity and challenges }\end{array}$ & & Low & Low & High & High \\
\hline ENERGY SECTOR & & \multicolumn{4}{|c|}{ WFaS "fast-track" scenario } \\
\hline $\begin{array}{l}\text { Technological change } \\
\text { (annual change rate) }\end{array}$ & $\begin{array}{l}\text { SSP1-SUQ } \\
\text { SSP2-BAU } \\
\text { SSP3-DIV }\end{array}$ & $\begin{array}{l}1.1 \% \\
0.6 \% \\
0.3 \%\end{array}$ & $\begin{array}{l}1.1 \% \\
1.0 \% \\
0.6 \%\end{array}$ & $\begin{array}{l}1.2 \% \\
1.1 \% \\
1.0 \%\end{array}$ & $\begin{array}{l}1.1 \% \\
1.0 \% \\
0.6 \%\end{array}$ \\
\hline $\begin{array}{l}\text { Structural change }{ }^{\mathrm{b}} \text { (change in } \\
\text { cooling system, i.e., from } \\
\text { one-through to tower cooling) }\end{array}$ & $\begin{array}{l}\text { SSP1-SUQ } \\
\text { SSP2-BAU } \\
\text { SSP3-DIV }\end{array}$ & $\begin{array}{l}40 \mathrm{yr} \\
\text { None } \\
\text { None }\end{array}$ & $\begin{array}{l}40 \mathrm{yr} \\
40 \mathrm{yr} \\
\text { None }\end{array}$ & $\begin{array}{l}40 \mathrm{yr} \\
40 \mathrm{yr} \\
40 \mathrm{yr}\end{array}$ & $\begin{array}{l}40 \mathrm{yr} \\
40 \mathrm{yr} \\
\text { None }\end{array}$ \\
\hline MANUFACTURING SECTOR & & & & & \\
\hline $\begin{array}{l}\text { Technological change } \\
\text { (annual change rate) } \\
\text { Structural change (change in } \\
\text { intensity over time relative to } \\
\text { GDP per capita) }\end{array}$ & $\begin{array}{l}\text { SSP1-SUQ } \\
\text { SSP2-BAU } \\
\text { SSP3-DIV } \\
\text { SSP1-SUQ } \\
\text { SSP2-BAU } \\
\text { SSP3-DIV }\end{array}$ & $\begin{array}{l}1.1 \% \\
0.6 \% \\
0.3 \% \\
\text { Yes } \\
\text { Yes } \\
\text { Yes }\end{array}$ & $\begin{array}{l}1.1 \% \\
1.0 \% \\
0.6 \% \\
\text { Yes } \\
\text { Yes } \\
\text { Yes }\end{array}$ & $\begin{array}{l}1.2 \% \\
1.1 \% \\
1.0 \% \\
\text { Yes } \\
\text { Yes } \\
\text { Yes }\end{array}$ & $\begin{array}{c}1.1 \% \\
1.0 \% \\
0.6 \% \\
\text { Yes } \\
\text { Yes } \\
\text { Yes }\end{array}$ \\
\hline DOMESTIC SECTOR & & & & & \\
\hline $\begin{array}{l}\text { Technological change } \\
\text { (annual change rate) } \\
\text { Structural change } \\
\text { (decrease over given time) }\end{array}$ & $\begin{array}{l}\text { SSP1-SUQ } \\
\text { SSP2-BAU } \\
\text { SSP3-DIV } \\
\text { SSP1-SUQ } \\
\text { SSP2-BAU } \\
\text { SSP3-DIV }\end{array}$ & $\begin{array}{c}1.1 \% \\
0.6 \% \\
0.3 \% \\
20 \% \text { until } 2050 \\
\text { None } \\
\text { None }\end{array}$ & $\begin{array}{c}1.1 \% \\
1.0 \% \\
0.6 \% \\
20 \% \text { until } 2050 \\
\text { None } \\
\text { None }\end{array}$ & $\begin{array}{c}1.2 \% \\
1.1 \% \\
1.0 \% \\
20 \% \text { until } 2050 \\
\text { None } \\
\text { None }\end{array}$ & $\begin{array}{c}1.1 \% \\
1.0 \% \\
0.6 \% \\
20 \% \text { until } 2050 \\
\text { None } \\
\text { None }\end{array}$ \\
\hline
\end{tabular}

a The HE classification calculates for each country a compound indicator (values 0-1) for socio-economic capacity to cope with water-related risks (economic-institutional capacity) and their exposure to hydrologic challenges and complexity (hydrological complexity). In this way each country was located in a two-dimensional space and grouped into four HE classes termed HE-1 to HE-4; ${ }^{b}$ When economies have sufficient investment potential (HE-2 and HE-3) or the societal paradigm strives for resource-efficient economies (SSP1) we assume power plants to be replaced after a service life of 40 years by plants with modern water-saving tower-cooled technologies. ${ }^{\mathrm{c}}$ Only in SSP1 (Sustainability Scenario) do we assume by 2050 a $20 \%$ reduction in domestic water use intensity due to behavioral changes.

narios for the quantification of spatially explicit global water use until 2050 using the state-of-the-art global water models H08 (Hanasaki et al, 2008a, b), PCR-GLOBWB (Van Beek et al., 2011; Wada et al., 2014b), and WaterGAP2.2 (Flörke et al., 2013; Müller Schmied et al., 2014). These SSPs were chosen to envelop an upper (SSP3-RCP6.0), a middle (SSP2-RCP6.0), and a lower (SSP1-RCP4.5) range of plausible changes in future socio-economics and associated greenhouse gas emissions based on data availability of SSP scenarios when the WFaS "fast-track" analysis was conducted. Tables 4 and 5 summarize quantitative scenario assumptions applied in the water model calculations. The Appendix A3 summarizes how we generate scenario assumptions based on SSP and HE classification.

Note that future land use changes including irrigated areas and livestock numbers according to the new SSP scenarios are still under development, therefore, we were not able to in- clude irrigation and livestock sector in this "fast-track" analysis. For a comprehensive assessment of future irrigation under the latest RCP scenarios, we refer to Wada et al. (2013b) who used a set of seven global water models to quantify the impact of projected global climate change on irrigation water demand by the end of this century, and to assess the resulting uncertainties arising from both the global water models and climate projections. In addition, due to limited data available for future ecosystem service, we did not include the assessment of environmental flow requirements. We refer to Pastor et al. (2014) for a comprehensive assessment of global environmental flow requirements. Thus, here we primarily focus on the industrial (electricity and manufacturing) and domestic sectors. 


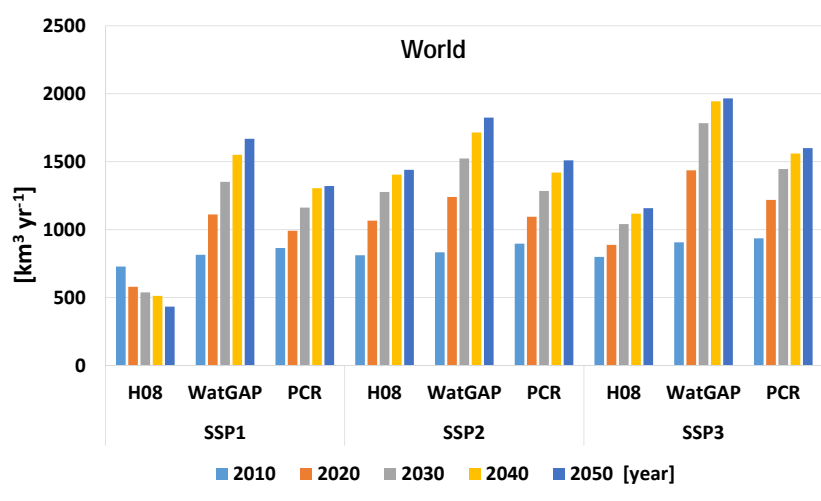

Figure 2. Ensemble of three global industrial water withdrawal projections calculated by the global water models H08, WaterGAP (WatGAP), and PCR-GLOBWB (PCR) for the years 2010, 2020, 2030, 2040, and 2050, respectively, under three SSP scenarios (SSP1, SSP2, and SSP3).

\section{First global water use model intercomparison}

Using an ensemble of three global water models: H08 (Hanasaki et al., 2008a, b), PCR-GLOBWB (Wada et al., 2010, 2011a, b, 2014b), and WaterGAP (Müller Schmied et al., 2014; Flörke et al., 2013), here we analyze the characteristic behavior of sectoral water use (= withdrawals), based on various input data and associated scenario assumptions described above. Note that although global water use models estimate sectoral water use at a $0.5^{\circ}$ by $0.5^{\circ}$ grid, all results are presented at a country scale since the scenario assumptions for technology and structural change are also considered at a country scale, and the future change in water use intensity is most obvious at this scale. Note that hereafter SSP scenarios denote the WFaS "fast-track" scenarios according to Tables 4 and 5 (see also Appendix A3), rather than the original SSP scenario descriptions (O'Neill et al., 2015).

\subsection{Industrial sector}

Ensemble results of global industrial water withdrawals highlight a steep increase in almost all SSP scenarios (Fig. 2). It should be noted that WaterGAP makes a distinction between thermoelectric and manufacturing water use, while the other two global water models, PCR-GLOBWB and H08, calculate aggregated industrial water demands only.

Global withdrawals are projected to reach nearly $2000 \mathrm{~km}^{3} \mathrm{yr}^{-1}$ by 2050 , more than double the present industrial water use intensity in $2010\left(850 \mathrm{~km}^{3} \mathrm{yr}^{-1}\right)$. A different trend can be seen in a reduction of water use (40\%) projected by H08 for SSP1 compared to PCR-GLOBWB and WaterGAP, which project about 50 and $100 \%$ increases, respectively. Under the SSP2 and SSP3 scenarios, the results are more consistent. Global industrial water withdrawal is projected to increase by $70-120 \%$ under the "business-as-usual" SSP2 scenario and by $45-120 \%$ under the "divided world"
SSP3 scenario. H08 results show the largest range among the SSP projections, falling between a $-40 \%$ decrease (SSP1) and an $80 \%$ increase (SSP3). PCR-GLOBWB has a relatively a narrow range between an increase of $50 \%$ (SSP1) to $70 \%$ (SSP3). The range is even narrower for WaterGAP with an increase of $105 \%$ for SSP1 and $119 \%$ for SSP2. By 2050 WaterGAP projects the largest net increase under SSP2, while the other models project that under SSP3.

In order to investigate reasons for the major differences among the three global water models we now scrutinize regional trends in industrial water withdrawals projections under the same sets of SSP scenarios. Figure 3 shows regional trends in projected industrial water withdrawals among the three models to highlight the uncertainty in water use projections. We selected regional major water users with significantly different projections across the three models. Each country has been assigned to a HE classification (Appendix A2), for which a consistent set of socio-economic scenarios and assumptions for technological and structural change has been developed under each SSP (see Tables 4 and 5). In the mature, industrialized economy of the USA and Germany, the projected industrial water withdrawals exhibit a steadily decreasing trend toward the year 2050 for almost all projections. However, H08 features an increasing trend (after a sharp drop in 2020) for both countries under the SSP3 scenario.

For the emerging economies (China, Brazil, and Russia), the ensemble projections show large differences among the three global water models. WaterGAP projects a much larger net increase in industrial water withdrawals for China and Brazil by 2050 under all SSPs, while H08 results show a net decrease under SSP1 (China, Brazil, Egypt and Russia) and SSP2 (Brazil and Russia). PCR-GLOBWB follows a similar trend with WaterGAP for China and Russia, but shows a much lower net increase for Brazil compared to WaterGAP. For PCR-GLOBWB and WaterGAP, the relative increase is similar for China and Russia. However, the different quantities of industrial water withdrawals at the starting year of the simulations lead to large differences in the absolute amounts by 2050 among the water models (due to the use of different data sets at the reference year of 2005). This is particularly obvious for Russia, where industrial water withdrawals differ by a factor of 4 at the reference year between PCRGLOBWB and WaterGAP. H08 results show a decreasing trend for SSP1 in these countries as shown in the global trend. The higher industrial water withdrawal estimated by WaterGAP in emerging economies is often due to an increase in manufacturing water use. H08 and PCR-GLOBWB do not disaggregate the industrial sector into manufacturing and thermal electricity, which results in a homogeneous response in projected trends among these sub-sectors. In India, Brazil, and China, where economies are projected to grow rapidly in the coming decades, industrial water withdrawals are projected to increase by a factor of more than 2 by 2050 . Here H08 again shows a decreasing trend for India and Egypt 

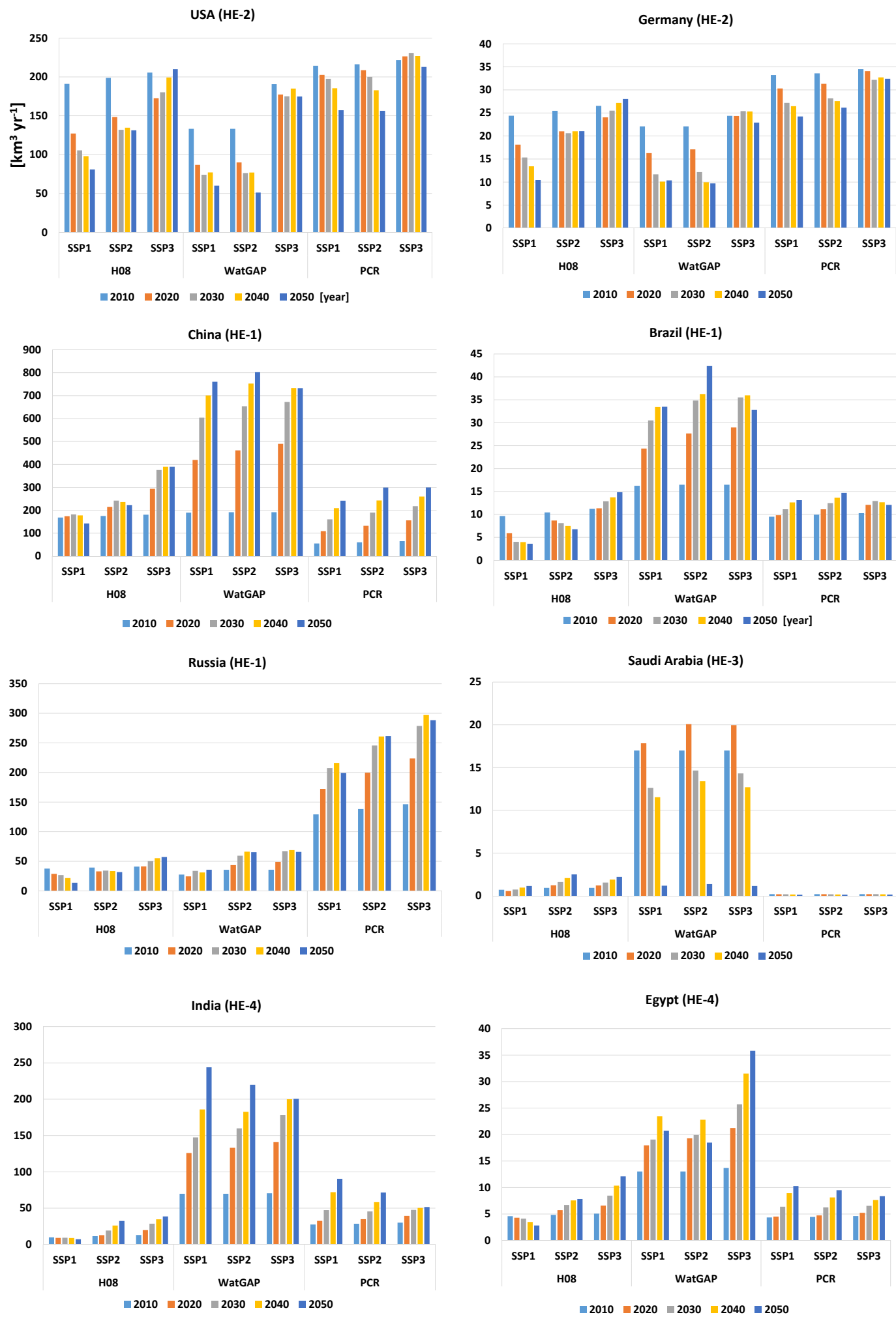

Figure 3. Industrial water withdrawal projections for selected countries calculated by the global water models H08, WaterGAP (WatGAP), and PCR-GLOBWB (PCR) for the years 2010, 2020, 2030, 2040, and 2050, respectively, under three SSP scenarios (SSP1, SSP2, and SSP3). HE denotes the hydro-economic classification (see Appendix A2). 


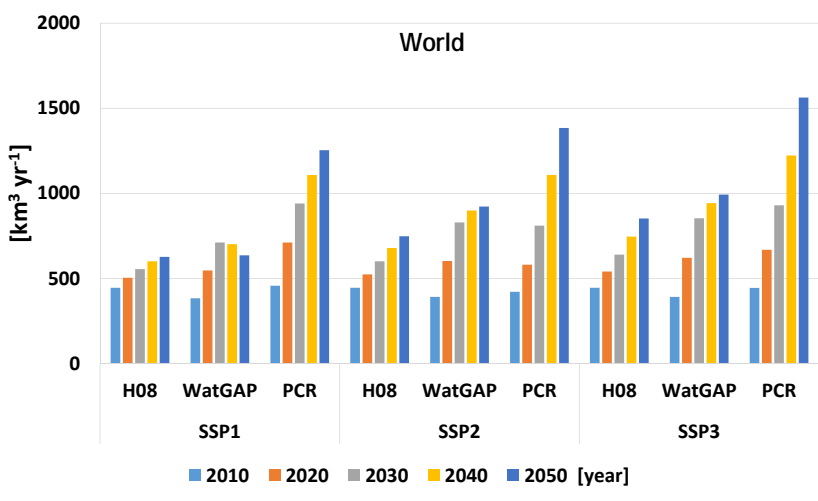

Figure 4. Global domestic water withdrawal projections calculated by the global water models H08, WaterGAP (WatGAP), and PCRGLOBWB (PCR) for the years 2010, 2020, 2030, 2040, and 2050, respectively, under three SSP scenarios (SSP1, SSP2, and SSP3).

under SSP1, while PCR-GLOBWB and WaterGAP project a steep increase. For WaterGAP, the large increase in industrial water withdrawals is partly explained by a sharp increase in manufacturing water use. In Saudi Arabia, the use of different data sets for the reference year causes a large spread in the ensemble projections. The net decrease in projected industrial water withdrawals is estimated by PCR-GLOBWB and WaterGAP, while $\mathrm{H} 08$ alone shows an increasing trend under all SSP scenarios considered.

\subsection{Municipal (domestic) sector}

Figure 4 shows ensembles of global domestic water withdrawal projections from the three global water models. Due to the rapid increase in world population, ensemble results among the three models show a sharp increase in domestic water withdrawals under all SSP scenarios. Depending on the scenario, global volume is projected to reach $700-1500 \mathrm{~km}^{3} \mathrm{yr}^{-1}$ by 2050 , which is an increase of 50 to $250 \%$ compared to the present water use intensity (400$450 \mathrm{~km}^{3} \mathrm{yr}^{-1}$ in 2010). In contrast to the industrial sector, the models agree in projecting a consistently increasing trend for future domestic water use by 2050, with a minor exception for WaterGAP, which projects a slight decrease in domestic water use after 2040 under the SSP1 scenario. However, compared to the present water use, WaterGAP still projects a $70 \%$ increase by 2050 under SSP1. However, PCR-GLOBWB projects a much higher increase in domestic water use by 2050 compared to H08 and WaterGAP. The increase by 2050 ranges between 40 and $70 \%$ (SSP1), 70 and $140 \%$ (SSP2), and 90 and 150\% (SSP3) for H08 and WaterGAP, respectively. For PCR-GLOBWB, the increase is projected to be much higher and reaches $170 \%$ (SSP1), $230 \%$ (SSP2), and $250 \%$ (SSP3).

Model results are shown in Fig. 5 for domestic water withdrawals for the same set of countries as shown in the industrial sector (Fig. 3). Although the agreement among modeled trends is high for the global sums, trends are not clear on the country scale. For example, for the USA and Germany, the projected trends in domestic water withdrawals show different signals by 2050 across the models. H08 projects an steadily increasing trend for both countries under all SSPs. For WaterGAP, the domestic water withdrawals are projected to increase up to 2020 or 2030 but decrease thereafter under all scenarios as a result of structural change and population development. The decrease is much larger under SSP1, where the domestic water withdrawals are projected to decrease by 10-20\% compared to the present water withdrawal. PCR-GLOBWB projects for the USA a rapid increase in domestic water withdrawals by 2050 under all scenarios, but for Germany, only a moderate or negligible increase under SSP1 and SSP2 and a large increase under SSP3.

For China, Brazil, India, and Egypt, ensemble projections show rather a consistent pattern across the models. For those countries, present domestic water withdrawals share altogether one-third of the global total, and population is projected to grow more rapidly than in other countries. H08 projects an increasing trend by 2050 under all scenarios, but the increase is much larger for SSP2 and SSP3 than SSP1. For PCR-GLOBWB, the projections show a steep increase under all scenarios. There is a pronounced increase in countries with large population growth (China, India, Egypt, Brazil), where the domestic water withdrawals are projected to quadruple in almost all scenarios and models. In Brazil WaterGAP shows a similar increasing trend with PCR-GLOBWB. However, the increase in domestic water withdrawals is much milder for the other countries in WaterGAP, particularly after the 2030s, where the domestic water withdrawals start decreasing for China, India, and Egypt under the SSP1 scenario due to a stabilization or decreasing trend in population. For Russia, PCR-GLOBWB projects a pronounced increase that is similar in China, Brazil, India, and Egypt under all scenarios, while H08 and WaterGAP show rather a constant or decreasing trend towards 2050 under almost all scenarios, except for a slight increase under the SSP3 scenario for H08. Similar to the industrial sector, the initial value at the reference year (2005) has a large difference between PCR-GLOBWB and the other two models, leading to a large spread in absolute values by 2050 . This is also the case for Germany, but between WaterGAP and the other two models. The ensemble projections show a consistent pattern for Saudi Arabia among the three models under all scenarios, where domestic water withdrawals are projected to increase by $100-200 \%$ until 2050 due to a growing population.

\section{Discussion}

Historically estimated water use intensity for industrial and domestic sectors by H08 (Hanasaki et al., 2008a, 

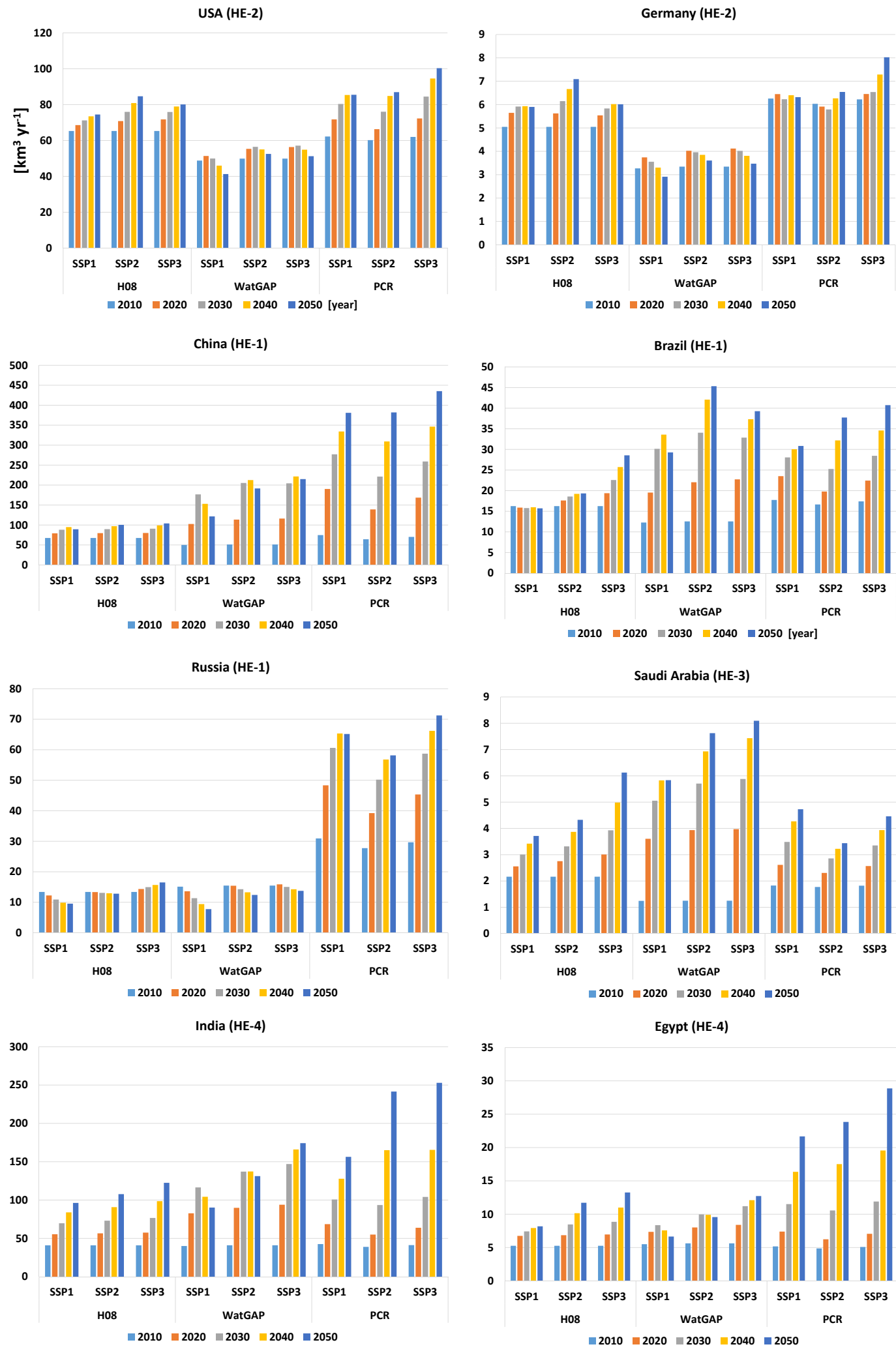

Figure 5. Domestic water withdrawal projections for selected countries calculated by the global water models H08, WaterGAP (WatGAP), and PCR-GLOBWB (PCR) for the years 2010, 2020, 2030, 2040, and 2050, respectively, under three SSP scenarios (SSP1, SSP2, and SSP3). HE denotes the hydro-economic classification (see Appendix A2). 
b), PCR-GLOBWB (Wada et al., 2010, 2011a, b, 2014b), and WaterGAP (Müller Schmied et al., 2014; Flörke et al., 2013) has been validated and compared well with reported statistics, primarily for developed countries $\left(R_{2}>0.8\right.$ and $0.9<$ slope $<1.1$ ) (e.g., FAO AQUASTAT, EUROSTAT, USGS) for a historical period (e.g., 1960-2010). However, our first global water use model intercomparison shows a remarkable difference between the three global water models (H08, PCR-GLOBWB, and WaterGAP) used, despite efforts to harmonize the socio-economic drivers (population, economy, and energy use) and the assumptions of technological and structural changes. Thus our current capability for providing consistent messages concerning future global water use remains uncertain. For the domestic sector, the direction of ensemble-projected water withdrawal trends is in good agreement across the models at the global level, although significant differences exist regionally (e.g., China, India, Russia). However, projected global and regional industrial water withdrawals are substantially different among the models. These results suggest that the current modeling framework may not be adequate for future assessments that use diverse ranges of scenarios (e.g., SSPs) and associated assumptions about socio-economic and technological change. Variability among the water use estimates is primarily affected by socioeconomic drivers and the modeling framework inherent in each model, while the impact of climate change is indirectly considered, e.g., energy water use in the industrial sector. For climate change impact on hydrology, we refer to Schewe et al. (2014). Here we discuss different sources of the uncertainty causing the large spread in ensemble water use projections. We also suggest methods to reduce uncertainty in global water use modeling and hence improve the robustness in following WFaS water use projections for the 21 st century.

\subsection{Sensitivity of modeling approaches to the results}

A major difference among the employed water models relates to the sector specific details and the number of input socio-economic variables employed in the calculation procedures. As discussed in the method section (Sect. 2), existing global water models use different methodological approaches to estimate sectoral water use. This is also true for the three water models applied in this study. As previously noted, H08 and PCR-GLOBWB determine water use for an aggregated industry sector. However, $\mathrm{H} 08$ uses primarily total electricity production, while PCR-GLOBWB uses GDP and total energy consumption in addition to total electricity production. For H08 and PCR-GLOBWB, these variables are used to estimate the future change in water use intensity by constructing the future trend, rather than actually calculating the absolute amount of industrial water use. In contrast, WaterGAP separates water use for thermal electricity production (e.g., technologies and cooling system types) and manufacturing, and uses those for the calculation of absolute amounts of these industrial sub-sectoral water uses for each year. This results in more complex functions where either electricity water use or manufacturing water use can dominate the future change in industrial water use. For example, projected industrial water use is dominated by the manufacturing sector in Brazil, Pakistan, Indonesia, and Mexico, and by the thermal electricity sector in China, the USA, and Canada. In the H08 and PCR-GLOBWB models detailed changes in manufacturing or thermal electricity water use cannot be captured. A simple approach may neglect future dynamic changes in sub-sectoral water use within the industrial sector. For example, SSP scenario narratives correspond to different sources of energy and changes in the economy including the structure of GDP. This may result in large variations of sub-sectoral water use intensity across countries, which can be important in capturing regional water use characteristics.

\subsection{Use of different reference data sets}

In addition to the different methodological approaches, we found that the use of different data sets for the reference year (2005) causes a remarkable difference in future amounts of industrial water use. In $\mathrm{H} 08$, industrial water use at the reference year (2005) is globally $10 \%$ lower compared to PCRGLOBWB and $20 \%$ lower than WaterGAP, i.e., meaning that the models start their simulations from a different starting point. The difference among the models is less obvious for the domestic sector $( \pm 5 \%)$. H08 and PCR-GLOBWB project the same future trend in industrial water use, however, the use of different data sets for the reference year (i.e., the starting point) immediately impacts the results and subsequent amounts of future water use. This was clearly demonstrated in some countries such as Russia and India. Although we harmonized the model drivers of socio-economics (GDP, population, energy) and assumptions on technological and structural change, the use of the same reference data set was not considered in the WFaS "fast-track" assessment. This is partly due to a lack of available data for many countries of the world on water withdrawals and consumptive use, particularly in industry. Locations of water users, water efficiency technological changes over time, and quantities of water withdrawals are largely unknown, and although the general factors that influence water demand are known, we often do not have enough information to show statistical significance.

H08 and PCR-GLOBWB estimate their initial water withdrawal based on the widely used AQUASTAT data from the FAO. AQUASTAT compiles country reported statistics of sectoral water use including a quality check. In WaterGAP the initial water use for the year 2005 is based on a separate compilation of statistical sources from individual countries. Reasons for apparent differences between these two approaches, both using statistical data reported by countries, were not investigated and are therefore unknown. Improvements in available data could be achieved by bottomup assessments such as investigation of individual water uses 

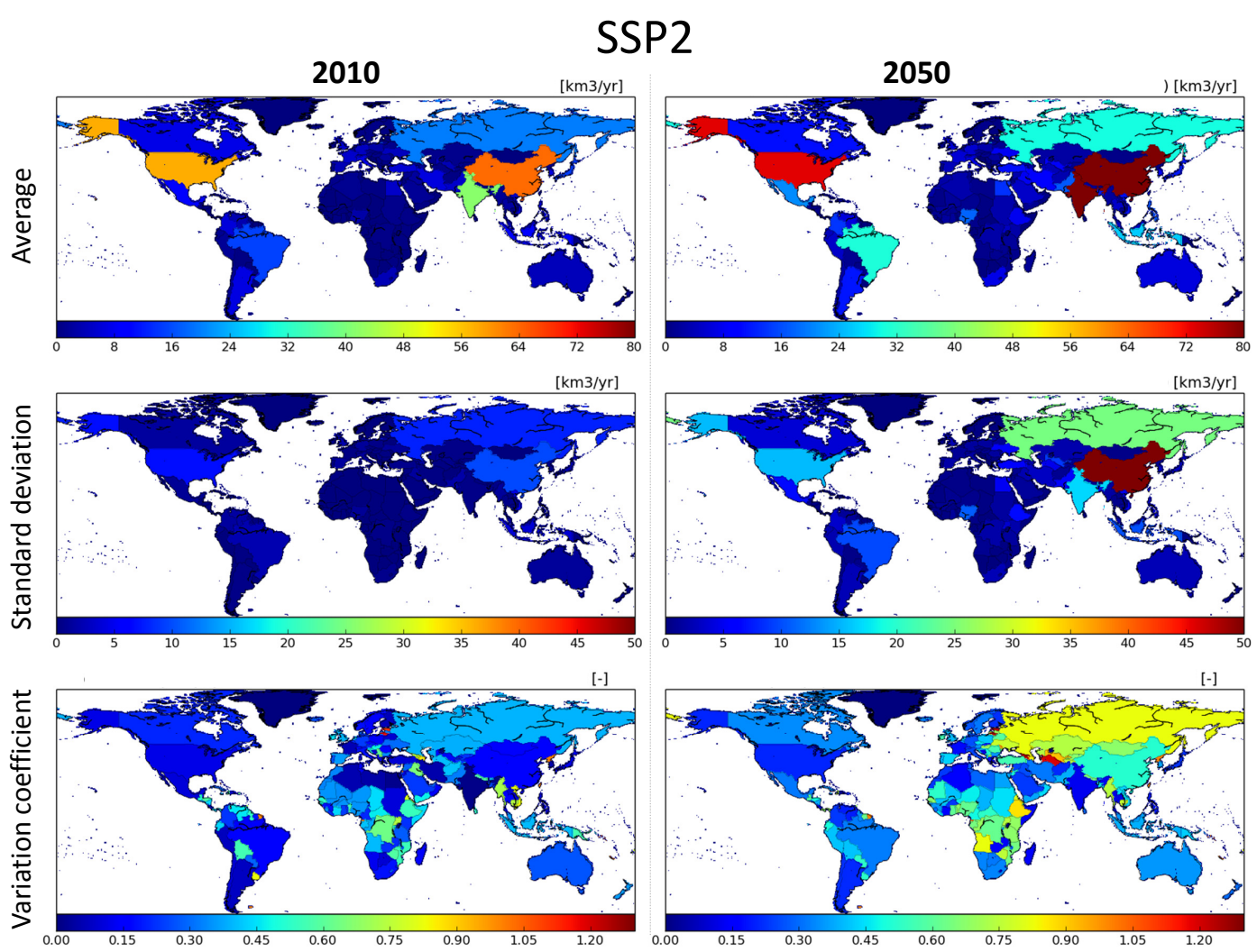

Figure 6. Global maps of projected domestic water withdrawals calculated by the global water models H08, PCR-GLOBWB, and WaterGAP for the years 2010 and 2050, respectively, under the SSP2 scenario. Avr, Std, and Std/Avr denote average, standard deviation, and coefficient of variations $(\mathrm{CV})$.

within the sectors and their influence on the total water demand for that sector. For example, household water uses for toilets, showers, washing machines, and dishwashers can be assessed along with technological changes in the appliances leading to improved water use efficiency over time, methods that are being investigated in the WaterGAP modeling framework. For industry the information sources used for water footprinting can be applied to better estimate water uses for different types of industry. Environmental economic accounting systems and water extended input-output modeling can provide data sources of water use intensities across sectors and can be used to assess changes over time in these industries. Applying this at the global scale may be challenging and involve significant data compilation work. Nevertheless, the use of the same reference data set for the start year could be considered in the next water use model intercomparison. Improved information can lead to the use of global water models for policy guidance and assessment of water management.

\subsection{Use of different socio-economic drivers}

Using different sets of socio-economic driver variables also results in significant differences. Future trends in industrial water use projections are similar among the three models for developed countries that correspond to the HE-2 classification (e.g., USA and Germany). H08 projects a decreasing trend under SSP1 for those emerging economies that correspond to HE-1 and HE-4. Apparently, projected increases in total electricity production are counterbalanced by assumed improvements in water use intensity due to technological changes. In contrast, PCR-GLOBWB and WaterGAP project a consistently increasing trend under the same scenario due to increasing GDP. However, it should be noted that the composition (sub-sectors) of GDP in the "Sustainability" scenario SSP1 is not known. There are some differences in projected trends between PCR-GLOBWB and WaterGAP, but these are mainly attributable to the difference in sub-sectoral water use calculation (aggregated vs. disaggregated). The use of different socio-economic variables such as GDP and energy consumption creates a different trend in PCR-GLOBWB and WaterGAP compared to that in H08. This was also the case for the domestic sector in which PCRGLOBWB projects a much higher increase in water use intensity by 2050 . GDP projections in the SSP scenarios increase significantly for almost all countries, particularly in emerging economies. The increase in total electricity production is much milder due to improvement in energy use inten- 

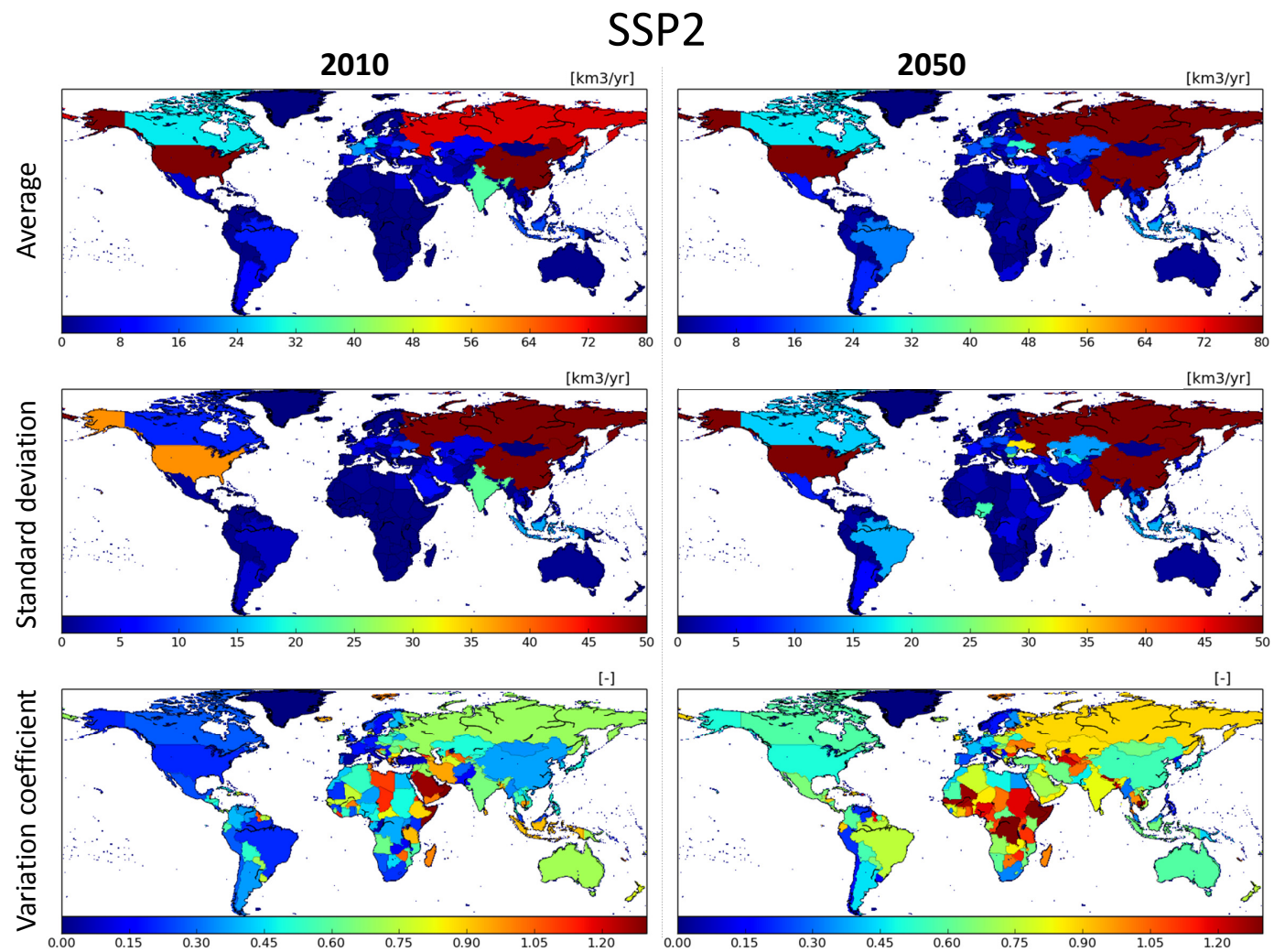

Figure 7. Global maps of projected industrial water withdrawals calculated by the global water models H08, PCR-GLOBWB, and WaterGAP for the years 2010 and 2050, respectively, under the SSP2 scenario. Avr, Std, and Std/Avr denote average, standard deviation, and coefficient of variations.

sity (i.e., higher electricity production per unit energy use), and technological and structural improvement. The calculation of (sub-)sectoral water use intensity using different sets of socio-economic variables should be further investigated.

\subsection{Spatial agreement among the models}

While the discussion above has focused on the difference in water use projections, there are also many regions where the estimated signals or trends are in agreement across the water models. Figure 6 shows global maps of projected domestic water withdrawals calculated by the three models. Since the projected trends and variability among the models are rather similar under the three SSP scenarios, here we show only the projections under the SSP2 scenario and we refer to Appendix A8 for the results of the SSP1 and the SSP3 scenario. For the domestic sector, the model agreement is rather high for almost all countries under the present condition $(\mathrm{CV}<0.3)$. However, by 2050 , the ensemble projections diverge and the model agreement becomes much lower for some countries such as Russia, China, Australia, and some countries in Central Asia (e.g., Afghanistan) and Africa (e.g., Ethiopia).

The model agreement for the industry sector is low $(\mathrm{CV}>0.5)$ for the current conditions in many countries
(Fig. 7). By 2050, the spread across the models becomes even wider for many countries in Asia, Africa, and South America by $2050(\mathrm{CV}>0.75)$. For both the industrial and domestic sector, the model agreement is particularly high for countries in North America (e.g., the USA), western Europe (e.g., Germany), and Japan both for present condition as well as the future projections $(\mathrm{CV}<0.3)$. These are countries where long time series of measured data do exist. Despite the differences in methodology and input data, the water models produce a smaller range in industrial and domestic water use projections for these countries compared to countries in the developing world and emerging economies. Thus future changes in water use projections of industrialized countries are apparently more robust. We consider the following reasons for attributing a higher confidence in future water use calculations of developed countries: (i) the scenario assumptions (i.e., technological changes according to SSPs narratives) and associated input data sources (e.g., GDP, electricity production, energy consumption) are more consistent with one another; (ii) the future change in socio-economic development is relatively stable so that the change is rather insensitive to the different methodological approaches of the models, and (iii) the input variable of total electricity production (which does not increase as strongly as in the developing world) dominates 
the calculation of (sub-)sectoral water use intensity for the three models. In addition, another important reason is that data availability is also higher in industrialized countries, where global water models produce their regression equations calculating water use intensity based on data in these areas. Therefore, the regressions are better fits in these areas, and extrapolations to other areas, particularly with extreme growth changes, will result in large extrapolation error.

\section{Conclusions and a way forward}

Global water models use generic yet diverse approaches to estimate water use per sector. The results produced from our first global water use model intercomparison showed a remarkable difference among the three global water models (H08, PCR-GLOBWB, and WaterGAP) used in the WFaS "fast-track" analysis. Although we harmonized model drivers and assumptions on technological and structural changes, the ensemble projections of water use showed a large variability across the models until 2050, and the spread was much larger in the industrial sector compared to the domestic sector. At the global level the signal of changes in future water use from the water models is as strong as the signal from the three scenarios employed. Although there is a high degree of variability across models and scenarios, all projections indicate significant increases in future industrial and domestic water uses. Despite potential model and data limitations, the WFaS initiative advances an important step beyond earlier work by attempting to account more realistically for the nature of human water use behavior in the 21 st century and to identify associated uncertainties and data gaps. Our results can be applied to assess future sustainability of water use under envisaged population growth and socio-economic developments.

Note that although this study does not include irrigation sector, extended explanations of irrigation scenario assumptions for key parameters (irrigation cropping intensity, utilization intensity of land equipped for irrigation, irrigation water use efficiency, and area equipped for irrigation) have been added in Appendix A9 to supplement the scenario development for irrigation sector, which completes the WFaS scenario development for all water use sectors. Comprehensive assessment of irrigation water use projections will be provided in a follow-up paper.

Below we address future perspectives for global water use model intercomparisons and possible improvements for a next step of model and study development.

1. The estimates are currently helping to identify hot spots where further investigation is needed, and in some cases may be used to test the implications of broad management and policy options, such as efficiency improvements.

2. The coarseness of current estimates and assumptions lead to a higher uncertainty in model results in some areas (e.g., Africa), and thus makes it more difficult to identify a robust solution with respect to water management options and where these are most needed.

3. As greater demands are placed on regions where water resources become increasingly scarce, we will need to improve our estimates to better assess the costs and benefits of a variety of water, energy, and land management strategies.

4. With respect to input data driver a breakdown of SSP scenarios for GDP projections in key sectors (agriculture, industry, services) would be very useful for improving the linkages between economic growth and water use.

5. For sub-sectoral differentiation, additional scenario assumptions and drivers are required that are so far not part of the socio-economic scenario development and need to be derived from expert and/or stakeholder consultation.

6. So far, global water use models have been driven by socio-economic variables, which probably do not totally reflect the development of water uses in the domestic and industrial sectors.

7. Current water use modeling approaches can be improved in the following ways:

- Harmonize the reference data set for a starting year under the present conditions

- Disaggregate the industrial sector into thermal electricity, manufacturing, and other sub-sectors (e.g., agro-industries) to incorporate the future dynamics of sub-sectoral water use.

However, both of these will require gathering more accurate information on present day water use (locations and quantities of water demands and technologies used), especially in countries where data is not available so far (close data gaps), so that agreement can be reached on the quality of input data and the various approaches can be tested and verified against measured data.

Finally, we note that currently not enough information is available to validate the water use modeling approaches consistently across the globe. Thus our object is not to assess which method or model provides better performance. We can only evaluate whether the resulting projections are reasonable, given the set of input data and associated scenario assumptions. Further analysis would be to contrast the change in future water use against available renewable water resource per country in order to assess realistic growth of future water use given projected economic development (e.g., GDP). 


\section{Appendix A}

\section{A1 Model descriptions}

\section{A1.1 H08}

A brief description of the water use submodel in the H08 model is presented here. A more detailed description is found in Hanasaki et al. (2006, 2008a, b, 2010, 2013a, b).

Industrial water withdrawal of individual country $(I)$ $\left(\mathrm{m}^{3} \mathrm{yr}^{-1}\right)$ is modeled as

$$
I=\operatorname{ELC} \times\left(i_{\text {ind }, t 0}+s_{\text {ind,cat }} \times\left(t-t_{0}\right)\right),
$$

where ELC is electricity production (MWh), $t 0$ is the base year, $i_{\text {ind }, t 0}$ is the industrial water intensity $\left(\mathrm{m}^{3} \mathrm{yr}^{-1} \mathrm{MWh}^{-1}\right)$ at $t 0$, and $s_{\text {ind,cat }}$ is the slope, or the rate of annual improvement in water intensity. The subscript cat indicates the three categories of industrial development stage. Industrial water withdrawal includes both manufacturing use and energy production. Therefore, $i_{\text {ind }, t 0}$ could be substantially higher if it included hydropower generation.

Municipal water withdrawal $\left(M ; \mathrm{m}^{3} \mathrm{yr}^{-1}\right)$ is modeled as

$M=\mathrm{POP} \times\left(i_{\mathrm{mun}, t 0}+s_{\mathrm{mun}, \mathrm{cat}} \times\left(t-t_{0}\right)\right) \times 0.365$,

where POP is the population (number of individuals), $i_{\text {mun }, t 0}$ is the municipal water intensity for the base year $\left(\mathrm{Lday}^{-1}\right.$ person $\left.^{-1}\right), s_{\text {mun,cat }}$ is slope, and the multiplier 0.365 is applied for unit conversion.

The performance of $\mathrm{H} 08$ has been assessed in earlier publications (Hanasaki et al., 2006, 2008a, b, 2010, 2013a, b). Hanasaki et al. (2013a) applied the industrial and municipal water withdrawal models for 16 and 21 countries and showed that the models reasonably reproduced the historical variation in water withdrawal.

\section{A1.2 PCR-GLOBWB}

A brief description of the water use calculation in the PCRGLOBWB model is provided here. A more detailed description is found in Wada et al. (2011a, b, 2013a, 2014a, b).

The calculation of industrial and household water demand considers the change in population and socio-economic and technological development. Gridded industrial water demand data for 2000 are obtained from Shiklomanov (1997), WRI (1998), and Vörösmarty et al. (2005). To calculate time series of industrial water demand, the gridded industrial water demand for 2000 is multiplied by water use intensities calculated with an algorithm developed by Wada et al. (2011a, b). The algorithm (Eqs. A3-A5) calculates country-specific economic development based on four socio-economic variables: gross domestic product (GDP), electricity production, energy consumption, and household consumption. Associated technological development per country was then approximated by energy consumption per unit electricity production, which accounts for industrial restructuring or improved water use efficiency.

$$
\begin{aligned}
& \operatorname{IWD}_{\mathrm{cnt}, t}= \operatorname{EDev}_{\mathrm{cnt}, t} \times \operatorname{TDev}_{\mathrm{cnt}, t} \times \mathrm{IWD}_{\mathrm{cnt}, t 0}, \\
& \operatorname{EDev}_{\mathrm{ent}, t}=\operatorname{average}\left(\left(\frac{\mathrm{GDP}_{\mathrm{pc}, t}}{\mathrm{GDP}_{\mathrm{pc}, t 0}}\right)^{0.5},\left(\frac{\mathrm{EL}_{\mathrm{pc}, t}}{\mathrm{EL}_{\mathrm{pc}, t 0}}\right)^{0.5},\right. \\
&\left.\left(\frac{\mathrm{EN}_{\mathrm{pc}, t}}{\mathrm{EN}_{\mathrm{pc}, t 0}}\right)^{0.5},\left(\frac{\mathrm{HC}_{\mathrm{pc}, t}}{\mathrm{HC}_{\mathrm{pc}, t 0}}\right)^{0.5}\right), \\
& \operatorname{TDev}_{\mathrm{cnt}}=\left(\frac{\mathrm{EN}_{\mathrm{pc}, t}}{\mathrm{EL}_{\mathrm{pc}, t}}\right) /\left(\frac{\mathrm{EN}_{\mathrm{pc}, t 0}}{\mathrm{EL}_{\mathrm{pc}, t 0}}\right),
\end{aligned}
$$

where IWD is industrial water demand, $\mathrm{EDev}_{\mathrm{cnt}}$ is economic development, and TDev is technological development. GDP, EL, EN and $\mathrm{HC}$ are gross domestic product, electricity production, energy consumption and household consumption, respectively. pc and cnt are per capita and per country. $t$ and t0 represent year and base year, respectively. Thus $\mathrm{IWD}_{\mathrm{cnt}, t 0}$ is industrial water demand for the year 2000.

Household water demand is estimated by multiplying the number of persons in a grid cell by the country-specific per capita domestic water withdrawal. The daily course of household water demand is calculated using daily air temperature as a proxy (Wada et al., 2011a). Water use intensity for household water demand is calculated as

$$
\begin{aligned}
\mathrm{DWD}_{\mathrm{cnt}, y} & =\mathrm{POP}_{\mathrm{cnt}, y} \times \mathrm{EDev}_{\mathrm{cnt}, y} \times \mathrm{TDev}_{\mathrm{cnt}, y} \\
& \times \mathrm{DWUI}_{\mathrm{cnt}, t 0},
\end{aligned}
$$

where DWD is domestic water demand, POP is national population and DWUI is domestic water use intensity. DWUI $\mathrm{cnt}_{\mathrm{nt}} t$ is the country per capita domestic water withdrawals in 2000 that were taken from the FAO AQUASTAT database and Gleick et al. (2009), and multiplied by $\operatorname{EDev}_{\mathrm{cnt}}$ and TDev to account for economic and technological development.

\section{A1.3 WaterGAP}

The global water model WaterGAP (Water - Global Assessment and Prognosis) is a grid-based, integrative assessment tool to examine the current state of global freshwater resources and to assess potential impacts of global change in the water sector. Its capabilities to simulate water availability and water use have been well tested in various scenario assessments including the Global Environment Outlook reports GEO-4/5, the State of the European Environment report, and the Millennium Ecosystem Assessment. The WaterGAP modeling framework consists of three main components: a global hydrology model to simulate the terrestrial water cycle (Döll et al., 2012; Müller Schmied et al., 2014), five sectoral water use models (Flörke et al., 2013) to estimate water withdrawals and water consumption of the domestic, thermal electricity production, manufacturing, and 
agricultural sectors, and a large-scale water quality model (Reder et al., 2015). A brief description of the water use calculation in the WaterGAP model is described here. A more detailed description is given in Flörke et al. (2013).

Spatially distributed sectoral water withdrawals and consumption are simulated for the five most important water use sectors: irrigation, livestock, industry, thermal electricity production, and households and small businesses. Countrywide estimates of water use in the manufacturing and domestic sectors are calculated based on data from national statistics and reports and are then allocated to grid cells within the country based on the geo-referenced population density and urban population maps (Klein Goldewijk, 2005; Klein Goldewijk et al., 2010) as described in Flörke et al. (2013).

WaterGAP estimates domestic water demand based on population and domestic water use intensity $\left(\mathrm{m}^{3}\right.$ capita $\left.^{-1} \mathrm{yr}^{-1}\right)$ that reflects structural and technological change. Structural change is described by a sigmoid curve, assuming that water use intensity increases along average income increase, but eventually either stabilizes or declines after a certain level. They use regional and national curves, depending on data availability. The concept of technological change takes improvement in water use efficiency into account.

$\mathrm{DWD}=\mathrm{MSWI} \times \mathrm{Pop} \times \mathrm{TC}$,

$\mathrm{MSWI}=\mathrm{MSWI}_{\min }+\frac{\mathrm{MSWI}_{\max }}{1-e^{-r_{d}\left(\frac{\mathrm{GDP}}{\mathrm{pop}}\right)^{2}}}$,

where DWD is domestic water demand (UNIT), MSWI is municipal structural water intensity (UNIT), TC is technological change rate, rd is the curve parameter that is determined iteratively to optimally fit the data set, Pop is population, and GDP is gross domestic product. In order to determine parameters, historical data of national statistics including environmental reports are used. GDP per country is given mainly from the World Bank's World Development Indicators. National population numbers are derived from the World Bank's World Development Indicators and the United Nations Population Division (http://www.un.org/en/ development/desa/population/).

WaterGAP estimates the thermoelectric water demand separately from manufacturing water demand. The amount of cooling water withdrawn and consumed for thermal electricity production is determined by multiplying the annual thermal electricity production with the water use intensity of each power station, respectively (see Eq. 3). Input data on location, type and size of power stations are based on the World Electric Power Plants Data Set 2004. The water use intensity is impacted by the cooling system and the source of fuel of the power station. Four types of fuels (biomass and waste, nuclear, natural gas and oil, coal and petroleum) with three types of cooling systems (tower cooling, once-through cooling, ponds) are distinguished (Flörke et al., 2013). The manufacturing module presents country level water demand

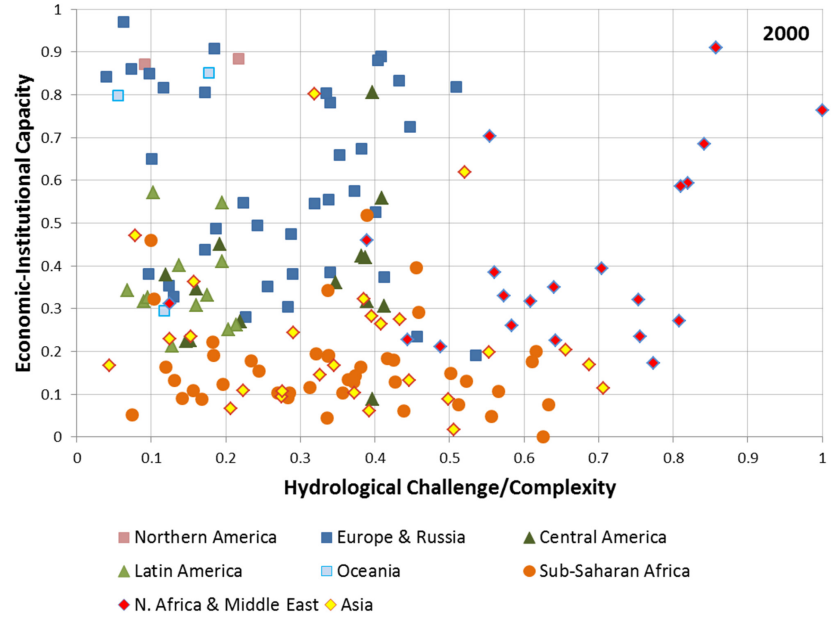

Figure A1. Hydro-economic (HE) classification of countries according to their level of hydrological complexity ( $x$ axis) and their economic-institutional coping capacity ( $y$ axis).

as a function of the manufacturing gross value added (GVA) (see Eq. 4).

\section{A2 Hydro-economic (HE) classification for use in water scenario analysis}

The global quantitative WFaS scenario assessment targets potentials, stressors and their interdependencies of the different water sectors affecting the earth ecosystems and the services they provide. A global assessment is essential in view of the increasing importance of global drivers such as climate change, economic globalization or safeguarding biodiversity. Developing a new systems approach to the water scenario futures of the WFaS initiative necessitates maintaining a global perspective while ensuring sufficient regional detail to identify appropriate future pathways and solutions (Fischer et al., 2015).

Following Grey's approach (Grey et al., 2013) to consider water security in a risk framework entails quantifying economic capacity and, often closely related, viable institutions for managing watersheds on the one hand and the prevailing natural conditions affecting the hydrology of water systems and water use on the other hand. Both dimensions, socio-economics and hydrological complexity are in principle quantifiable using appropriate proxies. The HE classification is derived from two broad dimensions representing (i) a country's economic and institutional capacity to address water challenges and (ii) each country's magnitude/complexity of water challenges in terms of water availability and variability within and across years. For each country two normalized compound indicators are calculated from a number of component indicators.

After selecting relevant indicator variables and data sources for $X$ and $Y$ dimensions of the hydro-economic clas- 
sification scheme (Fig. A1) the classification proceeds as follows:

1. For each indicator variable we define 5 classes along a relevant scale (decide on linear or log scale as appropriate). Typical class names would be, for instance, "very low", "low", "medium", "high", "very high" (or similar).

2. We map each indicator/variable to a normalized index value by first determining the interval (broad class) into which the indicator falls in each country/region and second calculating a normalized index value for the respective indicator/variable.

3. Decide on a weight for each sub-index.

4. Calculate the composite indicator as weighted sum of the normalized sub-indexes for the $X$ and $Y$ dimension separately.

For more details of the methodology for the calculation of indicators we refer to Fischer et al. (2015).

The HE classification is derived from two broad dimensions representing (i) a country's economic and institutional capacity to address water challenges and (ii) each country's magnitude/complexity of water challenges in terms of water availability and variability within and across years.

Economic-institutional coping capacity:

1. GDP per capita (purchasing power parity corrected) as a measure of economic strength and financial resources that could be invested in risk management; and

2. The Corruption Perception Index (CPI) indicator as a measure of institutional capacity to adopt good governance principles (efficiency, effectiveness, transparency, accountability, inclusiveness, rule of law) in governance and management of risks.

Hydrological complexity:

1. Total renewable water resources per capita as a measure of water availability

2. Ratio of total water withdrawal to total renewable water resource availability as a proxy for relative intensity of water use

3. The coefficient of variation over 30 years of monthly runoff as a proxy for both inter- and intra-annual variability of water resources

4. The share of external (from outside national boundaries) to total renewable water resources as a measure for the dependency of external water resources

Figure A1 presents a scatter plot of the two compound indicators calculated for 160 countries of the world for the

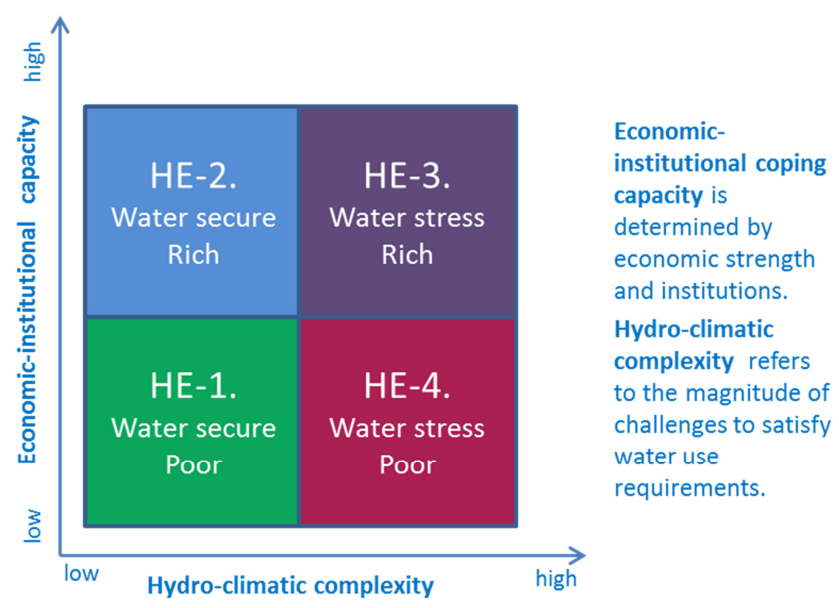

Figure A2. Hydro-economic (HE) quadrants for human-natural water development challenges.

year 2000. Data sources include the World Bank (GDP per capita, PPP in constant 2005 USD), the United Nations (population numbers), FAO AQUASTAT (total renewable water resources, total water withdrawal, external water resources), and a model ensemble of six hydrological models calculated from the ISI-MIP project (coefficient of variation of monthly runoff).

Countries with high HE development challenges are located towards the lower right corner of the scatter plot as their economic-institutional coping capacity is low while at the same time their hydrological complexity is high (e.g., Pakistan, Egypt, Sudan, Iraq). In contrast, the upper left corner includes countries with high economic-institutional coping capacity and relatively low hydrological complexity (e.g., USA, Japan, Germany, Canada). Over time, countries will shift their relative position in the scatter plot because of their demographic and economic development, but also because water resources may be affected by climate change.

To develop water scenario assumptions, it is useful to group the countries into a few classes. In the WFaS "fasttrack" analysis we divided the space of HE development challenges into four quadrants (Fig. A5). For simplicity these are termed hydro-economic 1 or HE-1 (water secure, poor), HE-2 (water secure, rich), HE-3 (water stress, rich), and HE4 (water stress, poor). Class HE-1 includes countries characterized as low- to mid-income and regarded as having only moderate hydrological challenges. Class HE-2 denotes countries of mid- to high income and with moderate hydrological challenges. Countries in class HE-3 have mid- to high income and are facing substantial hydrological challenges and, finally, class HE-4 comprises countries with low- to mid-income and substantial hydrological challenges; hence, countries require large economic development in a context of severe water challenges. Table A1 summarizes the HE country classification results in terms of number of countries, area and population belonging to each of the four HE classes. 
Table A1. Number of countries, area and population belonging to the four hydro-economic (HE) quadrants.

\begin{tabular}{rrrr}
\hline & $\begin{array}{r}\text { Number } \\
\text { of countries }\end{array}$ & $\begin{array}{r}\text { Area } \\
\text { in million km }\end{array}$ & $\begin{array}{r}\text { Population } \\
\text { in million people }\end{array}$ \\
\hline HE-1 & 94 & 75.7 & 3443 \\
HE-2 & 31 & 34.0 & 927 \\
HE-3 & 9 & 2.7 & 91 \\
HE-4 & 26 & 21.3 & 1643 \\
\hline
\end{tabular}

Note that over time countries will shift their relative position in the scatter plot because of their demographic and economic development but also because water resources may be affected by climate change. To keep the analysis simple the WFaS "fast-track" analysis retains countries over in the respective HE class of the year 2000. However, WFaS forthcoming scenario analysis plans to incorporate a dynamic process of HE classification over time. Table A2 provides the number of population belonging to each of the four HE classes for the different SSPs considered in this study in the year 2010, 2030, and 2050, respectively.

\section{A3 Summary of SSP storylines and WFaS "fast-track" scenario assumptions}

Here we provide in bullet form a brief summary of the salient features that characterize different shared socio-economic development pathways (SSPs) (O'Neill et al., 2015) by scrutinizing each SSP narrative for developments relevant for water use in the respective sector (agriculture, industry, domestic), and indicate some implications this may have for water use in each sector. This information together with the HE classes (see Sect. A2) was used to quantify WFaS "fasttrack" scenario assumptions (Table 5) as described below.

\section{A4 Agricultural sector}

We indicate some implications the SSP narratives may have for the agricultural sector, the use of rain-fed and irrigated land, and for associated irrigation water withdrawal and use.

\section{SSP1: sustainability - taking the green road}

- Sustainability concerns; more stringent environmental regulation implemented

- Rapid technological change

- Energy efficiency and improved resource efficiency

- Relatively low population growth; emphasis on education

- Effective institutions

- Wide access to safe water
- Emphasis on regional production

- Some liberalization of agricultural markets

- Risk reduction and sharing mechanisms in place

The above general tendencies of development in the SSP1 world, which is gradually moving towards sustainability, can be interpreted as having the following agriculture/irrigationrelated implications.

- Improved agricultural productivity and resource use efficiency

- Quite rapid reduction of prevailing yield gaps toward environmentally sustainable and advanced technology yield levels

- Improving nutrition with environmentally benign diets with lower per capita consumption of livestock products

- Enforced limits to groundwater over-exploitation

- Large improvements in irrigation water use efficiency where possible

- Reliable water infrastructure and water supply

- Enhanced treatment and reuse of water

- Concern for pollution reduction and water quality, implying widespread application of precision farming and nutrient management

- Risk management and related measures implemented to reduce and spread yield risks

\section{SSP2: middle of the road}

- Most economies are politically stable.

- Markets are globally connected but they function imperfectly.

- Slow progress in achieving development goals of education, safe water, and health care

- Technological progress but no major breakthroughs

- Modest decline in resource use intensity

- Population growth levels off in the second half of the century.

- Urbanization proceeds according to historical trends.

- Consumption is oriented towards material growth.

- Environmental systems experience degradation.

- Significant heterogeneities exist within and across countries. 
Table A2. Number of population belonging to the four hydro-economic (HE) quadrants under SSP1, SSP2, and SSP3 for the years 2010 , 2030, and 2050, respectively. HE99 indicates territories that are not assigned to HE classes.

\begin{tabular}{|c|c|c|c|c|c|c|c|c|c|}
\hline \multirow{2}{*}{$\begin{array}{l}\text { Population } \\
\text { millions }\end{array}$} & \multicolumn{3}{|c|}{2010} & \multicolumn{3}{|c|}{2030} & \multicolumn{3}{|c|}{2050} \\
\hline & SSP1 & SSP2 & SSP3 & SSP1 & SSP2 & SSP3 & SSP1 & SSP2 & SSP3 \\
\hline HE1 & 3816 & 3816 & 3816 & 4360 & 4508 & 4672 & 4504 & 4896 & 5407 \\
\hline HE2 & 985 & 985 & 985 & 1086 & 1076 & 1014 & 1165 & 1135 & 960 \\
\hline HE3 & 110 & 110 & 110 & 139 & 141 & 135 & 156 & 161 & 150 \\
\hline HE4 & 1939 & 1939 & 1939 & 2391 & 2513 & 2656 & 2609 & 2945 & 3402 \\
\hline HE99 & 20 & 20 & 20 & 24 & 25 & 26 & 26 & 28 & 31 \\
\hline TOTAL & 6870 & 6870 & 6870 & 8000 & 8263 & 8504 & 8459 & 9164 & 9949 \\
\hline
\end{tabular}

- Food and water insecurity remains in areas of lowincome countries.

- Barriers to entering agricultural markets are reduced only slowly.

- Moderate corruption slows effectiveness of development policies.

The SSP2 world is characterized by dynamics similar to historical developments. This would imply continuation of agricultural growth paths and policies, continued protection of national agricultural sectors, and further environmental damages caused by agriculture.

- Modest progress of agricultural productivity

- Slow reduction of yield gaps, especially in low-income countries

- Increasing per capita consumption of livestock products with growing incomes

- Persistent barriers and distortions in international trade of agricultural products

- No effective halt to groundwater over-exploitation

- Some improvements in water use efficiency, but only limited advances in low-income countries

- Some reduction of food insecurity due to trickle down of economic development

- Food and water insecurities remain as problems in some areas of low-income countries.

- No effective measures to prevent pollution and degradation by agricultural practices; environmental risks caused by intensive application of fertilizers and agrochemicals, and intensive and concentrated livestock production systems

- Only moderate success in reducing climate risks and vulnerability

\section{SSP3: regional rivalry - a rocky road}

- Growing concerns about globalization and focus on national/regional issues and interests

- Markets (agriculture, energy) are protected and highly regulated.

- Global governance and institutions are weak

- Low priority for addressing environmental problems

- Slow economic growth

- Low investment in education and technology development

- Poor progress in achieving development goals of education, safe water, health care

- Increase in resource use intensity

- Population growth low in developed, high in developing countries; overall large increase

- Urbanization proceeds slowly; disadvantaged continue to move to unplanned settlements.

- Serious degradation of environmental systems in some regions

- Large disparities within and across countries

- Weak institutions contribute to slow development.

Development in the SSP3 world will lead to manifold problems in food and agriculture, with implications for irrigation development and water challenges, characterized by

- Poor progress with agricultural productivity improvements in low-income countries due to lack of investment and education

- Widespread lack of sufficient investment and capacity for yield gap reduction in developing countries 
- Growing protection of national agricultural sectors and increasing agricultural trade barriers

- Low priority to halt environmental degradation caused by agriculture (erosion, deforestation, poor nutrient management, water pollution and exploitation)

- Widespread pollution and deterioration of ecosystems

- Continued deforestation of tropical rainforests

- Only modest improvements in irrigation water use efficiency

- Persistent over-exploitation of groundwater aquifers

- widespread lack of access to safe water and sanitation

- Unreliable water and energy supply for agricultural producers

- Food and water insecurity persist as major problems in low-income countries

- High population growth and insufficient development leave behind highly vulnerable human and environmental systems.

\section{SSP4: inequality - a divided road}

- Inequalities within and between countries increase; fragmentation increases.

- Wealth and income increasingly concentrate at the top.

- Global governance and institutions are weak.

- Public expenditures focus on and benefit a small, highly educated elite.

- Polarization creates a mixed world with income inequality increasing.

- Political and economic power becomes more concentrated in a small political and business elite

- Increasing price volatility in biomass and energy markets

- Well-educated elite induces technical progress and efficiency improvements.

- A world that works well for the elite but where development stagnates or decreases opportunities for those left behind

- Low fertility in developed countries. High fertility and high urbanization in low and middle income countries.

- Large disparities of incomes and well-being within and across countries
- Poor access to institutions by the poor

- No adequate protection for those losing out in development; these groups lose assets and livelihoods.

Development in the SSP4 world creates a polarization and unequal societies with small and well-educated elites and a large share of poor and under-privileged citizens. For agriculture/irrigation use, this may imply the following.

- In part, the trend is towards large, technologically advanced and profitable farms. Yet, at the same time, there is also poor progress of agricultural productivity in lowincome farm households due to lack of investment and education.

- Land and water grabbing to the benefit of elites and large international agro-complexes

- Efficient irrigation systems used for profitable and internationally traded cash crops. Little improvements in irrigation efficiencies of the low-income farm sector.

- In low-income countries, food and water insecurity persist as major problems outside the privileged elites.

- High population growth in developing countries and polarizing development leave behind highly vulnerable rural systems.

- No adequate protection for those losing out in development; these groups lose assets and livelihoods.

- Co-existence of well-organized agricultural production and marketing chains, run by the elite, and widespread subsistence and landless dwellers in rural areas

\section{SSP5: fossil-fueled development - taking the highway}

- The world is developing rapidly, powered by cheap fossil energy.

- Economic success of emerging economies leads to convergence of incomes.

- Decline in income inequality within regions

- World views oriented towards market solutions

- Developing countries follow the development model of the industrial countries.

- Rapid rise in global institutions

- Strong rule of law; lower levels of corruption

- Accelerated globalization and high levels of international trade

- Policies emphasizing education and health 
- Consumerism, resource-intensive status consumption, preference for individual mobility

- Population peaks and declines in the 21st century

- Strong reduction of extreme poverty

- Very high global GDP; continued large role of manufacturing sector

- All regions urbanize rapidly.

- Widespread technology optimism; high investments in technological innovations

- Local environmental problems addressed effectively; however, lack of global environmental concern and solutions

Development in the SSP5 world is rapid and based on consumerism, fossil energy, and fast technological progress. World views and policies follow an "economics and development first" paradigm.

- Agro-ecosystems become more and more managed in all world regions.

- Large increases in agricultural productivity; diffusion of resource-intensive management practices in agriculture

- Large improvements in irrigation water use efficiency

- Enhanced treatment and reuse of water

- High per capita food consumption and meat-rich diets globally

- Land and environmental systems are highly managed across the world.

- Large reduction of agricultural sector support measures

- Global agricultural markets are increasingly integrated and competitive.

- Improved accessibility due to highly engineered infrastructures

- Large-scale engineering of water infrastructure to manage and provide reliable water supply

- Economic use of land is given priority over nature protection and sustainability of ecosystems.

\section{A5 Industry sector}

The size, structure and technologies applied in the electricity and manufacturing sectors and their impact on water use and water use intensities are closely linked to resource efficiency of the economy, implementation of environmental regulations, and progress in water-saving technologies.

\section{SSP1: sustainability - taking the green road}

Elements of the SSP storyline relevant for the ELECTRICITY sector

- reduced overall energy demand over the longer term

- lower energy intensity, with decreasing fossil fuel dependency

- Relatively rapid technological change is directed toward environmentally friendly processes, including energy efficiency and clean energy technologies; favorable outlook for renewables - increasingly attractive in the total energy mix.

- Strong investment in new technologies and research improves energy access.

- advances alternative energy technologies

Implications for electricity water use intensity

- Reduction in energy demand will decrease the demand for water from the energy sector substantially even if world population, primary energy production, and electricity generation were to increase.

- A shift away from traditional biomass toward less consumptive energy carriers, as well as the changing energy mix in electricity generation, could lead to water savings.

- A favorable outlook for renewables will cause big structural and efficiency shifts in the choice of technology, with variable consequences for water use intensity and efficiency, depending on the renewable type. For example, an expanding output of biofuels will lead to a rise in water consumption, whereas a shift towards photovoltaic solar power or wind energy will lead to a decrease in water use intensity.

- Higher energy efficiency could translate into a relatively lower water demand and improvements in water quality, following high standards that commit industry to continually improving environmental performance.

- Overall, structural and technological changes will result in decreasing water use intensities in the energy sector. For example, the widespread application of watersaving technologies in the energy sector will significantly reduce the amount of water used not only for fuel extraction and processing, but also for electricity generation.

Elements of the SSP storyline relevant for the MANUFACTURING sector

- Improved resource-use efficiency 
- More stringent environmental regulations

- Rapid technological change is directed toward environmentally friendly processes.

- Research and technology development reduce the challenges of access to safe water.

- Risk reduction and sharing mechanism

Implications for manufacturing water use

- The importance of the manufacturing sector in the overall economy decreases further due to the increasing importance of the non-resource using service sector.

- Manufacturing industries with efficient water use and low environmental impacts are favored and increase their competitive position against water-intensive industries.

- Enhanced treatment, reuse of water, and water-saving technologies; widespread application of water-saving technologies in industry

\section{SSP2: middle of the road}

Elements of the SSP storyline relevant for the ELECTRICITY sector

- Continued reliance on fossil fuels, including unconventional oil and gas resources

- Stabilization of overall energy demand in the long run

- Energy intensity declines, with slowly decreasing fossil fuel dependency.

- Moderate pace of technological change in the energy sector

- Intermediate success in improving energy access for the poor

Implications for electricity water use intensity

- Reliance on fossil fuels may lead to only minor structural and efficiency shifts in technology.

- Stabilization of overall energy demand in the long run will lead to little or no change in water demand for fuel extraction, processing and electricity generation.

- A decline in energy intensity will lower water demand.

- A moderate pace in technological change will cause minor structural and efficiency shifts in technology, and ultimately water use intensity will change only slightly.

- Weak environmental regulation and enforcement trigger only slow technological progress in water use efficiencies.
- Regional stress points will increase globally. Power generation in regional stress points will likely have to deploy more and more technologies fit for waterconstrained conditions to manage water-related risks, though this can involve tradeoffs in cost, energy output and project siting.

- In general, if historic trends remain the same, water use intensities will continue to decrease in the most developed regions. However, there will be slow progress in Africa, Latin America and other emerging economies.

Elements of the SSP storyline relevant for the MANUFACTURING sector

- The SSP2 world is characterized by dynamics similar to historical developments.

- Moderate awareness of environmental consequences from natural resource use

- Modest decline in resource intensity

- Consumption oriented towards material growth

- Technological progress but no major breakthrough

- Persistent income inequality (globally and within economies)

Implications for manufacturing water use

- Manufacturing GVA further declines in relative terms.

- Moderate and regionally different decreases of manufacturing water use intensities

- Following historic trends, water use intensities further decrease in the most developed regions, but there is less progress in Africa, Latin America and other emerging economies.

- Weak environmental regulation and enforcement trigger only slow technological progress in water use efficiencies.

\section{SSP3: regional rivalry - a rocky road}

Elements of the SSP storyline relevant for the ELECTRICITY sector

- Growing resource intensity and fossil fuel dependency

- Focus on achieving energy and food security goals within their own region

- Barriers to trade, particularly in the energy resource and agricultural markets

- Use of domestic energy results in some regions increases heavy reliance on fossil fuels. 
- Increased energy demand driven by high population growth and little progress in efficiency.

Implications for electricity water use intensity

- Barriers in trade may trigger slow technological progress in water use efficiencies. A moderate pace in technological change will cause minor structural and efficiency shifts in technology, and ultimately water use intensity will change only slightly.

- Reliance on fossil fuels may lead to only minor structural and efficiency shifts in technology.

- An increase in energy intensity will increase water demand, whereas little progress in efficiency would trigger increased water demand as energy use intensifies.

- Weak environmental regulation and enforcement hamper technological progress in water use efficiencies; hence, very slow progress in water-saving technologies.

Elements of the SSP storyline relevant for the MANUFACTURING sector

- Low priority for addressing environmental problems

- Resource-use intensity is increasing.

- Low investment in education and technological development

- Persistent income inequality (globally and within economies)

- Weak institutions and global governance

Implications for manufacturing water use

- Manufacturing GVA in relative terms (\% of GDP) declines slower than historic trends.

- Weak environmental regulation and enforcement hamper technological progress in water use efficiencies.

- Very slow progress in water-saving technologies

- Water use intensities increase only marginally, primarily in the most developed regions.

\section{SSP4: inequality - a road divided}

Elements of the SSP storyline relevant for the ELECTRICITY sector

- Oligopolistic structures in the fossil fuel market leads to underinvestment in new resources.

- Diversification of energy sources, including carbonintensive fuels like coal and unconventional oil, but also low-carbon energy sources like nuclear power, largescale CSP (concentrated Solar power), large hydroelectric dams, and large biofuel plantations
- A new era of innovation that provides effective and well-tested energy technologies

- Renewable technologies benefit from the high technology development.

Implications for electricity water use intensity

- A move towards more water-intensive power generation will lead to a rise in water consumption. However, new technologies in processing primary energy, especially in the thermal electricity generation, as well as an increased use of renewable energy and improved energy efficiency, will have an impact on water savings.

- Rapid technical progress could trigger water efficiency improvements in the energy sector, which then will translate into a decrease in water use intensities. However, the progress will be mainly in richer regions, whereas the energy sector in low-income counties may stagnate, with little progress in decreasing water use intensities.

- Regional stress points will increase globally. Power generation in regional stress points will likely have to deploy more and more technologies fit for waterconstrained conditions to manage water-related risks, though this can involve tradeoffs in cost, energy output and project siting.

- For additional implication: ref. implications for both SSP1 and 2 depending on the energy path. Continued use of nuclear power and large-scale CSPs, for instance, will intensify water use.

Elements of the SSP storyline relevant for the MANUFACTURING sector

- Increasing inequality in access to education, a well educated elite

- Rapid technological progress driven by a well-educated elite.

- Persistent income inequality (globally and within economies)

- Labor-intensive, low-tech economy persists in lower income, poorly educated regions.

Implications for manufacturing water use

- Manufacturing GVA in relative terms (\% of GDP) declines in economically rich regions, but decreases very slowly in poorer regions.

- Rapid technical progress triggers water efficiency improvements in manufacturing. However, the progress is mainly implemented in rich regions.

- The manufacturing sector in low-income, poorly educated regions stagnates, with little progress in decreasing water use intensities. 


\section{SSP5: fossil-fueled development - taking the highway}

Elements of the SSP storyline relevant for the ELECTRICITY sector

- Adoption of energy-intensive lifestyles

- Strong reliance on cheap fossil energy and lack of global environmental concern

- Technological advancements in fossil energy mean more access to unconventional sources.

- Alternative energy sources are not actively pursued.

Implications for electricity water use intensity

- The structure of the energy sector is driven by market forces, with water-intensive energy sources and technologies persisting into the future. Nevertheless, a rapid technological change may lower water use intensities.

- The combined effect of structural and technological changes results in only moderate decreases in manufacturing water use intensities.

- The development of unconventional oil and gas resources, which also raises notable water-quality risks, will increase water use intensity in the energy sector, especially for fuel extraction and processing.

- Regional stress points will increase globally. Power generation in regional stress points will likely have to deploy more and more technologies fit for waterconstrained conditions to manage water-related risks, though this can involve tradeoffs in cost, energy output and project siting.

Elements of the SSP storyline relevant for the MANUFACTURING sector

- A continued large role of the manufacturing sector

- Adoption of the resource- and energy-intensive lifestyle around the world

- Robust growth in demand for services and goods

- Technology, seen as a major driver for development, drives rapid progress in enhancing technologies for higher water use efficiencies in the industrial sector.

- Local environmental impacts are addressed effectively by technological solutions, but there is little proactive effort to avoid potential global environmental impacts.

Implications for manufacturing water use

- Manufacturing GVA in relative terms (\% of GDP) declines only slowly.
- The structure of the manufacturing sector is driven by economics with water-intensive manufacturing industries persisting into the future.

- Yet, there is rapid technological change in the manufacturing industry contributing also to lowering the manufacturing water use intensities.

- The combined effect of structural and technological changes results in only moderate decreases in manufacturing water use intensities.

\section{A6 Domestic sector}

Extents of domestic water use primarily depend on population size and economic strength. Drivers for water use intensity (i.e., per capita water use) include access to water, behavior and technology applied for the different domestic water use components (drinking water, shower/bath, toilet, laundry, outdoor water use).

\section{SSP1: sustainability - taking the green road}

Elements of the SSP storyline relevant for the domestic sector

- Inequality reduction across and within economies

- Effective and persistent cooperation and collaboration across the local, national, regional and international scales and between public organizations, the private sector and civil society within and across all scales of governance

- Policies shift to optimize resource use efficiency associated with urbanizing lifestyles.

- Consumption and investment patterns change towards resource-efficient economies.

- Civil society helps drive the transition from increased environmental degradation to improved management of the local environment and the global commons.

- Research and technology development reduces the challenges of access to safe water.

- Emphasis on promoting higher education levels, gender equality, access to health care and to safe water, and sanitation improvements

- Investments in human capital and technology lead to a relatively low population.

- Better-educated populations and high overall standards of living confer resilience to societal and environmental changes with enhanced access to safe water, improved sanitation, and medical care.

Implications for domestic water use 
- Management of the global commons (including water) will slowly improve as cooperation and collaboration of local, national, and international organizations and institutions, the private sector, and civil society become enhanced.

- Decreasing population will ease the pressure on scarce water resources.

- Increasing environmental awareness in societies around the world will favor technological changes towards water-saving technologies.

- Industrialized countries support developing countries in their development goals by providing access to human and financial resources and new technologies.

- Achieving development goals will reduce inequality both across and within countries, with implications for improving access to and water quality in poor households, especially the urban slums.

- Higher levels of education will in poor urban slums improve awareness of household water management practices and in rich households induce behavioral changes towards efficient water use.

\section{SSP2: middle of the road}

Elements of the SSP storyline relevant for the domestic sector

- Moderate awareness of the environmental consequences of choices when using natural resources

- Relatively weak coordination and cooperation among national and international institutions, the private sector, and civil society for addressing environmental concerns

- Education investments are not high enough to rapidly slow population growth.

- Access to health care and safe water and improved sanitation in low-income countries makes unsteady progress

- Gender equality and equity improve slowly.

- Consumption is oriented towards material growth.

- Conflicts over environmental resources flare where and when there are high levels of food and/or water insecurity.

- Growing energy demand leads to continuing environmental degradation.

Implications for domestic water use

- Weak environmental awareness triggers slow water security and progress in water use efficiencies.
- Global and national institutions, and lack of cooperation and collaboration, make slow progress in achieving sustainable development goals.

- Growing population and intensity of resource aggravates degradation of water resources.

- Access to health care, safe water, and sanitation services are affected by population growth and heterogeneities within countries.

- Conflicts over natural resource access and corruption trigger the effectiveness of development policies.

\section{SSP3: regional rivalry - a rocky road}

Elements of the SSP storyline relevant for the domestic sector

- Societies are becoming more skeptical about globalization.

- Countries show a weak progress in achieving sustainable development goals.

- Environmental policies have very little importance.

- Weak cooperation among organizations and institutions

- Global governance, institutions and leadership are relatively weak in addressing the multiple dimensions of vulnerability.

- Low investment in education and in technology increases socio-economic vulnerability.

- Growing population and limited access to health care, safe water and sanitation services challenge human and natural systems.

- Gender equality and equity change little over the century.

- Consumption is material intensive and economic development remains stratified by socio-economic inequalities.

Implications for domestic water use

- National and regional security issues foster stronger national policies to secure water resource access and sanitation services.

- Material-intensive consumption triggers higher levels of domestic water use.

- Limited development in human capital results in inefficient use of water for households, especially in growing urban slums. 
- National rivalries between the countries slow down the progress towards development goals and increase competition for natural resources.

- Rational management of cross-country watersheds is hampered by regional rivalry and conflicts over crosscountry shared water resource increase.

\section{SSP4: inequality - a road divided}

Elements of the SSP storyline relevant for the domestic sector

- Increasing inequalities and stratification both across and within countries

- Limited environmental awareness and very little attention given to global environmental problems and their consequences for poorer social groups

- Power becomes more concentrated in a relatively small political and business elite.

- Vulnerable groups lack the capacity and resources to organize themselves to achieve a higher representation in national and international institutions.

- Low-income countries lag behind and in many cases struggle to provide adequate access to water, sanitation and health care for the poor.

- Economic uncertainty leads to relatively low fertility and low population growth in industrialized countries.

- In low-income countries, large numbers of young people result from high fertility rates.

- People rely on local resources when technology diffusion is uneven.

- Socio-economic inequities trigger governance capacity and challenge progress towards sustainable goals.

- Challenges to land use management and to adapt to environmental degradation are high.

Implications for domestic water use

- Although water-saving technologies have been developed in high-income areas, low-income countries cannot benefit, as they lack financial resources for investments.

- This results in prevailing unequal access to clean drinking water and sanitation.

- Such inequalities are especially large in the growing urban conglomerates.

- As social cohesion degrades, conflict and unrest over uneven distribution of scarce clean water resources become increasingly common, especially in mega-cities.
- As the poor and vulnerable lack the capacity to organize themselves, they have few opportunities to access water resources and security.

\section{SSP5: fossil-fueled development - taking the highway}

Elements of the SSP storyline relevant for the domestic sector

- Global economic growth promotes robust growth in demand for services and goods.

- Developing countries aim to follow the fossil- and resource-intensive development model of the industrialized countries.

- Rise in global institutions and global coordination

- Social cohesion, gender equality and political participation are strengthened, resulting in a gradual decrease in social conflicts.

- Higher education and better health care accelerate human capital development.

- Investments in technological innovation are very high.

- While local environmental impacts are addressed effectively by technological solutions, there is relatively little effort to avoid potential global environmental impacts due to a perceived tradeoff with progress on economic development.

- Environmental consciousness exists on the local scale, and is focused on end-of-pipe engineering solutions for local environmental problems that have obvious impacts on well-being, such as air and water pollution, particularly in urban settings.

Implications for domestic water use

- Access to water and management of domestic water use becomes more and more widespread in all world regions.

- Development policies, combined with rapid economic development, lead to a strong reduction of extreme poverty and significantly improved access to safe drinking water and piped water access.

- Large improvements in water use efficiencies of household water appliances (toilets, shower)

\section{A7 Qualitative and quantitative assessment}

\section{A7.1 Technological change rates}

A technological change (almost) always leads to improvements in the water use efficiency and thereby decreases water 
Table A3. The effect of technological changes on water use intensities in the industrial sector (H: high; M: middle; L: low).

\begin{tabular}{|c|c|c|c|c|c|c|c|c|c|c|}
\hline & & & \multicolumn{2}{|c|}{$\mathrm{L}$} & \multicolumn{2}{|c|}{ M } & \multicolumn{2}{|c|}{$\mathrm{H}$} & \multicolumn{2}{|c|}{ M } \\
\hline & & Socio-economic capacity & \multicolumn{2}{|c|}{ Poor } & \multicolumn{2}{|c|}{ Rich } & \multicolumn{2}{|c|}{ Rich } & \multicolumn{2}{|c|}{ Poor } \\
\hline & & Hydro-climatic complexity & \multicolumn{2}{|c|}{ Low } & \multicolumn{2}{|c|}{ Low } & \multicolumn{2}{|c|}{ High } & \multicolumn{2}{|c|}{ High } \\
\hline & & & \multicolumn{2}{|c|}{ HE-1 } & \multicolumn{2}{|c|}{ HE-2 } & \multicolumn{2}{|c|}{ HE-3 } & \multicolumn{2}{|c|}{ HE-4 } \\
\hline $\mathrm{H}$ & SSP1 & Sustainability (SSP dominant) & HL & B & $\mathrm{HM}$ & $\mathrm{B}$ & $\mathrm{HH}$ & A & $\mathrm{HM}$ & B \\
\hline M & SSP2 & Historic paths (SSP as HE) & ML & $\mathrm{D}$ & MM & $\mathrm{C}$ & MH & $\mathrm{B}$ & MM & $\mathrm{C}$ \\
\hline $\mathrm{L}$ & SSP3 & Fragmentation (HE dominant) & LL & $\mathrm{E}$ & LM & $\mathrm{D}$ & LH & $\mathrm{C}$ & LM & $\mathrm{D}$ \\
\hline M & SSP4 & Inequality (HE dominant) & ML & $\mathrm{D}$ & MM & $\mathrm{C}$ & MH & $\mathrm{B}$ & MM & $\mathrm{C}$ \\
\hline $\mathrm{H}$ & SSP5 & Market first (SSP dominant) & HL & $\mathrm{B}$ & $\mathrm{HM}$ & $\mathrm{B}$ & $\mathrm{HH}$ & A & $\mathrm{HM}$ & $\mathrm{B}$ \\
\hline
\end{tabular}

use intensities in the industry (including electricity and manufacturing) and domestic water use sectors. Water use intensities describe the amount of water required to produce a unit of electricity $\left(\mathrm{m}^{3} \mathrm{GJ}^{-1}\right)$ or manufacturing $\left(\mathrm{m}^{3}\right.$ gross value added in manufacturing ${ }^{-1}$ ). In the domestic sector technology influences the volume of water required for specific domestic uses (e.g., toilet, washing machine, dishwasher, shower). Water use intensities decrease with the availability and speed of introduction of new technologies.

Technological change is an integral part of the economy of a country or region. The legal, institutional, education and financial systems determine the potential for innovation and their implementation. Against this background we argue that the interpretation of technological change in the context of SSPs and position of individual countries in HE classes is similar in the industry and domestic sector. Therefore the qualitative and quantitative scenario assumptions specified in Sect. 2.3 are also valid for the domestic sector. This approach is compatible with global water use models, which apply similar technological change rates for the industry and domestic sector.

We first rate qualitatively the level of technological improvement separately for the five SSPs and four HE regions (Table A3).

Technological change in the SSP storylines: strong investments in new technology and research including technologies directed toward environmentally friendly processes are key in the narratives of SSP1, 4, and 5. In SSP1 and SSP5 technological progress disseminates globally although driven by different incentives. While the sustainability paradigm of SSP1 seeks global use of enhanced technologies, the SSP5 economic development priorities favor water-efficient technologies as the cheapest option. In contrast in the SSP4 narrative the technological progress developed by well-educated elites can often not be implemented by poor regions lacking access to investment capital. Overall, we assess the elite-induced technological progress (in SSP4) as somewhat lower compared to the sustainability (SSP1) and marketdriven (SSP5) technological progress. In SSP2 technological changes proceed at moderate pace, but lack fundamen- tal breakthroughs. In SSP3 low investments in both R\&D and education result in only slow progress in technological changes.

Technological change in the HE regions: limited access to investment in the poor countries of HE regions HE-1 and HE4 is a major barrier for the implementation of new technologies. However, the difficult hydro-climatic conditions in HE4 force even poor countries to spend some of their limited available capital for implementing new technologies, leading to higher progress in technological change compared to HE-1 where water is abundant. The rich countries of HE-2 and HE-3 have the economic and institutional potential to invest in and transfer to state-of-the-art technologies. Yet, in countries of the water-scarce region HE-3, the urgency to implement water-saving technologies results in stronger decreases of water use intensities driven by technological improvements compared to HE-2, which would also have the means to implement new technologies but lack the incentive due to sufficient water resources.

Combine SSP and HE: second, we regroup the combinations of the SSP and HE ratings into seven groups A to E indicating a decreasing speed of technological progress. A signifies the highest decreases in water use intensities due to technological changes and $\mathrm{E}$ the lowest decreases; i.e., water use efficiencies improve fastest in A and slowest in E. Assigning of the combined SSP, HE ratings to a group depends on the weight attached to the first-order SSP and HE ratings. The global dissemination of technological progress in SSP1 and SSP5 suggests to weigh the SSP higher compared to the first-order HE ratings ("SSP dominant"). Moreover SSP1 seeks development pathways directed towards reducing inequality globally. In contrast SSP3 and SSP4 are characterized by fragmentation and large disparities across countries and we therefore assign for the scenario assumptions a higher importance to the HE rating compared to the SSP rating ("HE dominant"). For SSP2 we assume an equal importance of the SSP and HE ratings ("SSP as HE").

Finally we apply quantified annual efficacy change rates (Table A4) for each of the five combinations of SSP and HE 


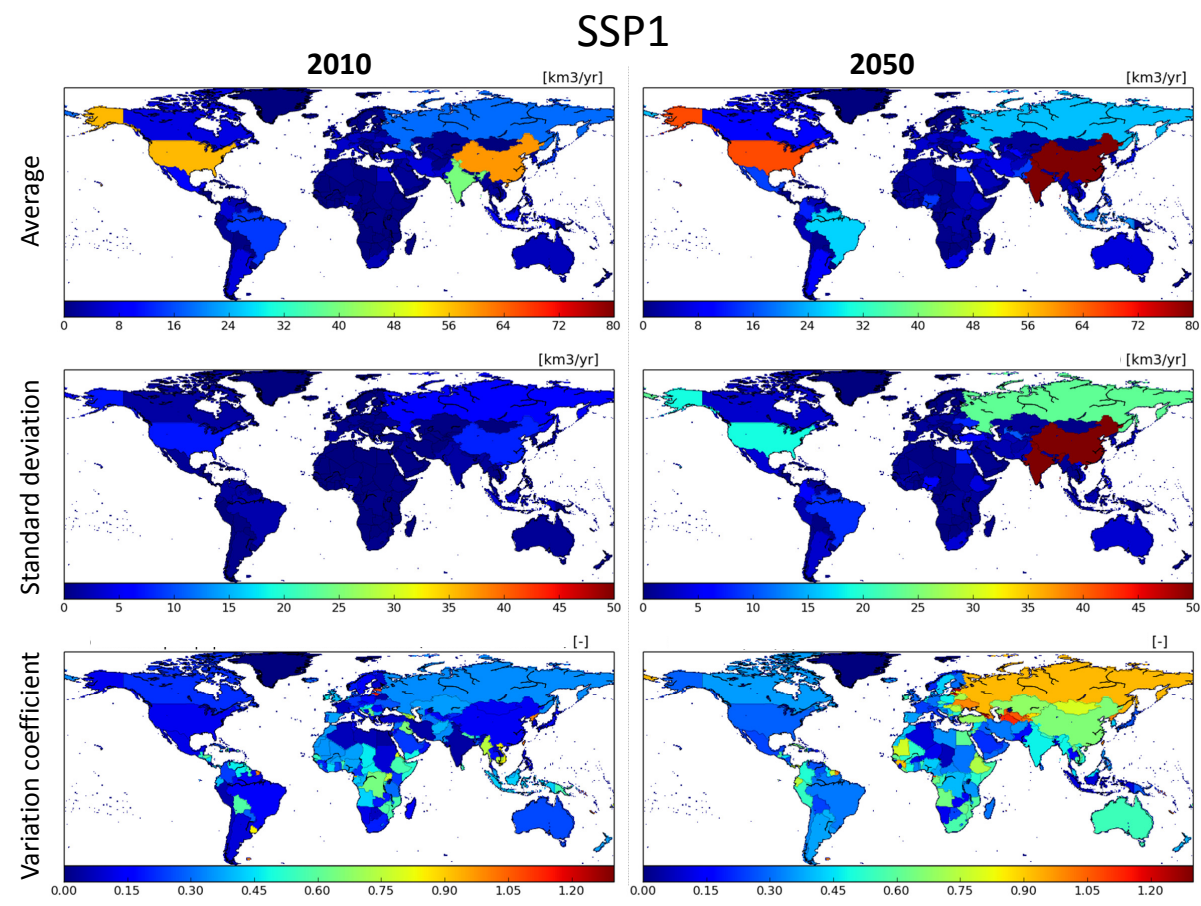

Figure A3. Global maps of projected domestic water withdrawals calculated by the global water models H08, PCR-GLOBWB, and WaterGAP for the years 2010 and 2050, respectively, under the SSP1 scenario. Avr, Std, and Std/Avr denote average, standard deviation, and coefficient of variations $(\mathrm{CV})$.

Table A4. Applied annual efficiency change rates.

\begin{tabular}{ccccc}
\hline $\mathrm{A}^{\mathrm{a}}$ & $\mathrm{B}$ & $\mathrm{C}$ & $\mathrm{D}$ & $\mathrm{E}^{\mathrm{b}}$ \\
\hline $1.2 \%$ & $1.1 \%$ & $1 \%$ & $0.6 \%$ & $0.3 \%$ \\
\hline
\end{tabular}

${ }^{\mathrm{a}}$ highest; ${ }^{\mathrm{b}}$ lowest.

classification using a range of historically observed technological change rates (Flörke et al., 2013).

\section{A7.2 Structural changes}

\section{Manufacturing sector}

Structural changes in manufacturing water use intensities depend on the one hand on the overall structure of a country's economy. On the other hand, the type of industry employed for earning GVA in the manufacturing sector determines amounts of water demand. For example, in the US, the five most water-intensive non-agricultural or non-power generation industries include forest products (esp. pulp and paper), steel, petroleum, chemicals, and food processing. Other water-intensive manufacturing sectors include textile production (for dyeing or bleaching) and semiconductor manufacturing. Structural changes also result from geographical shifts in production chains, e.g., installation of technologies from Western countries in developing countries or Western countries outsourcing their industries.

The WFaS "fast-track" does not consider assumptions for structural change in the manufacturing sector due to a lack of sector-specific economic modeling consistent with SSP storylines. However, in some global water models (e.g., WaterGAP), manufacturing water use intensity is correlated with economic development; i.e., water use intensity is lower in countries with higher GDP per capita.

\section{Electricity sector}

The vast majority of water used in the energy sector is for cooling at thermal power plants, as water is the most effective medium for carrying away huge quantities of waste heat. Water withdrawals for cooling depend on fuel type and cooling technology. For example, nuclear power plants require larger water withdrawals per unit of electricity produced compared to fossil powered plants. Gas-fired power plants are the least water intensive. There are three basic types of cooling technology in use: once-through-cooling, recirculation (tower) cooling, and dry cooling. The latter is the least water intensive from both water withdrawal and consumption point of view but also the least energy efficient (Koch and Vögele, 2009). By changing the cooling system of power plants from once-through systems to closed circuit systems, the vulnerability of power plants to water shortages can be reduced. 
Table A5. Current and projected cropping intensity (percent). CEAS refers to Central Asian countries.

\begin{tabular}{|c|c|c|c|c|c|c|c|c|c|}
\hline & \multicolumn{3}{|c|}{ Cropping intensity 2005/07 } & \multicolumn{3}{|c|}{ Cropping intensity 2030} & \multicolumn{3}{|c|}{ Cropping intensity 2050} \\
\hline & Rainfed & Irrig. & Total & Rainfed & Irrig. & Total & Rainfed & Irrig. & Total \\
\hline $\mathrm{HE}-1$ & 80 & 153 & 89 & 81 & 155 & 92 & 82 & 155 & 92 \\
\hline $\mathrm{HE}-2$ & 76 & 91 & 77 & 80 & 95 & 81 & 83 & 97 & 84 \\
\hline HE-3 & 53 & 134 & 104 & 61 & 129 & 104 & 65 & 127 & 104 \\
\hline $\mathrm{HE}-4$ & 90 & 118 & 99 & 92 & 121 & 101 & 93 & 122 & 103 \\
\hline CEAS & 75 & 82 & 77 & 76 & 91 & 81 & 76 & 94 & 83 \\
\hline Total & 80 & 127 & 88 & 82 & 131 & 90 & 84 & 132 & 92 \\
\hline
\end{tabular}

Source: Alexandratos and Bruinsma (2012).

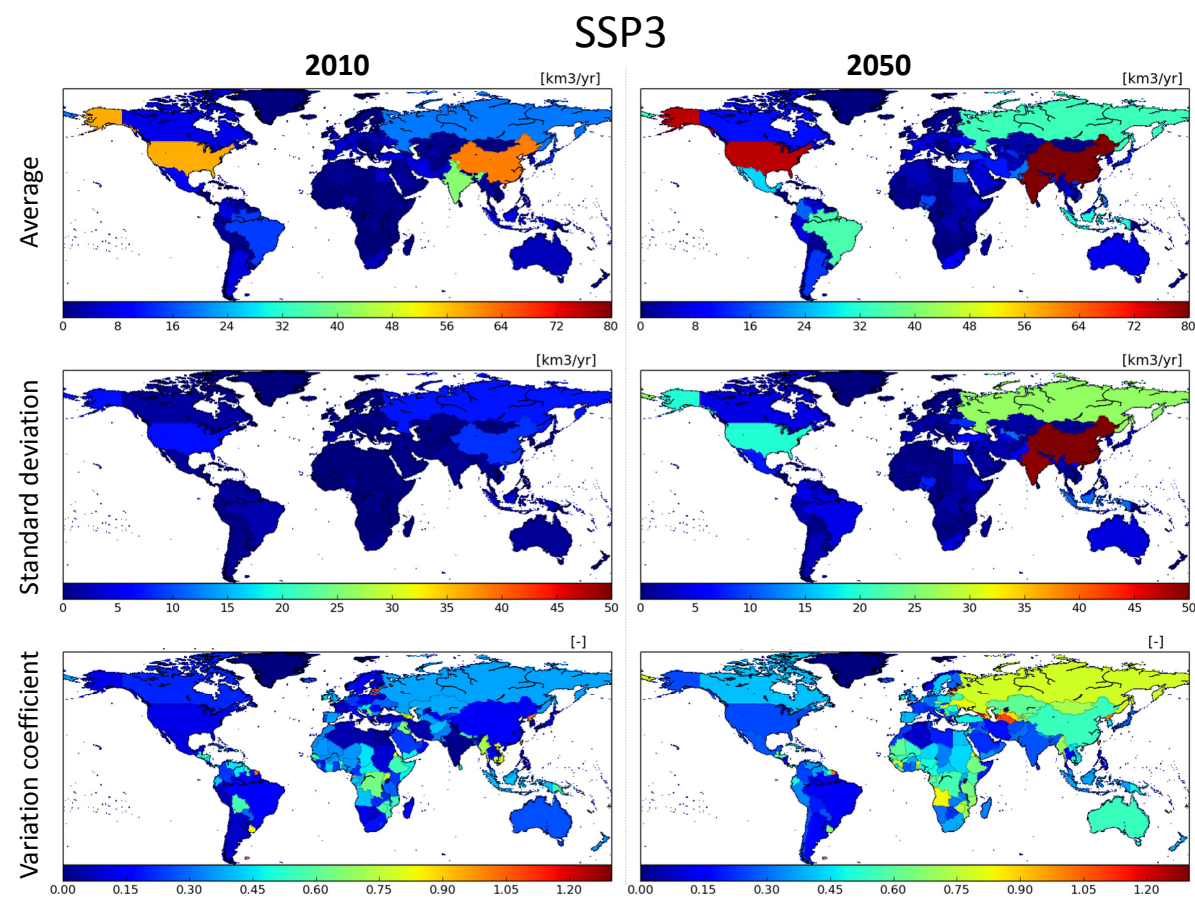

Figure A4. Global maps of projected domestic water withdrawals calculated by the global water models H08, PCR-GLOBWB, and WaterGAP for the years 2010 and 2050, respectively, under the SSP3 scenario. Avr, Std, and Std/Avr denote average, standard deviation, and coefficient of variations (CV).

In general, a power plant's lifetime is about 35 to 40 years (Markewitz and Vögele, 2001). When economies have sufficient investment potential (i.e., in HE-2 and HE-3) or the societal paradigm strives for resource-efficient economies (as in SSP1) we assume an improved water use efficiency due to structural changes. In these scenarios, power plants are replaced after a service life of 40 years by plants with modern water-saving tower-cooled technologies. Such replacement policy is in line with the EU's policy on "Integrated Pollution Prevention and Control" (IPPC). In addition all new power plants are assumed to have tower-cooling.

\section{Domestic sector}

Structural changes in the domestic sector refer to the number of people having access to water sources and behavior. Only in SSP1 (Sustainability Scenario) do we assume by 2050 a $20 \%$ reduction in domestic water use intensity due to behavioral changes. The WFaS "fast-track" applied global water use models to calculate domestic water use at the national level where access to safe drinking water is not considered.

\section{A8 Additional analyses}

See Figs. A3 to A6. 

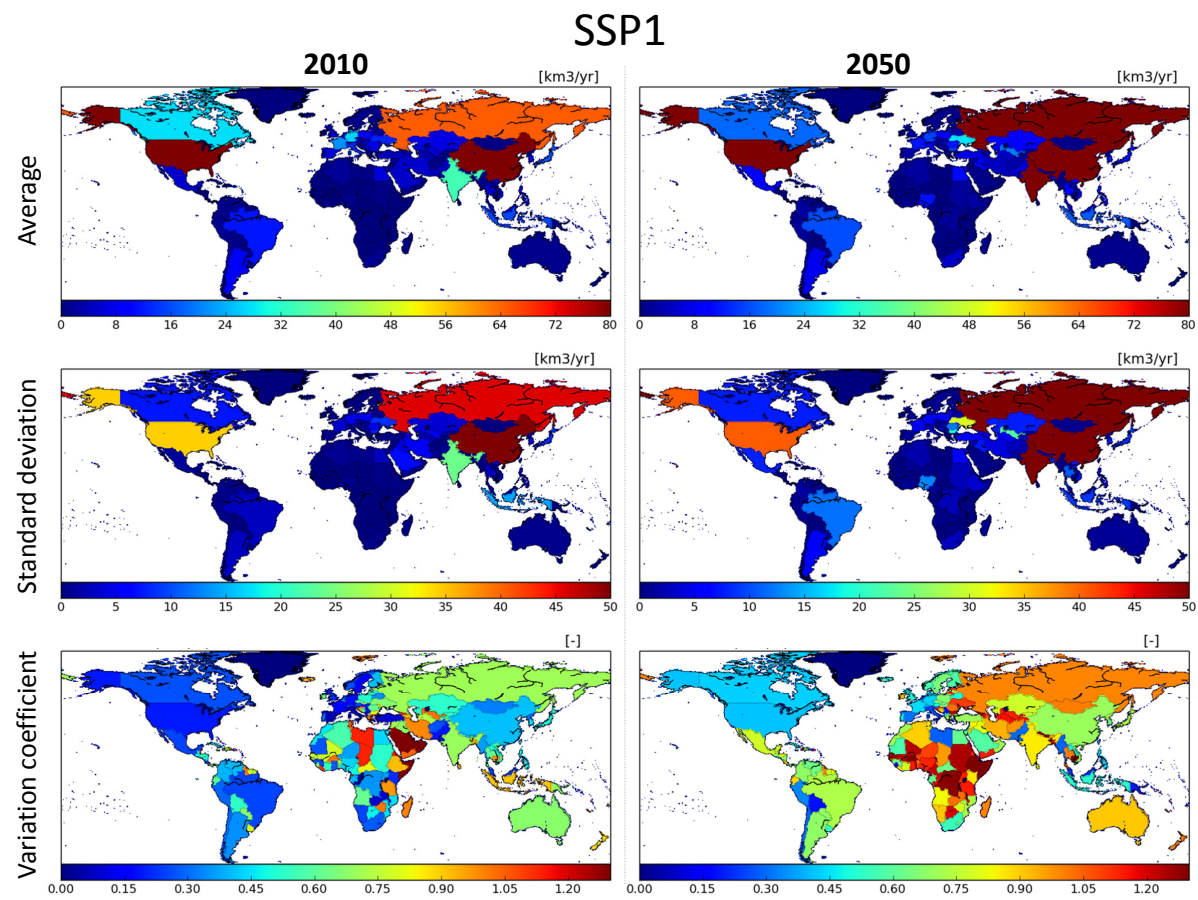

Figure A5. Global maps of projected industrial water withdrawals calculated by the global water models H08, PCR-GLOBWB, and WaterGAP for the years 2010 and 2050, respectively, under the SSP1 scenario. Avr, Std, and Std/Avr denote average, standard deviation, and coefficient of variations.
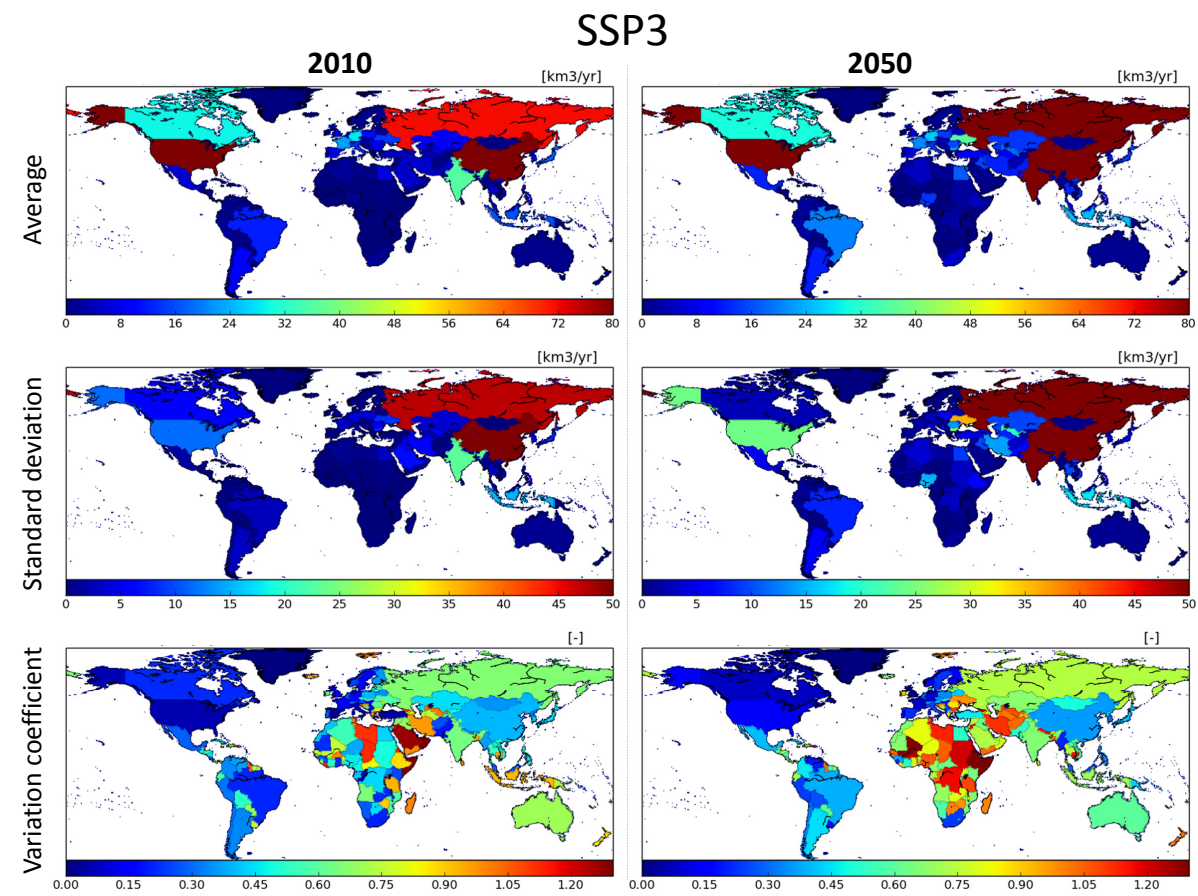

Figure A6. Global maps of projected industrial water withdrawals calculated by the global water models H08, PCR-GLOBWB, and WaterGAP for the years 2010 and 2050, respectively, under the SSP3 scenario. Avr, Std, and Std/Avr denote average, standard deviation, and coefficient of variations. 
Table A6. Water dimension - irrigation cropping intensity assumptions.

\begin{tabular}{lllllll}
\hline & SSP/class & HE-1 & HE-2 & HE-3 & HE-4 \\
& & & T & T & WL & WL \\
\hline irrigation cropping intensity (harv ha/irrig ha) & SSP1 & EL & EL-T & EL-T & EL-WL & EL-WL \\
& SSP2 & T & T & T & T-WL & T-WL \\
& SSP3 & T & T & T & T-WL & T-WL \\
& SSP4 & T & T & EL-T & T-WL & T-WL \\
& SSP5 & EL & EL-T & EL-T & EL-WL & EL-WL \\
\hline
\end{tabular}

Table A7. Water dimension - irrigation cropping intensity rating.

\begin{tabular}{lllllll}
\hline & SSP/class & HE-1 & HE-2 & HE-3 & HE-4 \\
WL & T & WL & WL \\
\hline Irrigation cropping intensity (irrig harv ha/act. irrig ha) & SSP1 & EL & B & B & C & C \\
& SSP2 & T & A & A & B & B \\
& SSP3 & T & A & A & B & B \\
& SSP4 & T & A & B & B & B \\
& SSP5 & EL & B & B & C & C \\
\hline
\end{tabular}

\section{A9 Discussion of key water dimensions in irrigation sector}

\section{A9.1 Irrigation cropping intensity}

As pointed out, changes in cropping intensity on irrigated land - i.e., multiple use of the land within 1 year (ideally measured as irrigated cropping days per year) - critically depend on changes in the thermal (and possibly precipitation) regime of a location and/or removal of economic and water-related constraints that may limit the possibility and profitability of investing in more efficient irrigation systems and more reliable water supply that would allow increased multi-cropping. Estimates of prevailing cropping intensities compiled by the FAO (Alexandratos and Bruinsma, 2012) indicate (i) a much higher cropping intensity in irrigated land compared to rain-fed conditions, and (ii) a higher irrigation cropping intensity in countries of class HE-1 compared to countries in water-complex class HE-4 (Table A5).

Water shortage, high economic costs of irrigation and shortage of labor/mechanization could mean that farmers are not able or do not want to exploit longer thermal growing seasons (under climate change). Such socio-economic and demographic limitations are more likely to occur under SSP1 and SSP5 conditions. According to our definition of hydroeconomic classes, physical and economic water scarcity may limit cropping intensity in the countries of HE-3 and HE-4.

In Table A6 for "Irrigated cropping intensity", the symbol " $\mathrm{T}$ " is used to indicate "according to thermal regime trend", "EL" means "economically limited" to indicate belowpotential intensities due to demographic/economic limitations, and "WL" means "water limited"; i.e., intensities will be below the thermal agro-climatic potential due to water limitations.

In sector-specific or comprehensive integrated assessment modeling where the various explanatory factors are simulated in sufficient detail, the rationale reflected in the assumptions table can be explicitly incorporated into the simulated cropping and land use decisions. For modeling and exploratory assessments, where such detail is not possible, the assumptions table can be condensed into a simple rating table, as given in Table A7.

In Table A7, an "A" rating is used to indicate an expected further increase in irrigation cropping intensity with warming; note that this will still depend on broad climatic characteristics, e.g., by thermal climate zones (tropics $=$ no increase due to changes in thermal conditions; sub-tropics $=$ very modest increase; temperate zone $=$ significant lengthening of growing season and increase in potential multi-cropping with temperature increases). The " $\mathrm{B}$ " rating is used when economic factors or water scarcity will somewhat limit further increases in cropping intensity. The " $\mathrm{C}$ " rating means that both economic reasons and insufficient water availability could limit actual increases in multi-cropping on irrigated land.

\section{A9.2 Utilization intensity of land equipped for irrigation}

Changes in the actual utilization of "areas equipped for irrigation" will also depend on a mixture of agronomic and economic factors including biophysical changes, costs and profitability, risk mitigation objectives, and capital constraints in rehabilitation and maintenance of irrigated areas. It is worth noting that FAO estimates a 40-year average lifetime of an 
Table A8. Area equipped for irrigation and actually irrigated around the year 2000.

\begin{tabular}{lcccc}
\hline & All countries & \multicolumn{3}{c}{$\begin{array}{l}\text { Of which countries for which data on area equipped and area actually } \\
\text { irrigated are both available in AQUASTAT }\end{array}$} \\
\cline { 3 - 5 } & $\begin{array}{c}\text { Area equipped for } \\
\text { irrigation (mill. ha) }\end{array}$ & $\begin{array}{c}\text { Area equipped for } \\
\text { irrigation (mill. ha) }\end{array}$ & $\begin{array}{c}\text { Area equipped actually } \\
\text { irrigated (mill. ha) }\end{array}$ & $\begin{array}{c}\text { \% of equipped } \\
\text { actually irrigated }\end{array}$ \\
\hline HE-1 & 122.87 & 103.10 & 86.72 & 84.1 \\
HE-2 & 50.06 & 44.97 & 35.52 & 79.0 \\
HE-3 & 3.18 & 2.30 & 2.18 & 94.7 \\
HE-4 & 111.41 & 92.54 & 81.83 & 88.4 \\
Total & 287.53 & 242.91 & 206.25 & 84.9 \\
\hline
\end{tabular}

Source: FAOSTAT and AQUASTAT.

Table A9. Water dimension - irrigation utilization intensity assumptions.

\begin{tabular}{lllllll}
\hline & SSP/class & HE-1 & HE-2 & HE-3 & HE-4 \\
& & & L & L & M \\
\hline Irrigation utilization intensity (irrig ha/equ. ha) & SSP1 & L & L-M & L & L & L-M \\
& SSP2 & M & M & M & M-L & M \\
& SSP3 & L/M & L-M & M-L & M-L & L-M \\
& SSP4 & L & L-M & L & L & L-M \\
& SSP5 & M & M & M-L & M-L & M \\
\hline
\end{tabular}

irrigation system, which implies that on average $2.5 \%$ of the area equipped has to be rehabilitated/re-equipped each year. Available data from AQUASTAT were compiled for years closest to 2000 and were aggregated by different hydroeconomic classes, as shown in Table A8.

The results suggest that on average 85 percent of the area equipped for irrigation was actually irrigated. The utilization shares were highest for countries in water-complex classes HE-3 and HE-4. Note, there is only limited empirical information available in reported statistics. Estimates of areas actually irrigated are incomplete, albeit they are available for countries accounting for more than $80 \%$ of the global total area equipped for irrigation, and only estimates for a few time points but no complete time-series exist. Therefore, the assumptions table concerning the utilization intensity of areas equipped for irrigation is somewhat speculative and would benefit from inputs by sector stakeholders.

Our assumption concerning different hydro-economic classes is that utilization of irrigation systems in economically rich countries (classes HE-2 and HE-3) could decrease (as indicated by "L") due to the fact that areas may increasingly be equipped for irrigation to reduce drought risks, stabilize production and buffer against possible increasing climate variability (Table A9). For other countries, we expect that current utilization rates will be maintained. Across SSPs, we consider conditions in development pathways SSP1 (more areas equipped for irrigation to cope with extremes), SSP3 (lack of maintenance in less developed areas and unreliable water supply could render irrigated land unusable) and SSP4
(SSP1 logic may apply to elites, SSP3 arguments apply to poor population segments in SSP4) to possibly lead to reduced utilization rates. A simplified rating table is presented in Table A10 where the " $C$ " rating indicates a tendency toward lowering utilization rates whereas an " $A$ " rating suggests maintaining or even increasing utilization rates of areas equipped for irrigation.

\section{A9.3 Irrigation water use efficiency}

Overall irrigation water use efficiency depends on the type of irrigation system being used and the specific technology available within each type. Future changes will largely depend on investments being made to shift to more efficient irrigation types and to updating each type's technology to state-of-the-art, and to some extent will depend on crop type (for instance, paddy rice needs flood irrigation and additional irrigation water for cultivation; for some crops sprinkler cannot be used; for some drip irrigation may be too expensive). Available data from AQUASTAT were compiled as available for years closest to 2000 and were aggregated for countries in different hydro-economic classes, as shown in Table A11 below.

Data available in AQUASTAT mean that around 2000 (or the closest available year) some $2563 \mathrm{~km}^{3}$ of water were withdrawn for agriculture. The countries where estimates of crop water requirements are provided account for nearly $2500 \mathrm{~km}^{3}$ of agricultural withdrawals, with an overall implied irrigation efficiency of $52 \%$. As might be expected, countries in class HE-1 had the lowest efficiency, on average 
Table A10. Water dimension - irrigation utilization intensity rating.

\begin{tabular}{lllllll}
\hline & SSP/class & HE-1 & HE-2 & HE-3 & HE-4 \\
& & & M & L & L & M \\
\hline Irrigation utilization intensity (irrig ha/equ. ha) & SSP1 & L & B & C & C & B \\
& SSP2 & M & A & B & B & A \\
& SSP3 & L/M & B & A & A & B \\
& SSP4 & L & B & C & C & B \\
& SSP5 & M & A & B & B & A \\
\hline
\end{tabular}

Table A11. Water withdrawn for agriculture and water required for irrigation around the year 2000 .

\begin{tabular}{ccccc}
\hline \multirow{2}{*}{$\begin{array}{c}\text { All countries } \\
\text { Water withdrawn for } \\
\text { agriculture }\left(\mathrm{km}^{3} \mathrm{yr}^{-1}\right)\end{array}$} & $\begin{array}{c}\text { Of which countries for which data on water withdrawn and crop water } \\
\text { requirements are both available in AQUASTAT }\end{array}$ \\
\cline { 3 - 5 } & $\begin{array}{c}\text { Water withdrawn for } \\
\text { agriculture }\left(\mathrm{km}^{3} \mathrm{yr}^{-1}\right)\end{array}$ & $\begin{array}{c}\text { Crop water requirements } \\
\left(\mathrm{km}^{3} \mathrm{yr}^{-1}\right)\end{array}$ & $\begin{array}{c}\text { \% required compared } \\
\text { to withdrawn }\end{array}$ \\
\hline HE-1 & 1055.1 & 1009.8 & 457.3 & 45.3 \\
HE-2 & 368.4 & 368.2 & 215.0 & 58.4 \\
HE-3 & 42.1 & 26.3 & 14.5 & 55.1 \\
HE-4 & 1097.8 & 1094.5 & 617.6 & 56.4 \\
Total & 2563.3 & 2498.7 & 1304.4 & 52.2 \\
\hline
\end{tabular}

Source: FAOSTAT and AQUASTAT.

Table A12. Annual renewable water resources and irrigation water withdrawal.

\begin{tabular}{|c|c|c|c|c|c|c|c|}
\hline \multirow[t]{3}{*}{$\begin{array}{l}\text { Renewable water } \\
\text { resources }\end{array}$} & \multirow[b]{3}{*}{$\mathrm{Km}^{3} \mathrm{yr}^{-1}$} & \multicolumn{2}{|c|}{$\begin{array}{c}\text { Irrigation water } \\
\text { use efficiency ratio }\end{array}$} & \multicolumn{2}{|c|}{$\begin{array}{c}\text { Irrigation water } \\
\text { withdrawal }\end{array}$} & \multicolumn{2}{|c|}{$\begin{array}{c}\text { Pressure on } \\
\text { water resources } \\
\text { due to irrigation }\end{array}$} \\
\hline & & $2005 / 2007$ & 2050 & $2005 / 2007$ & 2050 & $2005 / 2007$ & 2050 \\
\hline & & \multicolumn{2}{|c|}{ percent } & \multicolumn{2}{|c|}{$\mathrm{Km}^{3} \mathrm{yr}^{-1}$} & \multicolumn{2}{|c|}{ percent } \\
\hline World & 42000 & 50 & 51 & 2761 & 2926 & 6.6 & 7.0 \\
\hline Developed countries & 14000 & 41 & 42 & 550 & 560 & 3.9 & 4.0 \\
\hline Developing countries & 28000 & 52 & 53 & 2211 & 2366 & 7.9 & 8.5 \\
\hline Sub-Saharan Africa & 3500 & 25 & 30 & 96 & 133 & 2.7 & 3.8 \\
\hline Latin America & 13500 & 42 & 42 & 183 & 214 & 1.4 & 1.6 \\
\hline Near East/North Africa & 600 & 56 & 65 & 311 & 325 & 51.8 & 54.1 \\
\hline South Asia & 2300 & 58 & 58 & 913 & 896 & 39.7 & 38.9 \\
\hline East Asia & 8600 & 49 & 50 & 708 & 799 & 8.2 & 9.3 \\
\hline
\end{tabular}

Source: Alexandratos and Bruinsma (2012)

$45 \%$. The highest aggregate irrigation efficiencies of 58 and $56 \%$ were computed, respectively, for countries in classes HE-2 and HE-4.

For comparison, Table A12 shows the estimates for their base year 2005/2007 and projections for the year 2050 from Alexandratos and Bruinsma (2012). According to their calculations, the implied irrigation water use efficiency was $50 \%$, ranging across different regions from as little as $25 \%$ (in Sub-Saharan Africa) to $58 \%$ (in South Asia).

In the assumptions table, the symbol " $\mathrm{H}$ " indicates a higher economic capacity (compared to trend) to improve irrigation efficiency; and when used across hydro-economic classes it means a high incentive exists to improve water use efficiency due to water scarcity and hydrological complex- ity. The symbols " $M$ " and "L" indicate, respectively, "average/moderate" and "low" capability or incentives.

As a general principal, we are assuming that (i) high hydrological complexity will tend to induce improvements in irrigation water use efficiency; (ii) high economic growth and income per capita will allow fast improvements in irrigation efficiency; and (iii) low-income, inefficient institutions and low hydrological complexity will combine to result in little or no improvement in irrigation water use efficiency.

Table A13 has been simplified into a rating table using five classes, rated "A" to "E", which reflect the combination of economic capacity and magnitude of water challenges that can be derived from the scenario narratives and hydroeconomic classification. The "A" rating is used for the com- 
Table A13. Water dimension - irrigation water use efficiency assumptions.

\begin{tabular}{llllllll}
\hline & SSP/class & HE-1 & HE-2 & HE-3 & HE-4 \\
& & & L & M & H & H \\
\hline Irrigation water use efficiency (water required/withdrawn) & SSP1 & H & H-L & H-M & H & H \\
& SSP2 & M & M-L & M & M-H & M-H \\
& SSP3 & L & L & L-M & L-H & L-H \\
& SSP4 & M & M-L & M & M-H & M-H \\
& SSP5 & H & H-L & H-M & H & H \\
\hline
\end{tabular}

Table A14. Water dimension - irrigation water use efficiency rating.

\begin{tabular}{lllllll}
\hline & SSP/class & HE-1 & HE-2 & HE-3 & HE-4 \\
& & L & M & H & H \\
\hline Irrigation water use efficiency (water required/withdrawn) & SSP1 & H & C & B & A & A \\
& SSP2 & M & D & C & B & B \\
& SSP3 & L & E & D & C & C \\
& SSP4 & M & D & C & B & B \\
& SSP5 & H & C & B & A & A \\
\hline
\end{tabular}

Table A15. Area equipped for irrigation (million ha).

\begin{tabular}{rrrrrrrr}
\hline & 1970 & 1980 & 1990 & 2000 & 2010 & Change 1970-1990 & Change 1990-2010 \\
\hline HE-1 & 80.0 & 97.3 & 112.0 & 122.9 & 142.5 & 32.0 & 30.5 \\
HE-2 & 38.0 & 43.5 & 48.0 & 50.1 & 49.9 & 9.9 & 2.0 \\
HE-3 & 1.5 & 1.8 & 3.0 & 3.2 & 3.0 & 1.5 & 0.0 \\
HE-4 & 64.4 & 78.1 & 94.7 & 111.4 & 122.1 & 30.3 & 27.4 \\
Total & 184.0 & 220.7 & 257.7 & 287.5 & 317.6 & 73.7 & 59.9 \\
\hline
\end{tabular}

Source: FAOSTAT

Table A16. Arable land and land under permanent crops (million ha).

\begin{tabular}{rrrrrrrr}
\hline & 1970 & 1980 & 1990 & 2000 & 2010 & Change 1970-1990 & Change 1990-2010 \\
\hline HE-1 & 710.0 & 739.6 & 797.1 & 797.9 & 852.4 & 87.0 & 55.3 \\
HE-2 & 420.8 & 415.9 & 415.5 & 397.2 & 364.9 & -5.3 & -50.6 \\
HE-3 & 5.5 & 5.5 & 7.1 & 7.5 & 6.6 & 1.7 & -0.4 \\
HE-4 & 286.9 & 290.4 & 299.7 & 310.3 & 316.0 & 12.8 & 16.3 \\
Total & 1423.0 & 1451.4 & 1519.3 & 1513.0 & 1539.9 & 96.2 & 20.6 \\
\hline
\end{tabular}

Source: FAOSTAT.

bination of high economic capability as well as high priority/urgency to increase water use efficiency due to limited water availability. On the opposite side of the rating scale, the "E" rating signals that neither the economic means nor the urgency exist to prioritize and incentivize investments in improving irrigation water use efficiency. Hence, we expect that the strongest incentives and economic capacity to move toward the technically possible will exist in SSP1 and SSP5 and particularly so in water-scarce countries in classes HE3 and HE-4. The least improvements in irrigation efficiency can be expected under SSP3 where slow economic development limits investment.

\section{A9.4 Area equipped for irrigation}

In the past, the area equipped for irrigation has been continuously expanding (from 142 million ha in 1961/63 to 302 million ha in 2005/07), although more recently this expansion has slowed down (Alexandratos and Bruinsma, 2012). The area changes since 1970 recorded by the FAO are summarized in Table A15, showing by hydro-economic class the areas equipped for irrigation, and in Table A16, presenting 
Table A17. Share of land equipped for irrigation in total cultivated land (percent).

\begin{tabular}{rrrrrrrr}
\hline & 1970 & 1980 & 1990 & 2000 & 2010 & Change 1970-1990 & Change 1990-2010 \\
\hline HE-1 & 11.3 & 13.2 & 14.1 & 15.4 & 16.7 & 2.8 & 2.7 \\
HE-2 & 9.0 & 10.5 & 11.5 & 12.6 & 13.7 & 2.5 & 2.1 \\
HE-3 & 27.9 & 33.1 & 42.1 & 42.4 & 45.1 & 14.3 & 3.0 \\
HE-4 & 22.5 & 26.9 & 31.6 & 35.9 & 38.7 & 9.1 & 7.1 \\
Total & 12.9 & 15.2 & 17.0 & 19.0 & 20.6 & 4.0 & 3.7 \\
\hline
\end{tabular}

Source: FAOSTAT.

Table A18. Current and projected (actually) irrigated land (million ha).

\begin{tabular}{|c|c|c|c|c|c|c|c|c|c|}
\hline & \multicolumn{3}{|c|}{ Cultivated land 2005/07 } & \multicolumn{3}{|c|}{ Cultivated land 2030} & \multicolumn{3}{|c|}{ Cultivated land 2050} \\
\hline & Rainfed & Irrig. & $\%$ Irrig. & Rainfed & Irrig. & $\%$ Irrig. & Rainfed & Irrig. & $\%$ Irrig. \\
\hline HE-1 & 698.6 & 105.9 & 13.2 & 739.9 & 121.0 & 14.0 & 822.8 & 121.8 & 12.9 \\
\hline HE-2 & 414.9 & 39.2 & 8.6 & 409.1 & 39.0 & 8.7 & 342.0 & 38.0 & 10.0 \\
\hline HE-3 & 1.2 & 2.1 & 63.3 & 1.1 & 1.9 & 62.9 & 1.0 & 1.8 & 63.9 \\
\hline HE-4 & 197.7 & 98.0 & 33.2 & 202.2 & 96.9 & 32.4 & 198.6 & 102.6 & 34.1 \\
\hline CEAS & 23.0 & 11.7 & 33.7 & 21.6 & 11.9 & 35.5 & 20.1 & 12.3 & 37.8 \\
\hline Total & 1335.4 & 256.9 & 16.1 & 1374.0 & 270.7 & 16.5 & 1384.7 & 276.5 & 16.6 \\
\hline
\end{tabular}

Source: Alexandratos and Bruinsma (2012).

Table A19. Water dimension - assumptions regarding expansion of area equipped for irrigation.

\begin{tabular}{lllllll}
\hline & \multicolumn{2}{c}{ SSP/class } & $\begin{array}{l}\text { HE-1 } \\
\text { M }\end{array}$ & $\begin{array}{l}\text { HE-2 } \\
\text { L }\end{array}$ & $\begin{array}{l}\text { HE-3 } \\
\text { L }\end{array}$ & $\begin{array}{l}\text { HE-4 } \\
\text { M }\end{array}$ \\
\hline Area equipped for irrigation & SSP1 & L & L-M & L & L & L-M \\
& SSP2 & M & M & M-L & M-L & M \\
& SSP3 & H/M & H-M & M-L & M-L & H-M \\
& SSP4 & M & M & M-L & M-L & M \\
& SSP5 & L/M & L-M & M-L & M-L & L-M \\
& & & & & &
\end{tabular}

Table A20. Water dimension - rating the growth of areas equipped for irrigation.

\begin{tabular}{lllllll}
\hline & \multicolumn{2}{c}{ SSP/class } & $\begin{array}{l}\text { HE-1 } \\
\text { M }\end{array}$ & $\begin{array}{l}\text { HE-2 } \\
\text { L }\end{array}$ & $\begin{array}{l}\text { HE-3 } \\
\text { L }\end{array}$ & $\begin{array}{l}\text { HE-4 } \\
\text { M }\end{array}$ \\
\hline Area equipped for irrigation & SSP1 & L & C & D & D & C \\
& SSP2 & M & B & C & C & B \\
& SSP3 & H/M & A & C & C & A \\
& SSP4 & M & B & C & C & B \\
& SSP5 & L/M & C & C & C & C \\
\hline
\end{tabular}

the trajectories of arable land and land for permanent crops (i.e., total cultivated land in our terminology).

As Tables A15 and A16 indicate, irrigated agriculture has been critically important for the growth of production during the last 40 years. While areas equipped for irrigation expanded by more than 130 million ha during 1970-2010, the total cultivated land increased by less than 120 million ha. In other words, overall there has been a net decrease in rainfed cultivated land (cultivated land not equipped for irriga- tion). In countries of hydro-economic classes HE-2 and HE-3 (developed countries and high-income developing countries), the area equipped for irrigation increased by about 11 million ha in 1970-1990 and stagnated during 1990-2010; total cultivated land in these countries decreased during both periods, but significantly so in 1990-2010. In contrast, both the area equipped for irrigation and the total cultivated land increased remarkably in HE-1 and HE-4. However, while area expansion in countries of HE-1 was dominated by develop- 
ment of rain-fed land, the expansion of irrigated areas was responsible for the cultivated land increase and agricultural production growth in the countries of class HE-4. As a result, the share of land equipped for irrigation in total cultivated land increased remarkably during the 4 decades of 1970-2010 (see Table A17), globally from $12.9 \%$ to more than $20 \%$, in countries of HE- 3 and HE-4 from, respectively, 27.9 and $22.5 \%$ in 1970 to 45.1 and $38.7 \%$ in 2010 .

In 2000, area equipped for irrigation accounted for some $18 \%$ of total cultivated land and for more than $40 \%$ of crop production. For a number of reasons, FAO experts expect a sharp slowdown in the growth of areas equipped for irrigation as compared to the historical trend, reflecting the projected declining growth rate of future crop demand and production (due to slow-down of population growth), increasing scarcity of suitable areas for irrigation, as well as the scarcity of water resources in some countries, the rising cost of irrigation investment, and competition for water with other sectors.

Below, in Table A18, we summarize by hydro-economic classes the FAO estimates of actually irrigated land. In this FAO scenario, net increases (period 2005/07 to 2050) of rainfed cultivated land amount to about 50 million ha; actually irrigated land increases by 20 million ha, of which 16 million ha are in countries of class HE-1. In contrast, expansion in class HE-4 is only 4.6 million ha.

As shown in Table A19, we conclude that incentives to increase the area equipped for irrigation will be low in scenarios with high technical progress and low population growth, such as SSP1 and SSP5, will be relatively high under SSP3, and will be moderate under SSP2 and SSP4. When looking across countries in different hydro-economic classes, incentives for expansion will be moderate to high in developing countries of HE-1 and HE-4, but only low in countries of HE-2 and HE-3 due to demographic and economic reasons.
For practical use, Table A19 can be simplified into a rating table using four classes, rated "A" to "D", which reflect the combination of demand growth, land abundance and magnitude of water challenges that can be derived from the scenario narratives and hydro-economic classification. While a "D" rating signals modest decline (or at best stagnation) of areas equipped for irrigation, the " $\mathrm{A}$ " rating indicates conditions under which the area equipped for irrigation can be expected to increase. Hence, the strongest need to expand the cultivated land and the irrigated areas will exist in developing countries under SSP3, the least in developed countries (HE-2 and HE-3) especially under SSP1 and SSP5.

It should be noted that Table A20 can provide general guidance only. In a country's reality, several and diverse factors will determine the future expansion of land equipped for irrigation: (1) water availability and reliability, and cost of access; (2) availability of suitable land resources for conversion to rain-fed agriculture (as an alternative to irrigated cropping); (3) prevailing yield gaps and scope for sustainable intensification on existing cultivated land; (4) demand growth for food and non-food biomass, and hence population growth; (5) state security and food self-reliance policies; (6) economic wealth. 
Acknowledgements. The Water Futures and Solutions Initiative (WFaS) was launched by IIASA, UNESCO/UN-Water, the World Water Council (WWC), the International Water Association (IWA), and the Ministry of Land, Infrastructure and Transport (MOLIT) of the Republic of Korea, and has been supported by the government of Norway, the Asian Development Bank, and the Austrian Development agency. More than 35 organizations contribute to the scientific project team, and an additional 25 organizations are represented in stakeholder groups. Furthermore, WFaS relies on numerous databases compiled and made available by many more organizations, which are referred to in this paper. The research described in this paper would not have been possible without the collaboration of all of these organizations in the WFaS Project Team. Y. Wada is supported by Japan Society for the Promotion of Science (JSPS) Oversea Research Fellowship (grant no. JSPS-2014-878). C. Ringler is supported from the CGIAR Research Program on Water, Land and Ecosystems. We cordially thank two anonymous referees who gave constructive and thoughtful comments and suggestions, which improved the quality of the manuscript.

Edited by: H. McMillan

\section{References}

Acreman, M. C. and Dunbar, M. J.: Defining environmental river flow requirements - a review, Hydrol. Earth Syst. Sci., 8, 861876, doi:10.5194/hess-8-861-2004, 2004.

Adam, J. C., Clark, E. A., Lettenmaier, D. P., and Wood, E. F.: Correction of global precipitation products for orographic effects, J. Climate, 19, 15-38, 2006.

Alcamo, J.: The SAS approach: Combining Qualitative and quantitative knowledge in environmental scenarios, Chaprter 6, in: Environmental Futures: The Practice of Environmental Scenario Analysis, edited by: Alcamo, J., Elsevier, Amterdam, 123-150, 2008.

Alcamo, J., Döll, P., Henrichs, T., Kaspar, F., Lehner, B., Rösch, T., and Siebert, S.: Development and testing of the WaterGAP 2 global model of water use and availability, Hydrol. Sci. J., 48, 317-337, 2003a.

Alcamo, J., Döll, P., Henrichs, T., Kaspar, F., Lehner, B., Rösch, T., and Siebert, S.: Global estimation of water withdrawals and availability under current and "business as usual" conditions, Hydrol. Sci. J., 48, 339-348, 2003 b.

Alcamo, J., Flörke, M., and Märker, M.: Future long-term changes in global water resources driven by socio-economic and climatic changes, Hydrol. Sci. J., 52, 247-275, 2007.

Alexandratos, N. and Bruinsma, J.: World agriculture towards 2030/2050: the 2012 revision, ESA Working paper No. 1203, FAO, Rome, available at: http://www.fao.org/docrep/016/ ap106e/ap106e.pdf (last access: August 2015), 2012.

Allen, R. G., Pereira, L. S., Raes, D., and Smith, M.: Crop evapotranspiration - Guidelines for computing crop water requirements, FAO Irrigation and Drainage Paper 56, FAO, Rome, 1998.

Arnell, N. W.: Climate change and global water resources, Global Environ. Change, 9, 31-49, 1999.
Arnell, N. W.: Climate change and global water resources: SRES emissions and socio-economic scenarios, Global Environ. Change, 14, 31-52, 2004.

Arnell, N. W.: Adapting to climate change: an evolving research programme, Clim. Change, 100, 107-111, doi:10.1007/s10584010-9839-0, 2010.

Arnell, N. and Lloyd-Hughes, B.: The global-scale impacts of climate change on water resources and flooding under new climate and socio-economic scenarios, Clim. Change, 122, 127 140, doi:10.1007/s10584-013-0948-4, 2014.

Bondeau, A., Smith, P. C., Zaehle, S., Schaphoff, S., Lucht, W., Cramer, W., Gerten, D., Reichstein, M., and Smith, B.: Modelling the role of agriculture for the 20th century, Global Change Biol., 13, 679-706, doi:10.1111/j.13652486.2006.01305.x, 2007.

Brown, R., Ashley, R., and Farrelly, M.: Political and professional agency entrapment: An agenda for urban water research, Water Resour. Manage., 25, 4037-4050, doi:10.1007/s11269-0119886-y, 2011.

Davie, J. C. S., Falloon, P. D., Kahana, R., Dankers, R., Betts, R., Portmann, F. T., Wisser, D., Clark, D. B., Ito, A., Masaki, Y., Nishina, K., Fekete, B., Tessler, Z., Wada, Y., Liu, X., Tang, Q., Hagemann, S., Stacke, T., Pavlick, R., Schaphoff, S., Gosling, S. N., Franssen, W., and Arnell, N.: Comparing projections of future changes in runoff from hydrological and biome models in ISI-MIP, Earth Syst. Dynam., 4, 359-374, doi:10.5194/esd-4359-2013, 2013.

Davies, E. G. R., Kyle, P., and Edmonds, J. A.: An integrated assessment of global and regional water demands for electricity generation to 2095, Adv. Water Resour., 52, 296-313, doi:10.1016/j.advwatres.2012.11.020, 2013.

DOE: Energy Demand on Water Resources: Report to Congress on the Interdependency of Energy and Water, United States Department of Energy, available online (November 2014): http://powi.ca/wp-content/uploads/2012/12/ Energy-Demands-on-Water-Resources-Report-to-Congress-2006. pdf (last access: August 2015), 2006.

Döll, P. and Siebert, S.: A digital global map of irrigated areas, ICID J., 49, 55-66, 2000.

Döll, P. and Siebert, S.: Global modeling of irrigation water requirements, Water Resour. Res., 38, 8.1-8.10, doi:10.1029/2001WR000355, 2002.

Döll, P., Kaspar, F., and Lehner, B.: A global hydrological model for deriving water availability indicators: model tuning and validation, J. Hydrol., 270, 105-134, 2003.

Döll, P., Fiedler, K., and Zhang, J.: Global-scale analysis of river flow alterations due to water withdrawals and reservoirs, Hydrol. Earth Syst. Sci., 13, 2413-2432, doi:10.5194/hess-13-24132009, 2009.

Döll, P, Hoffmann-Dobrev, H., Portmann, F. T., Siebert, S., Eicker, A., Rodell, M., and Strassberg, G.: Impact of water withdrawals from groundwater and surface water on continental water storage variations, J. Geodyn., 59-60, 143-156, 2012.

Doorenbos, J. and Pruitt, W. O.: Crop water requirements, Irrig. Drain. Pap. 24, FAO, Rome, 1977.

Dyson, M., Bergkamp, G., and Scanlon, J.: Flow: the essentials of environmental flows, IUCN, Gland, Switzerland and Cambridge, UK, 2003. 
Evans, L. T.: Adapting and improving crops: The endless task, Phil. Trans. R. Soc. Lond. B Biol. Sci., 352, 901-906, doi:10.1098/rstb.1997.0069, 1997.

Falkenmark, M., Kijne, J. W., Taron, B., Murdoch, G., Sivakumar, M. V. K., and Craswell, E.: Meeting Water Requirements of an Expanding World Population [and Discussion], Phil. T. Roy. Soc. Lond. B., 352, 929-936, 1997.

Famiglietti, J. S., Lo, M. Ho, S. L., Bethune, J., Anderson, K. J., Syed, T. H., Swenson, S. C., de Linage, C. R., and Rodell, M.: Satellites measure recent rates of groundwater depletion in California's Central Valley, Geophys. Res. Lett., 38, L03403, doi:10.1029/2010GL046442, 2011.

Fischer, G., Tubiello, F. N., van Velthuizen, H., and Wiberg, D. A.: Climate change impacts on irrigation water requirements: Effects of mitigation, 1990-2080, Technol. Forecasting Soc. Change, 74, 1083-1107, doi:10.1016/j.techfore.2006.05.021, 2007.

Fischer, G., Hizsnyik, E., Tramberend, S., and Wiberg, D.: Towards indicators for water security - A global hydro-economic classification of water challenges, IIASA Interim Report IR-15-013, IIASA, Laxenburg, Austria, 2015.

Flörke, M., Teichert, E., and Bärlund, I.: Future changes of freshwater needs in European power plants, Management of Environmental Quality, 22, 89-104, doi:10.1108/14777831111098507, 2011.

Flörke, M., Barlund, I., and Kynast, E.: Will climate change affect the electricity production sector? A European study, J. Water Clim. Change, 3, 44-54, doi:10.2166/wcc.2012.066, 2012.

Flörke, M., Kynast, E., Bärlund, I., Eisner, S., Wimmer, F., and Alcamo, J.: Domestic and industrial water uses of the past 60 years as a mirror of socio-economic development: A global simulation study, Global Environ. Change, 23, 144-156, doi:10.1016/j.gloenvcha.2012.10.018, 2013.

Food and Agriculture Organization of the United Nations (FAO): Gridded livestock of the world 2007, edited by: Wint, G. R. W. and Robinson, T. P., FAO, Rome, p. 131, 2007.

Frenken, K. and Gillet, V.: Irrigation water requirement and water withdrawal by country. AQUASTAT. Food and Agriculture Organization, Rome, Italy, available at: http://www.fao.org/nr/water/ aquastat/water_use_agr/index.stm (last access: August 2015), 2012.

Freydank, K. and Siebert, S.: Towards mapping the extent of irrigation in the last century: Time series of irrigated area per country, Frankfurt Hydrology Paper 08, Tech. rep., Institute of Physical Geography, University of Frankfurt, Frankfurt am Main, Germany, 2008.

Gerten, D., Schaphoff, S., and Lucht, W.: Potential future changes in water limitation of the terrestrial biosphere, Clim. Change, 80 , 277-299, doi:10.1007/s10584-006-9104-8, 2007.

Gleeson, T., Wada, Y., Bierkens, M. F. P., and van Beek, L. P. H.: Water balance of global aquifers revealed by groundwater footprint, Nature, 488, 197-200, doi:10.1038/nature11295, 2012.

Gleick, P. H.: Water use, Annu. Rev. Environ. Resour., 28, 275-314, doi:10.1146/annurev.eg.19.110194.001411, 2003.

Gleick, P. H., Cooley, H., Cohen, M. J., Morikawa, M., Morrison, J., and Palaniappan, M.: The Worlds Water 2008-2009, The Biennial Report on Freshwater Resources, Island Press, Washington, D.C., USA, 2009.

Gosling, S. N., Bretherton, D., Haines, K., and Arnell, N. W.: Global hydrology modelling and uncertainty: running multiple ensem- bles with a campus grid, Phil. Trans. R. Soc. A., 368, 4005-4021, 2010.

Gosling, S. N., Taylor, R. G., Arnell, N. W., and Todd, M. C.: A comparative analysis of projected impacts of climate change on river runoff from global and catchment-scale hydrological models, Hydrol. Earth Syst. Sci., 15, 279-294, doi:10.5194/hess-15279-2011, 2011.

Grey, D., Garrick, D., Blackmore, D., Kelman, J., Muller, M., and Sadoff, C.: Water security in one blue planet: twenty-first century policy challenges for science, Phil. Trans. R. Soc. A., 371, 20120406, doi:10.1098/rsta.2012.0406, 2013.

Haddeland, I., Skaugen, T., and Lettenmaier, D. P.: Anthropogenic impacts on continental surface water fluxes, Geophys. Res. Lett., 33, L08406, doi:10.1029/2006GL026047, 2006.

Haddeland, I., Clark, D., Franssen, W. H. P., Ludwig, F., Voss, F., Arnell, N. W., Bertrand, N., Best, M., Folwell, S., Gerten, D., Gomes, S., Gosling, S., Hagemann, S., Hanasaki, N., Harding, R., Heinke, J., Kabat, P., Koirala, S., Oki, T., Polcher, J., Stacke, T., Viterbo, P., Weedon, G. P., and Yeh, P.: Multimodel Estimate of the Global Terrestrial Water Balance: Setup and First Results, J. Hydrometeor., 12, 869-884, 2011.

Hanasaki, N., Kanae, S., and Oki, T.: A reservoir operation scheme for global river routing models, J. Hydrol., 327, 22-41, doi:10.1016/j.jhydrol.2005.11.011, 2006.

Hanasaki, N., Kanae, S., Oki, T., Masuda, K., Motoya, K., Shirakawa, N., Shen, Y., and Tanaka, K.: An integrated model for the assessment of global water resources - Part 1: Model description and input meteorological forcing, Hydrol. Earth Syst. Sci., 12, 1007-1025, doi:10.5194/hess-12-1007-2008, 2008a.

Hanasaki, N., Kanae, S., Oki, T., Masuda, K., Motoya, K., Shirakawa, N., Shen, Y., and Tanaka, K.: An integrated model for the assessment of global water resources - Part 2: Applications and assessments, Hydrol. Earth Syst. Sci., 12, 1027-1037, doi:10.5194/hess-12-1027-2008, 2008b.

Hanasaki, N., Inuzuka, T., Kanae, S., and Oki, T.: An estimation of global virtual water flow and sources of water withdrawal for major crops and livestock products using a global hydrological model, J. Hydrol., 384, 232-244, 2010.

Hanasaki, N., Fujimori, S., Yamamoto, T., Yoshikawa, S., Masaki, Y., Hijioka, Y., Kainuma, M., Kanamori, Y., Masui, T., Takahashi, K., and Kanae, S.: A global water scarcity assessment under Shared Socio-economic Pathways - Part 1: Water use, Hydrol. Earth Syst. Sci., 17, 2375-2391, doi:10.5194/hess-17-23752013, 2013a.

Hanasaki, N., Fujimori, S., Yamamoto, T., Yoshikawa, S., Masaki, Y., Hijioka, Y., Kainuma, M., Kanamori, Y., Masui, T., Takahashi, K., and Kanae, S.: A global water scarcity assessment under Shared Socio-economic Pathways - Part 2: Water availability and scarcity, Hydrol. Earth Syst. Sci., 17, 2393-2413, doi:10.5194/hess-17-2393-2013, 2013 b.

Harris, I., Jones, P. D., Osborn, T. J., and Lister, D. H.: Updated high-resolution grids of monthly climatic observations - the CRU TS3.10 Dataset, Int. J. Climatol., 34, 623-642, doi:10.1002/joc.3711, 2014.

Hayashi, A., Akimoto, K., Tomoda, T., and Kii, M.: Global evaluation of the effects of agriculture and water management adaptations on the water-stressed population, Mitig. Adapt. Strateg. Glob. Change, 18, 591-618, doi:10.1007/s11027-012-9377-3, 2013. 
Hejazi, M., Edmonds, J., Clarke, L., Kyle, P., Chaturvedi, V., Davies, E., Wise, M., Patel, P., Eom, J., and Calvin, K.: Long-term global water use projections using six socioeconomic scenarios in an integrated assessment modeling framework, Technol. Forecast. Social Change, 81, 205-226, doi:10.1016/j.techfore.2013.05.006, 2014.

Jägermeyr, J., Gerten, D., Heinke, J., Schaphoff, S., Kummu, M., and Lucht, W.: Water savings potentials of irrigation systems: global simulation of processes and linkages, Hydrol. Earth Syst. Sci., 19, 3073-3091, doi:10.5194/hess-19-3073-2015, 2015.

Kalnay, E., Kanamitsu, M., Kistler, R., Collins, W., Deaven, D., Gandin, L., Iredell, M., Saha, S., White, G., Woollen, J., Zhu, Y., Leetmaa, A., Reynolds, R., Chelliah, M., Ebisuzaki, W., Higgins, W., Janowiak, J., Mo, K. C., Ropelewski, C., Wang, J., Jenne, R., and Joseph, D.: The NCEP/NCAR 40-year reanalysis project, B. Am. Meteorol. Soc., 77, 437-471, doi:10.1175/15200477(1996)077<0437:TNYRP>2.0.CO;2, 1996.

Kim, H., Yeh, P. J. F., Oki, T., and Kanae, S.: Role of rivers in the seasonal variations of terrestrial water storage over global basins, Geophys. Res. Lett., 36, L17402, doi:10.1029/2009GL039006, 2009.

King, C. W., Holman, A. S., and Webber, M. E.: Thirst for energy, Nature Geosci., 1, 283-286, doi:10.1038/ngeo195, 2008.

Klein Goldewijk, K.: Three centuries of global population growth: a spatial referenced population (density) database for 1700-2000, Popul. Environ., 26, 343-367, doi:10.1007/s11111-005-3346-7, 2005.

Klein Goldewijk, K., Beusen, A., and Janssen, P.: Long term dynamic modelling of global population and built-up area in a spatially explicit way, HYDE 3.1., Holocene, 20, 565-573, doi:10.1177/0959683609356587, 2010.

Koch, H. and Vögele, S.: Dynamic modelling of water demand, water availability and adaptation strategies for power plants to global change, Ecol. Econom., 68, 2031-2039, doi:10.1016/j.ecolecon.2009.02.015, 2009.

Konikow, L. F.: Contribution of global groundwater depletion since 1900 to sea-level rise, Geophys. Res. Lett., 38, L17401, doi:10.1029/2011GL048604, 2011.

Konikow, L. F. and Kendy, E.: Groundwater depletion: A global problem, Hydrogeol. J., 13, 317-320, doi:10.1007/s10040-0040411-8, 2005.

Krysanova, V., Müller-Wohlfeil, D. I., and Becker, A.: Development and test of a spatially distributed hydrological/water quality model for mesoscale watersheds, Ecol. Model., 106, 261-289, doi:10.1016/S0304-3800(97)00204-4, 1998.

Kummu, M., Ward, P. J., de Moel, H., and Varis, O.: Is physical water scarcity a new phenomenon? Global assessment of water shortage over the last two millennia, Environ. Res. Lett., 5, 034006, doi:10.1088/1748-9326/5/3/034006, 2010.

Kyle, P., Davies, E. G., Dooley, J. J., Smith, S. J., Clarke, L. E., Edmonds, J. A., and Hejazi, M.: Influence of climate change mitigation technology on global demands of water for electricity generation, Int. J. Greenh. Gas Con., 13, 112-123, doi:10.1016/j.ijggc.2012.12.006, 2013.

Leff, B., Ramankutty, N., and Foley, J. A.: Geographic distribution of major crops across the world, Global Biogeochem. Cy., 18, GB1009, doi:10.1029/2003GB002108, 2004.
Llamas, R., Back, W., and Margat, J.: Groundwater use: Equilibrium between social benefits and potential environmental costs, Applied Hydrol., 1, 3-14, 1992.

Markewitz, P. and Vögele, S.: Der Strommarkt in den neuen Bundesländern : derzeitiger Stand und mögliche Entwicklung bis zum Jahr 2050, Forschungszentrum Jülich, Jülich, 2001 (in German).

Meeson, B. W., Corprew, F. E., McManus, J. M. P., Myers, D. M., Closs, J. W., Sun, K. J., Sunday, D. J., and Sellers, P. J.: ISLSCP Initiative I Global Datasets for Landatmosphere Models, 19871988, Tech. rep., NASA, Greenbelt, Maryland, 1995.

Mekonnen, M. M. and Hoekstra, A. Y.: The blue water footprint of electricity from hydropower, Hydrol. Earth Syst. Sci., 16, 179187, doi:10.5194/hess-16-179-2012, 2012.

Mitchell, T. D. and Jones, P. D.: An improved method of constructing a database of monthly climate observations and associated high-resolution grids, Int. J. Climatol., 25, 693-712, doi:10.1002/joc.1181, 2005.

Monfreda, C., Ramankutty, N., and Foley, J. A.: Farming the planet, part 2: the geographic distribution of crop areas and yields in the year 2000, Global Biogeochem. Cy., 22, GB1022, doi:10.1029/2007GB002947, 2008.

Moraes, M., Ringler, C., and Cai, X.: Policies and Instruments Affecting Water Use for Bioenergy Production, Special Issue: Bioenergy and Water. Biofuel, Bioprod. Bior., 5, 431-444, doi:10.1002/bbb.306, 2011.

Moss, R. H., Edmonds, J. A., Hibbard, K. A., Manning, M. R., Rose, S. K., van Vuuren, D. P., Carter, T. R., Emori, S., Kainuma, M., Kram, T., Meehl, G. A., Mitchell, J. F. B., Nakicenovic, N., Riahi, K., Smith, S. J., Stouffer, R. J., Thomson, A. M., Weyant, J. P., and Wilbanks, T. J.: The next generation of scenarios for climate change research and assessment, Nature, 463, 747-756, doi:10.1038/nature08823, 2010.

Msangi, S., Enahoro, D., Herrero, M., Magnan, N., Havlik, P., Notenbaert, A., and Nelgen, S.: Integrating livestock feeds and production systems into agricultural multi-market models: The example of IMPACT, Food Policy, 49, 365-377, doi:10.1016/j.foodpol.2014.10.002, 2014.

Müller Schmied, H., Eisner, S., Franz, D., Wattenbach, M., Portmann, F. T., Flörke, M., and Döll, P.: Sensitivity of simulated global-scale freshwater fluxes and storages to input data, hydrological model structure, human water use and calibration, Hydrol. Earth Syst. Sci., 18, 3511-3538, doi:10.5194/hess-18-35112014, 2014.

New, M., Hulme, M., and Jones, P. D.: Representing twentieth century space-time climate variability. Part 2: development of 1901-96 monthly grids of terrestrial surface climate, J. Climate, 13, 2217-2238, doi:10.1175/15200442(2000)013<2217:RTCSTC >2.0.CO;2, 2000.

New, M., Lister, D., Hulme, M., and Makin, I.: A high resolution data set of surface climate over global land areas, Clim. Res., 21, 1-25, 2002.

Ngo-Duc, T., Polcher, J., and Laval, K.: A 53-year forcing data set for land surface models, J. Geophys. Res., 110, D06116, doi:10.1029/2004JD005434, 2005.

Nijssen, B., O’Donnell, G. M., Lettenmaier, D. P., Lohmann, D. and Wood, E. F.: Predicting the discharge of global rivers, J. Climate, 14, 3307-3323, 2001a. 
Nijssen, B., Schnur, R., and Lettenmaier, D. P.: Global retrospective estimation of soil moisture using the variable infiltration capacity land surface model, 1980-93, J. Climate, 14, 1790-1808, 2001b.

Oki, T., Agata, Y., Kanae, S., Saruhashi, T., Yang, D., and Musiake, K.: Global assessment of current water resources using total runoff-integrating pathways, Hydrol. Sci. J., 46, 983-996, 2001.

O’Neill, B. C., Kriegler, E., Ebi, K. L., Kemp-Benedict, E., Riahi, K., Rothman, D. S., van Ruijven, B. J., van Vuuren, D. P., Birkmann, J., Kok, K., Levy, M., and Solecki, W.: The roads ahead: Narratives for shared socioeconomic pathways describing world futures in the 21 st century, Global Environ. Change, doi:10.1016/j.gloenvcha.2015.01.004, online first, 2015.

Onogi, K., Tsutsui, J., Koide, H., Sakamoto, M., Kobayashi, S., Hatsushika, H., Matsumoto, T., Yamazaki, N., Kamahori, H., Takahashi, K., Kadokura, S., Wada, K., Kato, K., Oyama, R., Ose, T., Mannoji, N., and Taira, R.: The JRA-25 Reanalysis, J. Meteorol. Soc. Jpn., 85, 369-432, 2007.

Pahl-Wostl, C., Arthington, A., Bogardi, J., Bunn, S. E., Hoff, H., Lebel, L., Nikitina, E., Palmer, M., Poff, L., Richars, K., Schluter, M., Schulze, R., St-Hilaire, A., Tharme, R., Tockner, K., and Tsegai, D.: Environmental flows and water governance: managing sustainable water uses, Curr. Opin. Environm. Sustainability, 5, 341-351, doi:10.1016/j.cosust.2013.06.009, 2013.

Pastor, A. V., Ludwig, F., Biemans, H., Hoff, H., and Kabat, P.: Accounting for environmental flow requirements in global water assessments, Hydrol. Earth Syst. Sci., 18, 5041-5059, doi:10.5194/hess-18-5041-2014, 2014.

Pokhrel, Y., Hanasaki, N., Koirala, S., Cho, J., Yeh, P. J. F., Kim, H., Kanae, S., and Oki, T.: Incorporating anthropogenic water regulation modules into a land surface model, J. Hydrometeorol., 13, 255-269, doi:10.1175/JHM-D-11-013.1, 2012a.

Pokhrel, Y. N., Hanasaki, N., Yeh, P. J.-F., Yamada, T., Kanae, S., and Oki, T.: Model estimates of sea level change due to anthropogenic impacts on terrestrial water storage, Nat. Geosci., 5, 389-392, doi:10.1038/ngeo1476, 2012b.

Portmann, F., Siebert, S., and Döll, P.: MIRCA2000 - Global monthly irrigated and rainfed crop areas around the year 2000: a new high-resolution data set for agricultural and hydrological modelling, Global Biogeochem. Cy., 24, GB1011, doi:10.1029/2008GB003435, 2010.

Portmann, F. T., Döll, P., Eisner, S., and Flörke, M.: Impact of climate change on renewable groundwater resources: assessing the benefits of avoided greenhouse gas emissions using selected CMIP5 climate projections, Environ. Res. Lett., 8, 024023, doi:10.1088/1748-9326/8/2/024023, 2013.

Puma, M. J., Bose, S., Chon, S. Y., and Cook, B. I.: Assessing the evolving fragility of the global food system, Environ. Res. Lett., 10, 024007, doi:10.1088/1748-9326/10/2/024007, 2015.

Reder, K.. Flörke, M., and Alcamo, J.: Modeling historical fecal coliform loadings to large European rivers and resulting instream concentrations, Environ. Model. Softw., 63, 251-263, doi:10.1016/j.envsoft.2014.10.001, 2015.

Richter, B. D.: Re-thinking environmental flows: from allocations and reserves to sustainability boundaries, River Res. Applic., 26, 1052-1063. doi:10.1002/rra.1320, 2010.

Robock, A., Vinnikov, K. Y., Schlosser, C. A., Speranskaya, N. A., and Xue, Y. K.: Use of mid-latitude soil moisture and meteorological observations to validate soil-moisture simulations with biosphere and bucket models, J. Climate, 8, 15-35, 1995.
Rodell, M., Velicogna, I., and Famiglietti, J. S.: Satellite-based estimates of groundwater depletion in India, Nature, 460, 999-1002, doi:10.1038/nature08238, 2009.

Rohwer, J., Gerten, D., and Lucht, W.: Development of functional types of irrigation for improved global crop modelling, PIK Report 104, Tech. rep., Potsdam Institute for Climate Impact Research, Potsdam, Germany, 2007.

Rosegrant, M. W. and the IMPACT Development Team: International Model for Policy Analysis of Agricultural Commodities and Trade (IMPACT): Model Description, International Food Policy Research Institute (IFPRI), Washington, D.C., 2012.

Rost, S., Gerten, D., Bondeau, A., Lucht, W., Rohwer, J., and Schaphoff, S.: Agricultural green and blue water consumption and its influence on the global water system, Water Resour. Res., 44, W09405, doi:10.1029/2007WR006331, 2008.

Rübbelke, D. and Vögele, S.: Impacts of climate change on European critical infrastructures: The case of the power sector, Environ. Sci. Policy, 14, 53-63, doi:10.1016/j.envsci.2010.10.007, 2011.

Rudolf, B., Becker, A., Chneider, U., Meyer-Christoffer, A., and Ziese, M.: "GPCC Full Data Reanalysis Version 5" providing high-quality gridded monthly precipitation data for the global land-surface is public available since December, Tech. Rep. December, GPCC Status Report, http://www.dwd.de/bvbw/generator/DWDWWW/Content/ Oeffentlichkeit/KU/KU4/KU42/en/Reports_Publications/ GPCC_status_report_2010,templateId=raw,property= publicationFile.pdf/GPCC_status_report_2010.pdf (last access: 18 November 2015), 2010.

Schewe, J., Heinke, J., Gerten, D., Haddeland, I., Arnell, N. W., Clark, D. B., Dankers, R., Eisner, S., Fekete, B., ColónGonzález, F. J., Gosling, S. N., Kim, H., Liu, X., Masaki, Y., Portmann, F. T., Satoh, Y., Stacke, T., Tang, Q., Wada, Y., Wisser, D., Albrecht, T., Frieler, K., Piontek, F., Warszawski, L., and Kabat, P.: Multi-model assessment of water scarcity under climate change, P. Natl. Acad. Sci. USA, 111, 3245-3250, doi:10.1073/pnas.1222460110, 2014.

Shen, Y., Oki, T., Utsumi, N., Kanae, S., and Hanasaki, N.: Projection of future world water resources under SRES scenarios: Water withdrawal, Hydrolog. Sci. J., 53, 11-33, doi:10.1623/hysj.53.1.11, 2008.

Shiklomanov, I. A.: Assessment of water resources and water availability in the world, Comprehensive assessment of the freshwater resources of the world, World Meteorological Organization and the Stockholm Environment Institute, Stockholm, Sweden, 1997.

Shiklomanov, I. A.: World Water Scenarios Analyses, chap. World water resources and water use: Present assessment and outlook for 2025, Earthscan, London, UK, 2000a.

Shiklomanov, I. A.: Appraisal and assessment of world water resources, Water Int., 25, 11-32, 2000b.

Siebert, S. and Döll, P.: Quantifying blue and green virtual water contents in global crop production as well as potential production losses without irrigation, J. Hydrol., 384, 198-217, 2010.

Siebert, S., Döll, P., Hoogeveen, J., Faures, J.-M., Frenken, K., and Feick, S.: Development and validation of the global map of irrigation areas, Hydrol. Earth Syst. Sci., 9, 535-547, doi:10.5194/hess-9-535-2005, 2005.

Siebert, S., Döll, P., Feick, S., Hoogeveen, J., and Frenken, K.: Global Map of Irrigation Areas Version 4.0.1., Tech. rep., In- 
stitute of Physical Geography, University of Frankfurt, Frankfurt am Main, Germany, 2007.

Siebert, S., Burke, J., Faures, J. M., Frenken, K., Hoogeveen, J., Döll, P., and Portmann, F. T.: Groundwater use for irrigation - a global inventory, Hydrol. Earth Syst. Sci., 14, 1863-1880, doi:10.5194/hess-14-1863-2010, 2010.

Siebert, S., Kummu, M., Porkka, M., Döll, P., Ramankutty, N., and Scanlon, B. R.: A global data set of the extent of irrigated land from 1900 to 2005, Hydrol. Earth Syst. Sci., 19, 1521-1545, doi:10.5194/hess-19-1521-2015, 2015.

Smakhtin, V., Revenga, C., and Döll, P.: A pilot global assessment of environmental water requirements and scarcity, Water Int., 29, 307-317, doi:10.1080/02508060408691785, 2004.

Smakhtin, V. U., Shilpakar, R. L., and Hughes, D. A.: Hydrologybased assessment of environmental flows: An example from nepal, Hydrol. Sci. J., 51, 207-222, doi:10.1623/hysj.51.2.207, 2006.

Smith, M.: CROPWAT - a computer program for irrigation planning and management, FAO Irrigation and Drainage Paper 46, FAO, Rome, 1992.

Steinfeld, H., Gerber, P.,Wassenaar, T., Castel, V., Rosales, M., and de Haan, C.: Livestocks long shadow: Environmental issues and options, FAO, Rome, Italy, ISBN 978-92-5-105571-7, 2006.

Sulser, T., Ringler, C., Zhu, T., Msangi, S., Bryan, E., and Rosegrant, M. W.: Green and blue water accounting in the Ganges and Nile basins: implications for food and agricultural policy, J. Hydrol., 384, 276-291, doi:10.1016/j.jhydrol.2009.10.003, 2010.

Taylor, R. G., Scanlon, B., Döll, P., Rodell, M., van Beek, R., Wada, Y., Longuevergne, L., Leblanc, M., Famiglietti, J. S., Edmunds, M., Konikow, L., Green, T. R., Chen, J., Taniguchi, M., Bierkens, M. F. P., MacDonald, A., Fan, Y., Maxwell, R. M., Yechieli, Y., Gurdak, J. J., Allen, D. M., Shamsudduha, M., Hiscock, K., Yeh, P. J.-F., Holman, I., and Treidel, H.: Groundwater and climate change, Nature Clim. Change, 3, 322-329, doi:10.1038/nclimate1744, 2013.

Thenkabail, P. S., Biradar, C. M., Turral, H., Noojipady, P., Li, Y. J., Vithanage, J., Dheeravath, V., Velpuri, M., Schull, M., Cai, X. L., and Dutta, R.: An Irrigated Area Map of the World (1999) derived from Remote Sensing, Res., Rep., 105, Tech. rep., International Water Management Institute, Colombo, Sri Lanka, p. 74, 2006.

UDI: World electric power plants database, Utility Data Institute, Platts Energy InfoStore, Available at http://www.platts.com/ (last access: June 2015), 2004.

Van Beek, L. P. H., Wada, Y., and Bierkens, M. F. P.: Global monthly water stress: I. Water balance and water availability, Water Resour. Res., 47, W07517, doi:10.1029/2010WR009791, 2011.

Van Vliet, M. T. H., Yearsley, J. R., Ludwig, F., Vögele, S., Lettenmaier, D. P., and Kabat, P.: Vulnerability of US and European electricity supply to climate change, Nature Clim. Change, 2, 676-681, doi:10.1038/nclimate1546, 2012.

Van Vliet, M. T. H., Vögele, S., and Rübbelke, D.: Water constraints on European power supply under climate change: impacts on electricity prices, Environ. Res. Lett., 8, 035010, doi:10.1088/1748-9326/8/3/035010, 2013.

Van Vuuren, P., Edmonds, J., Kainuma, M., Riahi, K., Thomson, A., Hibbard, K., Hurtt, G., Kram, T., Krey, V., Lamarque, J.F., Masui, T., Meinshausen, M., Nakicenovic, N., Smith, S., and Rose, S.: The representative concentration pathways: an overview, Clim. Change, 109, 5-31, doi:10.1007/s10584-0110148-z, 2011.

Vassolo, S. and Döll, P.: Global-scale gridded estimates of thermoelectric power and manufacturing water use, Water Resour. Res., 41, W04010, doi:10.1029/2004WR003360, 2005.

Vörösmarty, C. J., Leveque, C., and Revenga, C.: Millennium Ecosystem Assessment Volume 1: Conditions and Trends, chap. 7: Freshwater ecosystems, Island Press, Washington D.C., USA, 165-207, 2005.

Vörösmarty, C. J., McIntyre, P., Gessner, M. O., Dudgeon, D., Prusevich, A., Green, P., Glidden, S., Bunn, S. E., Sullivan, C. A., and Liermann, C. R.: Global threats to human water security and river biodiversity, Nature, 467, 555-561, 2010.

Wada, Y. and Bierkens, M. F. P.: Sustainability of global water use: past reconstruction and future projections, Environ. Res. Lett., 9, 104003, doi:10.1088/1748-9326/9/10/104003, 2014.

Wada, Y., van Beek, L. P. H., van Kempen, C. M., Reckman, J. W. T. M., Vasak, S., and Bierkens, M. F. P.: Global depletion of groundwater resources, Geophys. Res. Lett., 37, L20402, doi:10.1029/2010GL044571, 2010.

Wada, Y., van Beek, L. P. H., and Bierkens, M. F. P.: Modelling global water stress of the recent past: on the relative importance of trends in water demand and climate variability, Hydrol. Earth Syst. Sci., 15, 3785-3808, doi:10.5194/hess-15-37852011, 2011a.

Wada, Y., van Beek, L. P. H., Viviroli, D., Dürr, H. H., Weingartner, R., and Bierkens, M. F. P.: Global monthly water stress: II. Water demand and severity of water, Water Resour. Res., 47, W07518, doi:10.1029/2010WR009792, 2011b.

Wada, Y., van Beek, L. P. H., and Bierkens, M. F. P.: Nonsustainable groundwater sustaining irrigation: A global assessment, Water Resour. Res., 48, W00L06, doi:10.1029/2011WR010562, 2012a.

Wada, Y., van Beek, L. P. H., Weiland, F. C. S., Chao, B. F., Wu, Y.H., and Bierkens, M. F. P.: Past and future contribution of global groundwater depletion to sea-level rise, Geophys. Res. Lett., 39, L09402, doi:10.1029/2012GL051230, 2012b.

Wada, Y., van Beek, L. P. H., Wanders, N., and Bierkens, M. F. P.: Human water consumption intensifies hydrological drought worldwide, Environ. Res. Lett., 8, 034036, doi:10.1088/17489326/8/3/034036, 2013a.

Wada, Y., Wisser, D., Eisner, S., Flörke, M., Gerten, D., Haddeland, I., Hanasaki, N., Masaki, Y., Portmann, F. T., Stacke, T., Tessler, Z., and Schewe, J.: Multimodel projections and uncertainties of irrigation water demand under climate change, Geophys. Res. Lett., 40, 4626-4632, doi:10.1002/grl.50686, 2013 b.

Wada, Y., Gleeson, T., and Esnault, L.: Wedge approach to water stress, Nat. Geosci., 7, 615-617, doi:10.1038/ngeo2241, 2014a.

Wada, Y., Wisser, D., and Bierkens, M. F. P.: Global modeling of withdrawal, allocation and consumptive use of surface water and groundwater resources, Earth Syst. Dynam., 5, 15-40, doi:10.5194/esd-5-15-2014, 2014b.

Warszawski, L., Frieler, K., Huber, V., Piontek, F., Serdeczny, O., and Schewe, J.: The Inter-Sectoral Impact Model Intercomparison Project (ISI-MIP): Project framework, P. Natl. Acad. Sci. USA, 111, 3228-3232, doi:10.1073/pnas.1312330110, 2014.

WEO: World Energy Outlook 2012. International Energy Agency (IEA), Paris, France, available online (November 2014): http://www.worldenergyoutlook.org/publications/weo-2012/\#d. en.26099 (last access: June 2015), 2012. 
Wiberg, D. and Strzepek, K. M.: Development of Regional Economic Supply Curves for Surface Water Resources and Climate Change Assessments: A Case Study of China, IIASA Research Report RR-05-001, available at: http://webarchive.iiasa. ac.at/Admin/PUB/Documents/RR-05-001.pdf (last access: August 2015), 2005.

Wisser, D., Frolking, S., Douglas, E. M., Fekete, B. M., Vörösmarty, C. J., and Schumann, A. H.: Global irrigation water demand: Variability and uncertainties arising from agricultural and climate data sets, Geophys. Res. Lett., 35, L24408, doi:10.1029/2008GL035296, 2008.

Wisser, D., Fekete, B. M., Vörösmarty, C. J., and Schumann, A. H.: Reconstructing 20th century global hydrography: a contribution to the Global Terrestrial Network- Hydrology (GTN-H), Hydrol. Earth Syst. Sci., 14, 1-24, doi:10.5194/hess-14-1-2010, 2010.
World Resources Institute (WRI): World Resources: A Guide to the Global Environment 1998-99, World Resources Institute, Washington D.C., USA, 1998.

World Water Assessment Programme (WWAP): Water for people: Water for life, The United Nations World Water Development Report, UNESCO, Paris, France, 2003.

Yates, D. N.: Approaches to continental scale runoff for integrated assessment models, J. Hydrol., 291, 289-310, 1997.

You, L., Wood, S., and Wood-Sichra, U.: Generating global crop distribution maps: from census to grid, in: Selected paper at IAAE 2006 Conference, Brisbane, Australia, 11-18 August, available at: http://www.planttreaty.org/sites/default/files/ generating_global_crop.pdf (last access: August 2015), 2006. 